NBER WORKING PAPER SERIES

\title{
THE ECONOMIC CONSEQUENCES OF BEING DENIED AN ABORTION
}

\author{
Sarah Miller \\ Laura R. Wherry \\ Diana Greene Foster \\ Working Paper 26662 \\ http://www.nber.org/papers/w26662 \\ NATIONAL BUREAU OF ECONOMIC RESEARCH \\ 1050 Massachusetts Avenue \\ Cambridge, MA 02138 \\ January 2020, Revised January 2022
}

We would like to thank Andreas Hagemann, Chris Hollrah, Ted Joyce, Jason Lindo, Heather Royer, and David Slusky, and seminar participants at the APPAM, ASHEcon, and ASSA annual meetings, Brookings Institution, Dartmouth University, George Washington University, Harvard University, Imperial College London, NBER Summer Institute, RAND Corporation, Stanford University, Simon Fraser University, and the University of Michigan for their helpful comments. We also thank Cathleen Kelmar for her help in linking to Experian records. This study was supported by research and institutional grants from the Wallace Alexander Gerbode Foundation, the David and Lucile Packard Foundation, The William and Flora Hewlett Foundation, and an anonymous foundation. The authors thank Jasmine Powell, Elizabeth Gonzalez, and Rana Barar for study coordination and management. Laura Wherry also gratefully acknowledges nonfinancial support from the California Center for Population Research at UCLA, which receives core support (R24-HD041022) from the Eunice Kennedy Shriver National Institute of Child Health and Human Development. The views expressed herein are those of the authors and do not necessarily reflect the views of the National Bureau of Economic Research.

NBER working papers are circulated for discussion and comment purposes. They have not been peer-reviewed or been subject to the review by the NBER Board of Directors that accompanies official NBER publications.

(C) 2020 by Sarah Miller, Laura R. Wherry, and Diana Greene Foster. All rights reserved. Short sections of text, not to exceed two paragraphs, may be quoted without explicit permission provided that full credit, including $\odot$ notice, is given to the source. 
The Economic Consequences of Being Denied an Abortion

Sarah Miller, Laura R. Wherry, and Diana Greene Foster

NBER Working Paper No. 26662

January 2020, Revised January 2022

JEL No. I1,I18

\section{$\underline{\text { ABSTRACT }}$}

This paper evaluates the economic consequences of being denied an abortion due to gestational limits. We link credit report data to the Turnaway Study, the first study to collect high-quality, longitudinal data on women receiving or being denied a wanted abortion in the United States. We compare financial outcomes over a ten-year period for women who had pregnancies just above and below a gestational age limit allowing for a wanted abortion. Outcome trajectories are similar for the two groups of women prior to the abortion encounter. Following the encounter, women who were denied an abortion experience a large increase in financial distress that is sustained for several years. There is also some evidence of a short-term reduction in credit access, but no change in measures of borrowing. Our results highlight important financial and economic consequences of restrictions on abortion access.

Sarah Miller

Ross School of Business

University of Michigan

701 Tappan Street

Ann Arbor, MI 48109

and NBER

mille@umich.edu

Laura R. Wherry

Wagner Graduate School of Public Service

New York University

295 Lafayette Street

New York, NY 10012

and NBER

laura.wherry@nyu.edu
Diana Greene Foster

diana.foster@ucsf.edu 
In the United States, restrictions on access to abortion are pervasive. States enforce a variety of regulations such as banning abortions after a certain gestational age of the pregnancy, requiring women to receive state-written information about abortion, imposing a waiting period to receive an abortion, and requiring parental consent for minors seeking abortion. In addition, some states have detailed requirements on the manner and setting in which an abortion is permitted. These include bans of the "telemedicine" prescribing of abortion medication, requirements that providers have admitting privileges to local hospitals, and detailed structural standards that must be met by the facility providing the abortion (Nash et al., 2013). These regulations have been shown to effectively reduce access to abortions by limiting the definition of qualifying pregnancies and reducing the number of available providers (e.g. Colman et al., 2011; Fischer et al., 2018; Grossman et al., 2014; Lindo et al., 2019; Quast et al., 2017; Venator and Fletcher, 2019). In addition, the prevalence of restrictions is increasing over time: between 2011 and 2017, 401 such restrictions were enacted, more than double the 189 that had been enacted in the entire preceding decade (Nash et al., 2013, 2018). However, despite the prevalence of such restrictions, the impact of these laws on the women for whom these restrictions bind is not well understood.

This paper provides the first causal evidence on the economic and financial consequences of being denied an abortion by linking high-quality administrative data to a sample of women who sought, but did not all obtain, abortions at facilities across the U.S. Being denied a wanted abortion has the potential to impact a woman's economic and financial security in numerous ways. If being denied an abortion results in a woman delaying an abortion she later obtains, the cost of that abortion may be higher; the cost differential between abortions obtained earlier versus later in the pregnancy can be substantial. ${ }^{1}$ An abortion denial may also result in psychological or emotional costs regardless of the final outcome of the pregnancy, which could affect a woman's productivity and financial well-being. If the woman is not able to obtain an abortion, she faces additional medical costs associated with prenatal care, birth, and postpartum recovery, as well as potential lost wages for time missed from work. In contrast to many medical expenses, earnings losses related to pregnancy and childbirth are largely

\footnotetext{
${ }^{1}$ The median cost of an early medication abortion in 2011-2012 was $\$ 500$ and a 10-week abortion procedure was $\$ 495$ (Jerman and Jones, 2014). Later first trimester and second trimester abortion procedures can range from $\$ 500$ to $\$ 3,000$ or more (Cowles, 2018). Since public health insurance does not cover abortion services in most cases, low-income women will have to bear the additional out-of-pocket costs that could result from a delay; the Hyde Amendment bans federal funding for abortion except in cases of life endangerment, rape, and incest, although some states choose to cover abortions under their Medicaid programs using their own funds (Salganicoff et al., 2020). In addition, later abortions require a longer period for the procedure to be performed and for recovery, which may lead to additional expenses in the form of time off of work or child care (Cowles, 2018). Later abortions may also require the woman to travel further and make additional childcare arrangements; Lindo and Pineda-Torres (2019) estimate that the cost of even modest delays in receiving an abortion can increase total costs by over $\$ 900$.
} 
uninsured, mirroring the general nature of insurance coverage for non-pregnancy hospitalizations in the U.S. (Dobkin et al., 2018). ${ }^{2}$ There is a well-documented large and persistent decline in earnings (i.e. "child penalty") that women experience on average following the birth of a child (e.g. Adda et al., 2017; Agüero and Marks, 2008; Kleven et al., 2019; Sandler and Szembrot, 2019). There are also additional costs associated with raising a child, which typically exceed $\$ 9,000$ in annual expenses (Lino et al., 2017). While social supports may offset some of these expenses, it may still be the case that denying a woman access to a wanted abortion could have large, negative, and long-lived effects on her financial and economic well-being.

This paper builds on the Turnaway Study, which is a unique public health survey of women's experiences when denied an abortion due to gestational limits. The study recruited women seeking abortions at 30 different clinics in 21 states. Each of these clinics had the latest abortion gestation limit within 150 miles, making it difficult for women to receive abortions elsewhere if denied based on a gestational limit. The study collaborated with participating clinics to enroll women who were past the gestation limit (by up to 3 weeks) for each clinic, and were turned away without receiving the abortion they sought (we refer to these women as the "Turnaway" group). The majority of these women, 68 percent, ended up giving birth; 32 percent either obtained abortions elsewhere or experienced a miscarriage or stillbirth. ${ }^{3}$ Other women who were within the gestation limit, but only by up to two weeks, and received a wanted abortion were recruited as a comparison group (the "Near Limit" group). The Study surveyed these two groups of women over a five year period, as well as a group of women who sought and received abortions early in their pregnancies (during the first 14 weeks) for an additional point of comparison.

We take advantage of the success of the Turnaway Study in identifying and recruiting this hard to reach population and link the study participants to ten years of credit report data. These data contain high-quality, administratively-collected information that may be used to study financial health. They allow us to observe measures of financial stress such as lateness in paying bills, having bills sent to collection agencies, and serious adverse financial events like evictions and bankruptcies. They also allow us to observe markers of financial self-sufficiency and resiliency, such as having access to a reserve of credit, and information on consumer borrowing in the form of credit cards, mortgages, and

\footnotetext{
${ }^{2}$ The United States does not require that employers provide paid maternity leave, although some employers provide this benefit. A small number of states have paid leave policies but the length of time and rules around benefits vary across states (Kaiser Family Foundation, 2020). Employers may also have short-term disability policies that provide some portion of earnings for a six week or longer period depending on the type of birth and whether there are any complications.

${ }^{3}$ These percentages are based on all women in the Turnaway Study for whom we have follow-up information about the outcome of the pregnancy. For some women, no such follow-up information is available.
} 
automobile loans.

This new linkage to administrative data offers important advancements over previous studies using the Turnaway Study data. First, we are able to link the study participants to credit report data that predate the abortion encounter when they were recruited into the study. This allows us to observe the women's trajectories of financial outcomes both before and after the pregnancy. In the original study, no data from prior to the abortion encounter was available, making it impossible to assess whether the Near Limit group had similar trends in outcomes prior to the pregnancy. Using our newly linked data, we are able to test the validity of the Near Limit group as an appropriate comparison group for women who were denied an abortion by comparing the evolution of pre-study outcomes for the two groups of women. In addition, having both pre- and post-data on financial well-being allows us to document the change in individual well-being resulting from the abortion denial for women in the Turnaway group by including individual fixed effects in our regression models.

Second, this longitudinal administrative data allow us to apply several "causal inference" techniques common to economics to analyze Turnaway Study data. Previous studies with the Turnaway data largely relied on cross-sectional comparisons across the Turnaway and Near Limit group, which could be confounded by differences in these groups that predated the abortion encounter. Using these new data, we estimate an "event study" design that accounts for fixed differences across the Near Limit and Turnaway groups. We supplement this main approach by taking advantage of detailed information on gestational age at the time of the abortion encounter with a regression discontinuity (RD) design that compares outcomes for women just above and below the abortion gestational limit at each clinic. These approaches account for any systematic differences in the two groups of women even prior to the abortion or abortion denial, which could not fully be addressed in previous Turnaway studies due to data limitations.

Finally, our use of administrative data increases our sample size substantially relative to the original Turnaway Study and avoids any selection concerns that result from survey non-response. Because we only require information collected when women were initially recruited into the study to perform the linkage, we are able to observe outcomes for women who later opted not to participate in Turnaway Study survey interviews. This is particularly important when observing long-term outcomes. While 85 percent of those enrolled in the study completed the first survey, by the end of the 5-year study period only 58 percent responded (Foster et al., 2018). In addition, by using administrative records rather than self-reported information to study these outcomes, we avoid concerns of 
non-random misreporting of economic outcomes often observed in survey data. ${ }^{4}$

Just as insights and methods from economics may serve to further advance findings from the Turnaway Study, our use of rich and detailed public health data on the experiences of women seeking abortion can increase our understanding of the impact of abortion policy in the field of economics. To date, studies of the impact of abortion restrictions within economics have relied on aggregated, state- or county-level data for analysis, without information on which women actually sought, and were denied, an abortion. Since these women represent only a small fraction of the total population in any given year, such studies are limited in their power to detect the effects of abortion restrictions on outcomes other than childbirth or abortion itself. ${ }^{5}$ Furthermore, the small number of studies that do attempt to analyze the impact of abortion restrictions on outcomes other than birth and abortion rates tend to focus on child outcomes (e.g. Bitler and Zavodny, 2002, 2004). Better understanding the effects of restricted access to reproductive health care on women's outcomes is important as local, state, and federal government actors continue to weigh policies that reduce women's ability to access abortion. Our focus on the women who are close to the cutoff of being denied versus being provided an abortion are exactly the population most likely to be affected by additional restrictions on access to abortion services.

In our main event study approach, we find that, prior to the pregnancy, financial outcomes in the Near Limit and Turnaway groups evolved very similarly. However, around the time of the birth, women in the Turnaway group experienced much higher rates of financial problems, increasing a summary measure of financial distress by approximately one tenth of a standard deviation. We find that abortion denial resulted in increases in the amount of debt 30 days or more past due of $\$ 1,750$, an increase of 78 percent relative to their pre-birth mean, and in negative "public records" on the credit report such as bankruptcy, evictions, and tax liens, of about 0.07 additional records, or an increase of 81 percent. These effects are persistent over time, with elevated rates of financial distress observed the year of the birth and for the entire 5 subsequent years for which we observe the women. Our point estimates also suggest that being denied an abortion may reduce credit access and self-sufficiency, particularly in the years immediately following the birth, although these estimates are not always

\footnotetext{
${ }^{4}$ For example, in a Turnaway Study of socioeconomic outcomes, Foster et al. (2018) found that women living at home with their parents were less likely to know their household income.

${ }^{5}$ According to the Centers for Disease Control and Prevention surveillance data, the abortion rate for 2015 was 11.8 abortions per 1,000 women aged 15-44, or 1.18 percent of women of reproductive age. Even when focusing on effects among birth cohorts, the frequency of abortions relative to births is low (188 abortions per 1,000 live births, see Jatlaoui et al., 2018). In addition, it is likely that a much smaller number of women (and births) are affected by abortion restrictions of the type described above.
} 
statistically significant. We detect no changes in measures of borrowing, which include number of automobile loans, total credit card balance, and having a mortgage. However, this lack of effect may capture counterbalancing supply and demand responses if increased borrowing needs or demand is met with greater reluctance to lend by credit suppliers.

In additional analyses, we implement a regression discontinuity (RD) design that compares outcomes for women just above and below the abortion gestational limit at each clinic. Complicated factors affect the timing of when women seek abortions; for instance, the rules around gestation limits are often opaque and vary across clinics, and women may be unaware of both the cutoffs and the precise dating of their pregnancies. This suggests that women who seek abortions just above and below gestational limits might be otherwise very similar. In support of this, we find no evidence of discontinuities in observable characteristics, or for our outcomes of interest prior to the abortion encounter, at the gestational cutoff. We do, however, find results consistent with the event study design: we observe an increase in financial distress following the birth for those women who just met the criteria for an abortion denial. These effects are largest during the year of the birth and the following three years, although the confidence intervals for these estimates tend to be large due to their reliance on a small number of data points around the gestational cutoff.

We also conduct exploratory analyses that use the longitudinal Turnaway Study survey data to better understand the mechanisms underlying these financial effects, drawing on survey outcomes originally published in Foster et al. (2018). The Turnaway Study recruited participants at the time of the abortion encounter, so pre-encounter survey data are unavailable. However, we are able to examine changes in survey outcomes over time from the initial survey interview, which occurred approximately one week after the abortion encounter. We implement a difference-in-differences analysis using these data for our specific study sample. We find that women in the Turnaway group often cared for an additional child without experiencing an increase in personal or household income. As a result, their income as a percent of the Federal Poverty Level (FPL) fell over time relative to the Near Limit group. Women in the Turnaway group did not appear to move in with male partners and were less likely to live with adult family (such as parents or grandparents) or roommates after the initial interview compared to the Near Limit group; instead, they experienced increases in the incidence of living alone with a child or children. While we find evidence that public support (via the WIC program) increased for the Turnaway relative to Near Limit group in the first year following the birth, we do not find significant increases in receipt of other public benefits and only marginally significant, 
modest increases in the amount of child support received. In sum, our analysis of the survey data is consistent with abortion denials resulting in greater parental obligations for women without obvious corresponding increases in support from the government, family members, or male partners, providing some context for the higher financial stress documented in our analysis.

We also explore how the financial stress for women in the Turnaway group who give birth compares to the experience following a "typical" birth among women of similar socioeconomic status. In general, very little is known regarding the financial consequences of childbirth, despite well-documented child penalties in earnings. ${ }^{6}$ We examine this by documenting how financial outcomes change among women in the Near Limit group who obtained an abortion but went on to give birth later in the study period. We find evidence suggesting that the financial distress associated with a new baby is greater for women who were denied an abortion and carried an unwanted pregnancy to term than what may generally be experienced by women with similar socioeconomic characteristics after a birth. This analysis suggests that births occurring after an abortion denial may carry additional economic penalties over and above what is typically experienced by disadvantaged women when they have a new child, and that greater access to abortion services and more optimally timed births may result in fewer adverse economic consequences.

Together these analyses offer strong evidence that being denied an abortion has large and persistent negative effects on measures of financial well-being. These results highlight important financial and economic consequences of restrictions on abortion access. Given that the women affected tend to be disproportionately low-income, these effects may serve to further reinforce or exacerbate existing economic inequalities.

\section{Background}

While abortions are infrequent events when compared to births (e.g. there were 188 abortions per 1,000 live births in 2015, see Jatlaoui et al., 2018), they are not infrequent when observed over the full length of a woman's reproductive years. Projections based on the current abortion rate estimate that nearly 1 in 4 women in the U.S. is expected to have an abortion during her reproductive years (Jones and Jerman, 2017). ${ }^{7}$ The majority of abortions are surgical procedures (73.1 percent in 2015), although

\footnotetext{
${ }^{6}$ We know of no prior event study analyses of pregnancy or childbirth using credit report data. Dobkin et al. (2018) document substantial financial effects following adult hospital admissions, but their analysis is limited to non-pregnancy admissions.

${ }^{7}$ Based on data on receipt at abortion clinics, this is likely an underestimate since it does not include abortions obtained outside of the formal medical system (Foster, 2017).
} 
just over one-quarter (26.8 percent) are nonsurgical abortions that occur at up to 10 weeks of gestation (Jatlaoui et al., 2018). Nonsurgical abortions use medications to terminate the pregnancy, but require that a woman know that she is pregnant and receive abortion services early in her pregnancy. ${ }^{8}$

\subsection{Abortion Restrictions and the Women Affected}

Women seeking abortions, and abortion providers, face a variety of restrictions in most states. Until recently, most restrictions involved who could receive an abortion or introduced additional requirements for women seeking abortion, such as mandatory waiting periods, counseling, or parental notification and consent laws for minors. ${ }^{9}$ While there have been a number of studies examining the effects of mandatory waiting periods or additional barriers to receipt for minors, ${ }^{10}$ there has been less attention paid to the consequences of gestational limits for the provision of abortion services.

Yet, gestational limits are among the most prevalent restriction for women seeking abortion services; 43 states have gestational limits in place that ban abortions for most women after a certain point in their pregnancy (Kaiser Family Foundation, 2019). Twenty states ban abortion at the point of fetus "viability," which is typically understood to range from 22 to 24 gestation weeks and is determined on an individual basis at the discretion of the patient's physician. In contrast, another 20 states have adopted bans that specify limits from 20 to 24 weeks. An additional 13 states have attempted to ban abortion earlier in pregnancy or at any time during pregnancy, but these changes have been stopped by court order (Guttmacher Institute, 2019). ${ }^{11}$ In addition, each abortion facility sets its own gestational limits based on a variety of factors, including physician training and staff comfort (Foster et al., 2013). This can make it difficult for a woman seeking a later abortion to locate a provider willing to

\footnotetext{
${ }^{8}$ For context, gestation length is measured from the date of women's last menstrual period with an average menstrual cycle length of 28 days, but ranging from 21 to 45 days. Therefore, women may be unaware that they are pregnant until the 6th week of pregnancy or much later if they do not experience symptoms.

${ }^{9}$ As policies regulating providers have become more common (i.e."supply-side" regulations), a new literature examines the consequences for access to abortion providers and abortion receipt. These papers have primarily focused on the introduction of a series of stringent regulations for abortion providers in Texas and document sizeable decreases in abortion rates (see Colman et al., 2011; Fischer et al., 2018; Grossman et al., 2014; Lindo et al., 2019; Quast et al., 2017). More recently, Venator and Fletcher (2019) examine the closure of clinics in Wisconsin under increased provider regulation and find fewer abortions and increased birth rates. Kelly (2019) studies reduced clinic capacity following new regulations for abortion providers in Pennsylvania and finds evidence of delays in abortion receipt as a result. In some cases, the law changes being studied also include restrictions on the patients seeking abortions (i.e. "demand-side" regulations) but the papers in this literature often focus on the supply-side components.

${ }^{10}$ See, for example Bitler and Zavodny (2001); Blank et al. (1996); Colman et al. (2008); Colman and Joyce (2009); Girma and Paton (2013); Joyce and Kaestner (1996, 2000, 2001); Joyce et al. (2006); Joyce (2010); Levine (2003); Myers (2021), for studies of the effects of the restrictions on abortion timing and receipt and birth rates. A related strand of literature has examined the effects of changes in public funding for abortion and finds decreased abortion rates under more restrictive funding (see e.g. Blank et al., 1996; Levine et al., 1996).

${ }^{11}$ All of these gestation lengths are in terms of weeks since the date of the women's last menstrual period. In addition, there are exceptions for the life and health of the woman, also at the discretion of the patient's physician. In addition to the state rules described here, two other states have attempted to ban abortion at 20 weeks and 22 weeks, but these changes have also been stopped. See additional details in Guttmacher Institute (2019).
} 
perform the service.

Outside of the U.S., most of the 60 countries that allow abortions without legal restrictions regarding the reason for termination have specified gestational limits in place. ${ }^{12}$ The first trimester, or 12 weeks, is the most common gestational limit, but 9 countries have limits between 14 to 18 weeks, one allows abortions up to 24 weeks, one specifies up to the point of viability, and 4 countries have no limits. There are relatively few cross country travel restrictions for EU citizens, making it possible to seek abortion care outside of one's home country (e.g., Garnsey et al., 2021). Although the U.S. is not alone in placing restrictions on the timing of an abortion, in practice, abortions may be more difficult for certain women to access in the U.S. since most of these other countries have national health insurance programs that cover abortion services (Singh et al., 2018). Since the Hyde Amendment prohibits the use of public funds to cover abortions except in the cases of life endangerment, rape, or incest, women enrolled in public insurance programs such as Medicaid are essentially uninsured for abortion services even if they have health insurance that covers other aspects of their care. In addition, many states restrict coverage of abortion services by private insurance plans that are not self-insured, plans participating in the Affordable Care Act marketplaces, or restrict abortion coverage under public employee insurance plans (Salganicoff et al., 2019; Kaiser Family Foundation, 2020). These type of coverage restrictions may make it difficult to access services in the time frame permitted by the law.

Descriptive studies document that the women most likely to be affected by gestational limits in the U.S. are a particularly vulnerable population. A survey of women in the state of Georgia who had an abortion at or after 20 weeks just prior to implementation of a 20-week abortion ban found that over half were Black women, more than three-fourths were single, and most did not have education beyond high school (Roberts et al., 2015). In the Turnaway Study, the majority of the women presenting for an abortion with gestational ages close to facility gestational limits had incomes below the poverty line and reported that they did not have enough money to make ends meet (Foster et al., 2018).

Although the reasons why women seek abortions are complex, interviews with abortion seekers often find that financial or material concerns and timing are among the most important considerations, with many women indicating that having a child would interfere with their education or livelihood (e.g. Biggs et al., 2017; Finer et al., 2005). While a number of factors are associated with delays in seeking abortion, the most common reasons given are later recognition of pregnancy and the amount of

\footnotetext{
${ }^{12}$ The majority of high-income countries allow abortion without restriction to reason. Only one (Ireland) restricts abortion to cases where it will save the woman's life; some require women to qualify on the basis of preserving their physical or mental health status, or due to socioeconomic reasons (Singh et al., 2018).
} 
time needed to decide and make arrangements for the abortion (Finer et al., 2006). ${ }^{13}$ Women receiving abortions during the second trimester report a logistical reason (such as difficulty finding an abortion provider or referral to another clinic) as the primary factor that caused their delay (Drey et al., 2006); they are also more likely to have concerns about raising the money to cover the cost of the abortion (Finer et al., 2006).

Finally, informational barriers may also contribute to delays in seeking care. Evidence indicates that women are often not aware of clinic gestational limits for abortion or may be confused about limits (e.g. Assifi et al., 2016; Lara et al., 2015). This may be exacerbated in states with laws on the books that are not currently enforced due to ongoing litigation (Tavernise, 2019). Furthermore, women often do not have accurate dating information regarding their pregnancy, particularly if they have irregular menstrual cycles. Providers use ultrasound methods to determine gestation length, which may differ from patients' recalled date of last period.

\subsection{Existing Evidence on Economic Effects of Abortion Policy}

Very few studies have examined the economic consequences for women who are denied an abortion or who carry an unwanted pregnancy to term. An older literature focused on abortion legalization in the 1970s suggests that access to abortion may have important effects on women's human capital attainment and economic outcomes. Angrist and Evans (2000) document increased rates of high school graduation, college attendance, and employment for Black women under state laws increasing abortion access during this time period. In addition, a number of studies examine changes in childhood living circumstances for the children born following abortion legalization. For instance, Gruber et al. (1999) find that the children born after legalization lived in better economic conditions; for instance, they were less likely to live in poverty or receive cash welfare. ${ }^{14}$ This finding indicates that fewer disadvantaged women were selecting into parenthood following abortion legalization, but does not provide any information on how this change affected their economic outcomes or career trajectories. ${ }^{15}$

\footnotetext{
${ }^{13}$ Nearly half of pregnancies in the U.S. are unplanned (Finer and Zolna, 2016); therefore, not knowing one is pregnant is a common experience among women with irregular periods, those who do not have pregnancy symptoms, and those who have health conditions that mask pregnancy such as having recently given birth (Drey et al., 2006).

${ }^{14}$ Ananat et al. (2009) follow these cohorts into young adulthood and show further evidence of improved outcomes. In addition, Bitler and Zavodny $(2002,2004)$ find evidence of decreased child maltreatment following abortion legalization. Donohue and Levitt (2001), Joyce (2004), and Joyce (2009) examine the question of whether the change in the composition of births following abortion legalization led to lower rates of crime. More recently, Sun (2019) focuses on the older siblings born just prior to abortion legalization who then experienced smaller family sizes in areas with abortion service roll-out. He finds evidence of better living circumstances and significant improvements in the long-term outcomes for these children, with gains in both human capital attainment and economic self-sufficiency as adults.

${ }^{15}$ However, follow up work has examined the effects on fertility over the lifespan, indicating that the reduction in births was permanent for many women (i.e. they remained childless and did not just delay childbearing, see Ananat et al., 2007).
} 
A large body of evidence from studies of expanded access to contraception also indicates that there may be important consequences for women's outcomes. ${ }^{16}$ Many of these studies examine the effects of increased legal access to the birth control pill in the 1960s and 1970s and document delayed marriage and increased educational attainment, employment, and earnings among young women as a result (e.g. Bailey, 2006; Bailey et al., 2012; Goldin and Katz, 2002; Hock, 2008). However, more recent work by Myers (2017) indicates that it might be the legalization of abortion, rather than access to the pill, driving the findings in these studies. ${ }^{17}$ A recent survey of the evidence suggests that the mixed findings on the magnitude of the pill's effects may be due, at least in part, to difficulty defining state policies that were enforced during the period of study and differing interpretations across researchers (Bailey and Lindo, 2017).

Part of the challenge with this prior body of work and its interpretation is that it estimates the effects of changes in access to contraception or abortion services under federal or state policies among women who are expected to be affected (e.g. women of reproductive age). However, these studies are unable to identify the individual women who are actually denied an abortion or whose use of contraception changed as a result of these policies. Thus, the authors must rely on cohort-level changes in women's outcomes that are associated with the particular policy change or diffusion of birth control technology being studied. Given that different policy or access changes that affect a woman's use of reproductive health services can happen simultaneously, ${ }^{18}$ and that only a relatively small share of the female population may actually be affected, this can make it difficult to pinpoint effects that occur at the individual level.

\footnotetext{
${ }^{16}$ Another relevant literature focuses on the effects of motherhood or motherhood timing on women's human capital and career outcomes. A number of these papers find that having a child negatively affects a woman's labor supply (e.g. Cristia, 2008; Lundborg et al., 2017) or document the presence of large and persistent child penalties with regards to employment or earnings (e.g. Adda et al., 2017; Agüero and Marks, 2008; Kleven et al., 2019; Sandler and Szembrot, 2019). In addition, some studies document that fertility delay for teenagers (e.g. Ashcraft et al., 2013; Fletcher and Wolfe, 2009; Klepinger et al., 1999; Schulkind and Sandler, 2019) and women in their 20s and 30s (Miller, 2011) improves education or labor market outcomes, although the estimates are sometimes modest in size. Note that child penalties for labor market outcomes have been documented across developed countries, even those with more progressive family policies, and may be related to cultural or gender norms (Kleven et al., 2019).

${ }^{17}$ Joyce (2013) also argues that the legalization of abortion is a potentially important confounder in this literature, although Bailey et al. (2013) discusses how findings tied to increased access to the pill in Bailey et al. (2012) and Bailey (2006) are robust to analyses that address this criticism.

${ }^{18}$ Examples of this include abortion legalization and state liberalization of access to the birth control pill (Joyce, 2013); changes in multiple types of state abortion restrictions including Medicaid funding restrictions, parental involvement laws and mandatory delay laws (Bitler and Zavodny, 2001); and, the enactment of new state regulations of abortion providers coupled with cuts in public funding for family planning services, as recently seen in Texas (Fischer et al., 2018) and Wisconsin (Venator and Fletcher, 2019).
} 


\subsection{Evidence from the Turnaway Study}

The Turnaway Study offers a unique opportunity to overcome these data challenges. Data from this study allow researchers to follow women who are actually seeking abortions, allowing a direct examination of the relevant women rather than relying on comparisons across broad groups such as cohorts or states. The focus of the study was women who were denied an abortion due to facility gestational limits (Turnaway group). In addition to successfully identifying and recruiting these women to participate, another innovation of the study was the construction of a suitable comparison group by recruiting women seeking and receiving abortions at gestational lengths just below facility limits (Near Limit group). Data on a wide range of outcomes were collected for study participants one week after the abortion encounter and then every six months over a five-year period. Participants received a $\$ 50$ gift card to a large retail store after completion of each interview (Dobkin et al., 2014). ${ }^{19}$

Using the survey data, the study team documented important differences in the well-being of women in the Turnaway group compared to the Near Limit group, many of which persisted over the study period. This body of work finds that women who were turned away by the abortion clinics experienced worse mental health in the short-run (Biggs et al., 2017); poorer physical health among those who gave birth, including two maternal deaths (Gerdts et al., 2016; Ralph et al., 2019) and increased risk of physical violence from the man involved in the pregnancy (Roberts et al., 2014), when compared to women in the Near Limit group who received abortions. Researchers also documented worse economic outcomes following the abortion denial for women in the Turnaway group, including higher rates of poverty, lower employment, and greater use of public assistance both in the short-term (6 months following the service denial) and over a longer time horizon (4 years later) (Foster et al., 2018). We present a more detailed overview of the Turnaway Study in Miller et al. (2020).

These studies provide some of the first evidence on the potential short- and long-term economic, health, and social consequences of being denied a wanted abortion. However, without information on the relative trajectories of these outcomes prior to the abortion encounter, an inherent limitation of the Turnaway Study is the inability to rule out pre-existing differential trends across the two groups of women. Previous studies also documented some differences between the Turnaway and Near Limit study participants at the time of the abortion encounter: women in the Turnaway group were slightly younger, less likely to be employed, and had fewer children. They also discovered their pregnancies

\footnotetext{
${ }^{19}$ To track participants, the study asked them to provide contact information for two people who would always know where the participant was. This information was used to re-contact participants if their contact information became stale. Participants also received a phone call every two months to confirm their contact information.
} 
at later gestational ages than women in the Near Limit group (Upadhyay et al., 2014). ${ }^{20}$ While the analyses described above adjusted for these observed differences, such differences could be related to unobserved differences in characteristics, such as family or partner support, which affect outcomes related to health and well-being and cannot be easily controlled for. In addition, these analyses were necessarily limited to an increasingly small and selected subgroup of participants who responded to the Turnaway Study's follow-up surveys over time.

Our study builds on these initial results by linking Turnaway Study participants to high-quality administrative, longitudinal data that includes information on financial outcomes from even prior to the pregnancy. These linkages allow us to assess the validity of using women from the Near Limit group as a comparison for the Turnaway group by examining whether outcomes evolved similarly for the two groups prior to the abortion encounter, which was not possible with the original study data. In addition, we are able to trace out the impacts of an abortion denial without relying on a selected sample of survey respondents. In sum, the Turnaway Study provided an important first look at the economic consequences of an abortion denial. By linking this pathbreaking study of a difficult-toreach population with large-scale administrative data, we are able to greatly expand our knowledge base on this understudied question.

\section{Data and Outcomes}

\subsection{Data and Sample Construction}

Our analysis relies on a new source of data that links individual-level information from the Turnaway Study to longitudinal credit report data. The Turnaway Study recruited women seeking abortions in 30 abortion facilities across the United States between 2008 and 2010 in order to survey them about their experiences. Facilities with the latest abortion gestational limit (i.e. highest number of gestation weeks at which an abortion could be performed) within 150 miles were selected to partner with the Turnaway research team to recruit women to participate in the study. ${ }^{21}$ The research team sought to represent many different geographic areas in the country, while prioritizing locations with earlier gestation limits (see further details in Dobkin et al., 2014). The clinics' gestational limits ranged from 10 weeks to the end of the second trimester of pregnancy (the end of week 26), with most falling

\footnotetext{
${ }^{20}$ These studies use a slightly different sample than the one matched to the credit records; see Tables 1 and 2 for our own comparisons of pre-birth sample characteristics across the groups.

${ }^{21}$ Note that many women in the study traveled to seek abortion care, so the nearest alternative clinic may be closer or farther to their residence than this 150 mile distance criteria implies. Among study participants, 17.8 percent reported traveling 50 to 100 miles, and 23 percent reported traveling more than 100 miles, to seek an abortion (Upadhyay et al., 2014).
} 
during the second trimester (weeks 14-26).

The study recruited women age 15 and older whose pregnancies exhibited no known fetal anomalies and who spoke either English or Spanish. ${ }^{22}$ If the gestational age of the pregnancy, as measured by an ultrasound, was no more than two weeks below the gestational age limit of the clinic, these women were considered part of the Near Limit group. If the gestational age was up to three weeks past the gestational age limit of the clinic, such that they were not permitted to obtain the abortion, the women were considered to be part of the Turnaway group. There were 536 and 292 women in each of these groups, respectively. Among women approached, a very similar percent of the Turnaway group and Near Limit group consented to participate in the study (41 and 42 percent respectively, see Dobkin et al., 2014). Figure 1 shows the distribution of the gestational ages of the pregnancy for the Turnaway group who were denied an abortion (dark blue) and at the time of the abortion for the Near Limit group (light blue). ${ }^{23}$ The distribution of gestational ages for the Near Limit group overlaps significantly with the Turnaway group, although it is shifted to the left; i.e., on average, the Near Limit group is seeking abortions at earlier points in the pregnancy than the Turnaway group. Notably, many in the Turnaway group are denied abortions at a gestational age lower than what is legally allowed.

While all women in the Near Limit group obtained an abortion, the converse is not true for the Turnaway group. Through the Turnaway Study surveys, we observe follow-up information regarding the outcome of the pregnancy for 217 of the 292 women in our Turnaway group sample. ${ }^{24}$ Among these 217 women, 32 percent reported either obtaining an abortion elsewhere or experiencing a miscarriage or stillbirth. The remaining 68 percent carried the pregnancy to term. In our analysis, we examine the impact of the abortion denial for all women in the Turnaway group, regardless of the outcome of the pregnancy. ${ }^{25}$

To conduct our analysis, we estimate how outcomes change over time for women in the Turnaway group relative to the Near Limit group. We do this by defining a variable "event time" to capture the number of years relative to the time a woman gave birth (for those in the Turnaway group who gave birth) or would have given birth (for those in the Near Limit group or those in the Turnaway

\footnotetext{
${ }^{22}$ One woman whose home address was outside of the United States was excluded from our analysis.

${ }^{23}$ This histogram shows the values for women in the main sample used in this paper, who were successfully matched to credit records and meet the sample criteria described in this section.

${ }^{24}$ Women for whom we do not have information about the pregnancy outcome include 61 women who did not complete the initial Turnaway Study survey, as well as 14 women who were pregnant when they responded to the initial survey but did not respond to any subsequent surveys.

${ }^{25}$ In addition to presenting average effects for the Turnaway group, a previous version of this paper also presented implied treatment effects for women who carried their pregnancies to term. We have removed this analysis due to the strong underlying assumption that only women who carry their pregnancies to term may be affected by an abortion denial.
} 
group who had an abortion, miscarried, or whose pregnancy outcome is unobserved). For example, a woman in the Turnaway group who gave birth after service denial would have event time equal to -1 in the 12 months preceding the birth, event time $=0$ during the month of the birth and the next 11 months, event time $=1$ in the 12 months after that, etc. Similarly, for those in the Turnaway group who had an abortion, miscarried, or had an unknown pregnancy outcome, and for those in the Near Limit group, we define event time relative to the year in which they would have given birth on the basis of the gestational age of the pregnancy, assuming a 40 week pregnancy. That is, event time $=0$ in the month they would have given birth and the following 11 months, event time=1 in the 12 months following, etc. ${ }^{26}$ For simplicity, throughout the manuscript we refer to event time $=0$ as the birth year.

We link study participants to annual Experian credit report data for 2006 through 2016. This range allows us to see event times up to 3 years prior to the birth (or counterfactual birth), the year of the birth, and five years after the birth year for all participants. ${ }^{27}$ To link to the Experian database, we used a "double blind" matching method that masked actual participants in the Turnaway Study by including approximately 50,000 randomly-selected women between the ages of 15 and 44, purchased from a marketing firm, in the data file sent to Experian to be matched. This "masking" sample prevented analysts at Experian from identifying who in our data actually sought abortions, providing an additional layer of data security to Turnaway Study participants.

The Experian credit report data include records for all individuals with any credit line, public record, or third party collection reported to the credit reporting agency. While quite comprehensive when it comes to formal credit extended by lenders, these records will miss informal loans between family and friends or short-term "payday" loans that are not reported to credit agencies. In addition, not all Turnaway Study participants were matched to the data. There are a couple of reasons why this might occur. The first is if the individual has never opened a credit account or had a collection or debt-related court record in their name. Since this is most likely to be true for dependents, we only include study participants who were at least 20 years old in event period zero, although we show that the results are robust to including women of all ages.

A second reason that a match may not occur is if the linking variables are not sufficient to establish a match. We matched study participants based on name, year of birth, and address. ${ }^{28}$ However, if

\footnotetext{
${ }^{26}$ We could also use the 40-week rule to define the birth year for those in the Turnaway group who gave birth. We choose, however, to use the actual birth year since we have this information.

${ }^{27}$ Since we only observe earlier event times for a small number of women who enrolled in the study at the end of the study period, and later event times for a small number of women who were first to enroll in the study, we exclude event periods outside of this range from our analysis.

${ }^{28}$ Note that Experian keeps records on previously used names and aliases, so name changes due to marriage should not
} 
the credit reporting agency does not have the address provided by the woman on file (e.g., if she provided a temporary address to the study that was not included in her Experian address history), we may not successfully match her to the Experian data even if she does have a credit record. About 82.0 percent of women in the Near Limit group were successfully matched to a credit record in at least one year, higher than the 76.3 percent of the Turnaway group who were matched in at least one year. In general, these match rates are comparable or better than those in other studies that have matched to credit reports using name and address (e.g. Finkelstein et al., 2012; Humphries et al., 2019), but lower than those generally reported in studies that included social security number as a match variable (e.g. Dobkin et al., 2018; Miller and Soo, 2018; Miller et al., 2021). ${ }^{29}$

We are able to use survey data collected by the original Turnaway Study to better understand who was successfully matched to the credit database. We observe that 83 percent (483) of the 581 matched participants, and 77 percent (110) of the 143 unmatched participants, completed an initial telephone survey as part of the study. These surveys were completed approximately one week after having sought the abortion. Within both the Turnaway and the Near Limit groups, those who were not matched to credit records tended to be somewhat more likely to have lower levels of educational attainment. Within the Turnaway group, those not matched were more likely to be in poverty and employed part time, were older, and were more likely to receive Food Stamps (see Appendix Table A1). Since our analyses necessarily only include individuals that are successfully linked to the credit report data, this suggests that the effects of an abortion denial that we estimate may not necessarily represent the experiences of the most disadvantaged members of the Turnaway group. For instance, it is possible that the economic consequences for the unmatched group might be even larger given their higher rates of disadvantage reported in the initial Turnaway Study survey.

Match rates for both the Turnaway and the Near Limit groups also increased over time as participants aged (see Appendix Figure A1). This is consistent with a general trend of the establishment of credit at older ages. However, when we examine differential match rates for the two groups in event time, we observe that match rates tend to increase in the Turnaway group relative to the Near Limit group in the post-period (see Appendix Figure A2). Events that could lead to a higher match rate include establishment of credit (i.e. open credit account), a creditor reporting delinquency on bills, or a public record event, such as an eviction, bankruptcy, or court judgement (e.g. being ordered to pay in principle be an impediment to successfully matching a woman to Experian's database.

${ }^{29}$ Reported match rates in each of these studies are 86\% (Dobkin et al., 2018), 69\% (Finkelstein et al., 2012), 61\% (Humphries et al., 2019), 95\% (Miller and Soo, 2018), and 99\% (Miller et al., 2021). 
child support or having wages garnished by a creditor). In order to isolate the impact of the abortion denial from changes in the matched sample composition over the study period, we limit the analytic sample to women who had a record with the credit agency prior to the birth year. ${ }^{30}$

Our estimates of the effects of an abortion denial will therefore be limited to the effects among women who already had credit records. This may miss important effects on women who are not in this sample, however. To further explore this, in sensitivity analyses, we conduct alternative analyses in which we either assume that women without credit records in the pre-period have zero delinquencies or credit cards, or we impute group-specific average values for the missing outcomes. Our results are very similar under both of these alternative approaches.

In addition, our results are specific to the financial consequences experienced by women for whom gestational limits affect their ability to get an abortion. With its focus on this set of women, the Turnaway study captures a different population as compared to the broader population of abortion seekers. Table 1 shows the characteristics measured in the initial survey of women in the different Turnaway Study groups who matched to the credit report data and were at least 20 years old. Compared to respondents to a Guttmacher survey of abortion patients (Jerman et al., 2016), members of the Turnaway group are more likely to have a high school degree education or less (45.3 percent in our study vs. 11.8 percent of abortion patients); are slightly less likely to be Black (26.7 vs 29.3 percent) and more likely to be white (40.2 vs. 36.6 percent); and are less likely to be married (9.3 vs 14.8 percent). These differences reflect the fact that women who seek abortions later in the pregnancy tend to have different characteristics, as may be seen by comparing the characteristics of the First Trimester and Turnaway Group in Table 1, but may also reflect differences in who chose to participate in the Turnaway Study vs. the Guttmacher survey. Notably, the differences between the Turnaway group and the comparison Near Limit group in our sample are small and, with the exception of the full time employment indicator, are not statistically significant. This is in contrast to previous studies that found differences in average age across the two groups (Upadhyay et al., 2014), and reflects the somewhat older sample represented in the credit records.

\subsection{Credit Report Outcomes}

The credit report data contain information on a wide range of outcomes related to a consumer's financial well-being and creditworthiness and have been used in a variety of contexts to measure the

\footnotetext{
${ }^{30}$ The flow chart in Appendix Figure A3 demonstrates how each of the sample inclusion criteria affects our final sample size.
} 
impact of different programs and events on a household's financial situation. Measures of financial distress drawn from credit reports are highly positively correlated with other adverse events such as evictions and health shocks, and negatively correlated with consumption, access to income supports, and health insurance coverage (Deshpande et al., 2019; Dobkin et al., 2018; Gross et al., 2020; Hu et al., 2018; Humphries et al., 2019). We may therefore consider deteriorating financial markers to correspond to declines in other welfare-relevant measures of well-being. ${ }^{31}$

We classify outcomes into three categories that (1) indicate financial problems, (2) suggest financial independence or access to credit, and (3) show consumer borrowing. In the first category, we include the amount of debt sent to a third party collection agency. This debt includes unpaid medical or utility bills, or severely delinquent credit card debt that has been sold to a third party. In addition to the debt in collections, we also examine debt that is 30 days or more past due on open accounts. This is debt that is delinquent but has not yet been sold to a third party, and would include, for example, unpaid credit card bills. We next include the number of "public records" from courts as a measure of serious financial distress. These records include any incident in which a credit interaction required an intervention via the court system-including actions such as bankruptcies, tax liens, or evictions. ${ }^{32}$ Finally, we include an indicator that a participant has a credit score at or below 600 , which is considered "subprime." 33

In the second category, measuring access to credit, we include the total amount of credit available on all credit cards (i.e., how much credit remains usable on all of the consumer's cards before hitting the cards' limits). More credit available indicates a greater cushion in case the consumer is faced with an unexpected expense. We also include an indicator that the consumer's credit score is in the "prime" (greater than 660) category. ${ }^{34}$ Finally, we include the credit score itself in this category.

The third category focuses on measures of consumer borrowing. We include an indicator that the consumer has a mortgage, the number of automobile loans, and her total credit card balance. Unlike the other two categories of outcomes, this category is more ambiguous with regards to the anticipated

\footnotetext{
${ }^{31}$ We pursued linkages to other measures of economic well-being, such as earnings as recorded in tax records, but were unsuccessful at getting the requisite agencies to agree to the match.

${ }^{32}$ Experian claims to have comprehensive public records, which it purchases from a third party vendor (although creditors also directly report bankruptcies to Experian). However, Experian has been accused of not promptly removing judgments that have been appealed through the courts system or vacated (e.g., because the borrower paid back the lender); see e.g. the court case Clark vs Experian Information Solutions Inc. So, it is possible the credit record includes some erroneous or "stale" public records.

${ }^{33}$ We use the Vantage score to measure credit score, which is similar to the FICO credit score and is used by all three major credit reporting agencies.

${ }^{34}$ Note that 601 to 660 is considered "near prime," see Experian (2015).
} 
effects of an abortion denial. While increased borrowing may reflect increases in living expenses or decreased income, it may also reflect lenders' willingness to supply credit, which likely grows with the consumer's income. Our analysis will necessarily detect the net effect of these underlying mechanisms.

In order to improve power, we combine these outcomes into three broad indices, a "financial distress index," a "credit access index," and a "borrowing index," by subtracting from each individual's value the mean of that outcome observed in the Near Limit group and dividing by the standard deviation of that outcome in the Near Limit group. We then average these standardized values across all outcomes. If credit score is missing, outcomes based on this variable are excluded; all other outcomes are always non-missing as long as the woman is matched to the credit record. This gives us a summary measure that we can use to test whether the entire category of outcomes was affected. ${ }^{35}$ Since the outcomes are equally weighted in these indices, however, they can potentially mask changes in individual outcomes if averaged with no effects or potentially opposite-signed effects on other outcomes. For this reason, we also present estimates for the individual components.

Table 2 presents summary statistics for the Near Limit and Turnaway groups at baseline, prior to the (counterfactual) birth year. We report the mean, standard deviations, and median values of these baseline characteristics. The mean values tend to be higher than the median values and in some cases they are substantially higher. This is due to the skewed distribution of financial data, in which a small number of individuals have very high levels of debt and delinquencies. Most financial characteristics are not significantly different across the Near Limit and the Turnaway groups in the pre-period. The only exception is that women in the Turnaway group are significantly less likely to have a mortgage. However, note that mortgages are very rare for both groups, with only 6 women in the Turnaway group and 27 women in the Near Limit group having a mortgage in the baseline period.

\section{Empirical approach}

For our main analysis, we examine how outcomes change over time for women in the Turnaway group relative to the Near Limit group using the "event time" variable that measures the number of years since the birth (for those in the Turnaway group who gave birth) or the number of years since the woman would have given birth (for those in the Near Limit group, and those in the Turnaway

\footnotetext{
${ }^{35}$ The use of summary indices with equally weighted components to combine related outcomes and limit the number of statistical tests follows the approach taken in many other recent empirical studies, including Bailey et al. (2020); Barr and Gibbs (2019); Hoynes et al. (2016); Kling et al. (2007).
} 
group who obtained abortions elsewhere, miscarried, or whose pregnancy outcome is unobserved). Event time is equal to zero in the year of the birth or counterfactual birth. Since our credit data are observed from 2006 to 2016, and since Turnaway participants were mostly enrolled in 2009 and 2010, we observe at least 3 years of pre-birth outcomes, outcomes during the year of the birth, and at least 5 years of post-birth outcomes for all participants. We use this 9 year period over which we observe outcomes for all participants in our analysis.

Figure 2 plots our primary outcome variables - the financial distress index (panel a), the credit access index (panel b), and the borrowing index (panel c) - by this event time measure. Similar plots for the components of these indices may be found in Appendix Figures A4 - A6. Prior to the birth, women in the Turnaway and Near Limit groups had very similar outcomes related to financial distress. These outcomes diverge beginning in the year of the birth, with an increase in financial problems observed among women in the Turnaway group and fairly stable outcomes in the Near Limit group. We also see similar trends in access to credit across the two groups (panel b), with a relative decrease in access to credit for the Turnaway group occurring around the time of the birth. This difference in access to credit, however, appears to close after three years. When we examine borrowing (panel c), there are more noticeable differences in the levels of the index during the pre-period. Changes over time, however, appear similar for the two groups during both the pre- and post-periods.

We formally test for the patterns presented in Figure 2 using an event study model that compares changes in financial outcomes for the Turnaway group to changes in the same outcomes in the Near Limit group before and after the birth or counterfactual birth. We estimate the regression

$$
Y_{i t}=\sum_{\substack{y=-3 \\ y \neq-1}}^{5} \beta_{y} \text { Turnaway }_{i} \times I\left(t-t_{i}^{*}=y\right)+\gamma_{y} I\left(t-t_{i}^{*}=y\right)+\delta_{i}+\epsilon_{i t} .
$$

In this model, we include event time indicators, $I\left(t-t_{i}^{*}=y\right)$, that denote time relative to the birth, $t_{i}^{*}$, for each individual $i$. Our estimates of interest are the coefficients on interaction terms for these event time indicators and an indicator that the participant was in the Turnaway group. These estimated coefficients, $\hat{\beta}_{y}$, measure the change in the relative outcome in year $y$ for the Turnaway group compared to the Near Limit group. The year immediately preceding the birth or counterfactual birth, $y=-1$, is the reference year. We include individual fixed effects $\left(\delta_{i}\right)$ in the model and robust standard errors are clustered at the individual level. ${ }^{36}$

\footnotetext{
${ }^{36}$ In our robustness section, we also conduct inference clustering at the level of the clinic.
} 
Ideally, the estimated coefficients $\hat{\beta}_{y}$ would be close to 0 for event years preceding the birth, and then diverge only after the birth if there were effects of the abortion denial. This would imply that the outcomes for the Turnaway and Near Limit groups evolved similarly prior to the birth and lend credence to the assumption that the trajectory of outcomes for the two groups would have been similar in the absence of the abortion denial.

We also estimate a differences-in-differences (DD) version of model (1) that replaces the event time indicators with a single post dummy for the year of birth and all years after. The effect of the abortion denial for the Turnaway group is estimated from an interaction of this post dummy and an indicator variable for the Turnaway group, providing a summary measure of the impact of abortion denial in all of the post-birth years:

$$
Y_{i t}=\beta_{D D} \text { Turnaway }_{i} \times \text { Post }_{t}+\beta_{2} \text { Post }_{t}+\delta_{i}+\epsilon_{i t} .
$$

The estimated coefficient $\hat{\beta}_{D D}$ captures the average change in outcomes for the Turnaway group relative to the Near Limit group after the abortion encounter.

Note that, in each of these models, any level differences in outcomes between the two groups are controlled for with the individual fixed effect; a simple comparison of means across the Turnaway and Near Limit groups without such an individual fixed effect may misestimate the impact of an abortion denial given the pre-birth differences between these groups. We demonstrate this later by comparing the estimates from our analysis with a simple post-period comparison between the Turnaway and Near Limit groups. A remaining concern, however, for our analysis is if any differences in individual characteristics lead the Turnaway and Near Limit groups to be differentially impacted by unobserved confounders during our study period. For example, one potential confounder is the Great Recession, the impact of which was related to household leverage and mortgage borrowing (Mian and Sufi, 2010). Since the Near Limit and Turnaway groups had different rates of having a mortgage in the pre-period, the recession may have affected the two groups differently, although as noted above mortgage rates were low in both groups.

To try and rule out the potential influence of any unobserved confounders that may have differentially impacted the two groups, we also present estimates that re-weight the Near Limit group to match the Turnaway group on pre-period changes in the delinquency, credit access, and borrowing indices using Oaxaca-Blinder weights (Kline, 2011, as used in, e.g., Busso, Gregory, and Kline, 2013). 
This analysis is designed to assess the sensitivity of our estimates when we improve the comparability of the two groups. We estimate standard errors using a bootstrap procedure. Further details about the weighting and bootstrapping procedure, and additional analyses that shows robustness to alternative methods of re-weighting the Near Limit group, are reported in Appendix Section A.

In addition to the main analyses described above, we also present results from several alternative sample definitions and specifications. First, we conduct additional analyses in which we include individuals even if they did not have a credit report match prior to the birth year. We include these observations by re-defining our dependent variable to assume that women who do not match to credit records in the pre-period have zero delinquencies, no mortgage, and no credit cards in these unmatched years. We then estimate the impact of abortion denial for this larger sample. Second, rather than assume that individuals without credit report matches have no financial activity in these years, we impute the average value for their group (Turnaway or Near Limit) for each outcome and year. Third, we include those who were under age 20 during the birth year and re-estimate our model using women of all ages. In addition to these alternative sample and variable definitions, we also conduct inference in our main analysis in an alternative way where we cluster our robust standard errors at the level of the clinic, rather than at the individual level. Next, we include calendar year fixed effects in the model to control for any secular changes in outcomes over time. We then assess the sensitivity of our estimates to outliers by re-coding observations in continuous variables that are above the 99th percentile of the outcome distribution or below the 1st percentile to these percentiles (i.e., "winsorizing" continuous variables). The influence of outliers may be particularly relevant in credit data, given the skewed distribution of financial outcomes. Next, we estimate an alternative specification that includes controls for changes in local economic conditions for both the Turnaway and Near Limit groups. We include a control for the state unemployment rate in each year, and also interact this unemployment rate with the indicator that the participant is in the Turnaway group.

Finally, we also examine whether allowing for a differential pre-trend for the Turnaway group affects the results in our event study model, following e.g. Gross et al. (2020). We implement this by including a linear term for the number of years relative to the birth/counterfactual birth for the Turnaway group that equals 0 in all years for the Near Limit group. We then estimate our event study model (1) including this term but omitting the pre-birth event study coefficients. 


\section{Results}

We report the event study coefficients, $\hat{\beta}_{y}$ of equation (1), for the delinquency and access indices in black in Figure 3. Estimates from the Oaxaca-Blinder reweighted analysis are presented in blue. The first graph (a) shows the effects of being denied an abortion on the financial distress index, which combines all delinquency outcomes into a single summary measure. Prior to the birth, outcomes of the Turnaway group and the Near Limit group had similar trajectories. Beginning in the year of the birth (year=0), however, we see a jump in markers of financial distress in the Turnaway group relative to the Near Limit group of between 0.10 and 0.20 standard deviations. Financial distress remains elevated in the Turnaway group over the entire post-period, although the coefficient estimates are not statistically significant toward the end of the period. Nonetheless, the pattern of coefficients indicates that financial delinquencies remain high over the 6 years following the birth.

Graph (b) shows the effect of abortion denial on measures related to access to credit. The coefficients on event years immediately following the birth are negative, indicating worse access for the Turnaway group with declines on the order of 0.05 to 0.1 standard deviations, but are not statistically significant. Starting three years after the birth year, the coefficients are close to zero, indicating no difference between the Turnaway and Near Limit group.

Graph (c) presents estimates for the borrowing index and shows no detectable difference in this outcome between two groups in either the pre- or post-periods.

Similar event study figures for the components of these indices are found in Appendix Figures A7-A9. In terms of financial distress measures (Appendix Figure A7), the post-birth coefficients are consistently positive (indicating worse outcomes) for the subprime credit score, the amount past due, and the number of public records, although the individual year coefficients are imprecisely estimated and not consistently statistically significant.

Among individual components of the access index (Appendix Figure A8), we see no evidence of an effect on the probability of having credit available, but a decrease in credit scores; the Turnaway group is less likely to be in the "prime" credit score range during the three years following the birth (although only statistically significant in the latter two years). Differences in this measure of creditworthiness appear to close by the third year after the birth year with coefficient estimates close to zero.

Finally, estimates for the individual components of the borrowing index (Appendix Figure A9) 
appear to be flat over the length of the study period, similar to the pattern seen for the summary index.

We present the DD estimates of equation (2) in Table 3, as well as the Oaxaca-Blinder reweighted DD estimates. The first row presents estimates from our main model for outcomes related to financial distress and delinquency, row two presents results for measures related to access to credit and financial self sufficiency, and the third row presents consumer borrowing. In the first column of Table 3, we see that outcomes related to financial distress increase by about one tenth of a standard deviation among the Turnaway group in the post period under both specifications, as compared to the Near Limit group. This effect is statistically significant at the 5 percent level.

We examine the components of the index in the subsequent columns. We find that the Turnaway group experienced significant increases in the amount of debt 30 days or more past due of $\$ 1,749.70$, a 78 percent increase relative to their pre-pregnancy mean. The estimated effect is slightly larger under the reweighted specification $(\$ 1,857.78$, or 83 percent). The number of public records, such as bankruptcies, tax liens, evictions, and other court judgements, significantly increases in the Turnaway group by 0.065 (under both specifications), or 81 percent. ${ }^{37}$ We observe positive effects of being denied an abortion on the probability of having a subprime credit score and the amount in collections, although these effects are not statistically significant. ${ }^{38}$

We also examine how being denied an abortion changed the probability that a woman in our sample had any collections or debt past due, the number of past due collections or accounts, as well as effects on the distributions of the amounts for each. To examine this, we construct indicator variables that the individual has debt past due or collections in each quartile of the pre-birth distribution of our sample and use these indicators as outcome variables. The results are reported in Appendix Table A4. We find that being denied an abortion did not change the likelihood of these events but did significantly reduce the probability a woman had $\$ 0$ in collections. Other estimated distribution effects are not statistically significant.

We present our estimates related to access to credit in the second row of Table 3. Although we

\footnotetext{
${ }^{37}$ In the Appendix, we separate public records into bankruptcies, tax liens, and all other court judgments, which are the most detailed categories permitted by our data. Although less precisely estimated, the results for the total number of public records appear to be driven by tax liens and judgments. See Appendix Table A2.

${ }^{38}$ Evaluating the impact of an abortion denial on collections of different types - for example, hospital bills versus utility bills - may be useful in determining the source of the financial distress. Unfortunately, such categorizations are only available in 2011 forward, which is entirely in the "post" period. We present differences across groups in the post period in Appendix Table A3; these differences are not statistically significant, but point estimates indicate that medical collections appear to be higher among the Turnaway group $(\mathrm{p}=0.17)$, which would be consistent with medical expenses associated with the birth and recovery being responsible for part of the financial distress effect.
} 
observe a negative point estimate for our overall DD coefficient, suggesting that the Turnaway group experienced decreases in credit access relative to the Near Limit group following the birth, it is small and imprecisely estimated. We also do not find any statistically significant estimates of abortion denial on the components of the access index under the DD model.

Finally, we present DD estimates for the borrowing index and its components in the last row of Table 3. The point estimates on the index coefficient are positive but close to zero and not statistically significant. We do not find significant estimates on the component measures, which also vary in sign.

An important feature of our study is our ability to compare changes in financial outcomes following the abortion encounter for the Turnaway and Near Limit groups, relative to their baseline measured using pre-data. To illustrate the importance of pre-data for our analysis, we show how estimates differ if we only compare the Turnaway and Near Limit groups using the post-period data in Table 4, without accounting for pre-existing differences across groups. As may be seen here, this comparison overstates the impact of an abortion denial on the borrowing index and the presence of a mortgage, and understates the impact on public records and amount past due, due to pre-birth differences across the groups.

\subsection{Sensitivity Analyses}

To assess the robustness of our results to alternative modeling, sample, and variable definitions, we present several additional estimates in Figure 4. For each summary index, this figure plots our baseline estimates from equation (1) in purple. Underneath the baseline estimate, we present estimates derived from a series of sensitivity analyses described below. In Appendix Tables A5-A7, we report the results of these analyses for each of the index component measures and for all outcomes using Oaxaca-Blinder reweighted methods.

First, we examine the sensitivity of our analysis to different sample definitions. Rather than exclude women with no credit report records during the pre-period but observed records in the postperiod, we assume that women who were not matched to the credit reports have no delinquencies (i.e., have $\$ 0$ past due and in collections and no public records) in our analyses of financial distress measures. With this re-coding, we observe a statistically significant increase in financial distress as indicated in yellow in the first panel of Figure 4. Appendix Table A5 shows the estimated increase is 0.117 standard deviations under our main specification and 0.125 under the reweighted specification. As may also be seen in this table, we continue to find significant and very similar estimates indicating 
an increase in the amount of debt 30 days or more past due and an increase in the number of public records.

Next, we impute the missing values for all participants who had at least one year matched to the credit records using the average amount observed in each year for members of their group. The estimates from this analysis are denoted in red in Figure 4. When we impute missing values in this way, we continue to see significant increases in indicators of financial distress of about 0.11 standard deviations, very similar to our baseline analysis. Combined with the analyses above, these results indicate that even with different assumptions and treatment of missing credit report records during the pre-period, the estimated financial effects of an abortion denial are robust.

Denoted in aquamarine on the graph, we show the estimates using women of all ages, rather than only including those who were at least 20 years old at the time of the birth (or counterfactual birth). This sample restriction was applied to avoid including the selected group of individuals who were teenagers in the pre-period and thus less likely to appear in credit report data (see Appendix Figure A1). The results using women of all ages are very similar to those reported for the main sample (see also Appendix Table A5). It remains the case, however, that these estimates are still more representative of older women since younger women are less likely to have established credit records during the pre-period in order to be included in this analysis.

We next re-estimate our main model but cluster our estimates at the clinic, rather than individual level, to account for any correlation of the error terms between women visiting the same clinic (depicted in orange on the graph). Our inference is essentially unchanged by this alternative level of clustering. Next, in blue, we estimate separate effects for each clinic and then aggregate these estimates, weighting each clinic-specific estimate by the fraction of the Turnaway group members in our sample at that clinic. Results are similar using this approach. Shown in grey, we include year fixed effects in our model, to account for any general trends by calendar time. The inclusion of these fixed effects does not noticeably affect our results. In green, we winsorize our data to reduce the influence of outliers for continuous variables. This recoding does not change the results very much, although the coefficient estimates are slightly smaller for some of the outcomes (see also Appendix Table A5). Finally, in tan, we include a control for the state unemployment rate in each year, and interact this unemployment rate with the indicator that the participant is in the Turnaway group. Including these variables may help account for any changes in the state's economic environment, and also allows for these changes to affect the Turnaway group differently than the Near Limit group. Our results change 
very little with the inclusion of these control variables, suggesting that our model is not picking up, for example, a differential response to local economic conditions by the Turnaway group.

To summarize, across multiple samples, variable definitions, methods of inference, and model specifications, we find strong evidence that being denied an abortion had large effects on markers of financial distress.

The next two panels of Figure 4 and Appendix Tables A6-A7 present the same robustness checks as those described above, but for our measures related to access and borrowing. In the first sensitivity analysis, we assume that women unmatched in the pre-period have $\$ 0$ in available credit during these years, and calculate the access index using this component only (i.e., we still allow credit score to be missing). For borrowing, we assume that women unmatched in the pre-period have zero credit card balances, automobile loans, and mortgages. All other analyses are implemented as described above. Consistent with the results in Table 3, we do not find statistically significant effects of being denied an abortion on any of these outcomes under these alternative sample, inference, and modeling choices, and the point estimates are all very similar to those provided by our baseline model.

Finally, it is important to note that although we do not find evidence that the Turnaway group was on a worse financial trajectory than the Near Limit group prior to the abortion denial, it may be the case that such differential trends were present but we do not have sufficient statistical power to detect them. Following the approach outlined in Roth (2019), we estimate that we can detect a positive linear pre-trend in the financial distress index in the unweighted model of 0.042 or larger with 80 percent power and of 0.017 or larger with 50 percent power. Even in this worst case scenario, where the largest possible undetectable trend exists, the resulting biases would not reach the size of our post-period coefficient estimates until the fourth year after the birth year for the trend estimated with 80 percent power, and never during the study period for the trend estimated with 50 percent power. ${ }^{39}$

We further explore whether such a differential trend might be driving our results by estimating an alternative version of our unweighted event study model that explicitly allows for a differential pre-trend. We estimate a version of equation (1) that includes a linear trend for the Turnaway group and omits the pre-birth event study coefficients, following Gross et al. (2020). The results are reported in Appendix Table A8. We continue to find higher rates of financial distress among the Turnaway group relative to the Near Limit group, although the point estimates are somewhat larger than in our

\footnotetext{
${ }^{39}$ We calculate the biases following the formula presented in Roth (2019), which takes into account the additional bias introduced by passing a pre-test.
} 
main specification. Consistent with our main results, we do not find evidence for changes in access to credit or borrowing.

\section{Additional Analyses}

We conduct a small number of additional analyses to provide more context for our results and to suggest possible directions for future research. Because of the limitations described along with each of these analyses, we consider these analyses to be mainly exploratory.

\subsection{Heterogeneous Effects by State Policy Environment}

First, we examine heterogeneity in the effect of an abortion denial based on the generosity of the social safety net in the state in which the woman resided at the time she sought an abortion. ${ }^{40}$ To characterize state safety net generosity, we examine the income threshold at which a household can gain eligibility for Temporary Aid to Needy Families (TANF). The federal government provides funding for this cash assistance program for low-income families to states who determine their own eligibility criteria for the program. We characterize states as "high generosity" if they allow TANF receipt at household incomes of 50.8 percent of the Federal Poverty Level or higher, corresponding to the average eligibility threshold observed in our data. ${ }^{41}$ The results are presented in Appendix Table A9. Women who live in low generosity states experience significant increases in financial distress following an abortion denial. We do not find a significant effect among women residing in high generosity states, although the point estimate is still positive indicating higher financial distress. In addition, the difference in coefficients is not statistically significant $(\mathrm{p}=0.18)$.

This result suggests that the financial impact of an abortion denial may vary according to the state policy environment. At the same time, we note that high and low generosity states differ on many dimensions other than TANF eligibility. For example, in our data, Turnaway group members who reside in high generosity states are denied abortions at significantly later gestational ages, indicating that these states permit abortions to occur later in the pregnancy. Differences in abortion restrictions and other state policies not included in this analysis may also be relevant in understanding the larger effects observed in the low generosity states.

\footnotetext{
${ }^{40}$ Note that although participating clinics were only in 21 states, more than 21 states are represented in this analysis because some women traveled to a different state to seek an abortion.

${ }^{41}$ Classification based on state eligibility rules in July 2008 drawn from Zedlewski and Golden (2010). States classified as "low generosity" are AL, AR, AZ, CO, DE, FL, GA, ID, IL, IN, KS, MA, MD, MO, MS, MT, NC, NJ, OR, PA, SC, TX and WV. States classified as "high generosity" are AK, CA, CT, IA, KY, ME, MI, ND, NM, NV, NY, OH, OK, SD, TN, VA, WA, and WI. Results are similar if we instead use the median (42 percent of the FPL) as the cutoff between "high generosity" and "low generosity" states.
} 


\subsection{Regression Discontinuity Model}

Next, we take advantage of the sampling design of the Turnaway Study to implement a regression discontinuity design that compares outcomes for women just above and below the gestation limit at each clinic. The RD approach aims to compare women who sought abortions at gestational ages just above or just below the age limit at their clinic. These women sought abortions at a very similar point in their pregnancy, but were treated differently by providers because of the gestational cutoff rules. An RD design that estimates level changes that occur at the cutoff abstracts from any systematic differences related to gestational age, providing an alternative method to estimate the causal effects of an abortion denial.

There are three important empirical challenges with applying the RD approach in our setting. First, since RD analyses effectively compare outcomes for individuals on either side of a given cutoff, this type of approach performs best when large sample sizes are available, which is not the case in our setting. For this reason, we use parametric regression, which uses all data available, to estimate the discontinuity at the cutoff (Lee and Lemieux, 2010). We also, however, present estimates using nonparametric methods (i.e. local linear regression).

Second, gestational age is determined by ultrasound measurement of the fetus under the assumption that its size is consistent with its age. As such, gestational age could be subject to mismeasurement or even manipulation by the ultrasound technician, which may result in women who are just "below" the cutoff differing systematically from women just "above" the cutoff. We can evaluate this empirically by looking at differences in financial outcomes for women just above or below the cutoff in the years prior to the pregnancy and (counterfactual) birth. For survey respondents, we can also assess whether there are any differences around the cutoff in other socioeconomic characteristics as measured one week after the abortion encounter. We also implement a "donut RD" (Barreca et al., 2016) that aims to limit any bias from possible manipulation by excluding women whose gestational ages are at the cutoff or within one day of the cutoff.

Third, we do not have information on the exact gestational age cutoff used at each clinic. Between 2008 and 2010, the period during which women were recruited into the Turnaway Study, several sample clinics changed their cutoffs, and these changes were not documented. In addition, even within a clinic, the latest age at which an abortion can be performed may vary due to physician availability or changes in the clinic's internal rules and practices. Given this lack of precise information on the relevant cutoff for each woman's specific clinic encounter, we use a data-driven procedure to estimate 
the most common gestational age cutoff used at each site. More details on this procedure are found in Appendix Section B.

We proceed with the RD analysis addressing each of these limitations as described above. Using each clinic-specific cutoff $\left(\right.$ cutoff $\left._{c}\right)$, we define the distance to the cutoff for each woman $i$ presenting at clinic $c$ as $g_{i c}=$ gestation days $_{i}-$ cutoff $_{c}$. If $g_{i c} \geq 0$, the woman is likely to be turned away; otherwise, she is likely to receive the abortion. Although this is a "fuzzy" RD, in the sense that some women past the cutoff received abortions while some before the cutoff were turned away (due to mismeasurement of the cutoff, changes in the cutoff over time, or physician availability), it is determined through examination of this information, and therefore, performs well in predicting whether a woman was turned away. Appendix Figure A10 shows the fraction of women who were turned away at each day of gestation relative to the estimated clinic-specific cutoff. There is a large increase of about 85 percentage points at the estimated cutoff.

Using this estimated cutoff, we implement the RD analysis in two ways. First, we estimate a simple parametric regression that includes a linear trend in days from the cutoff that is allowed to vary on either side of the cutoff and an indicator variable that a woman's pregnancy is at or over the estimated gestational week cutoff for the clinic. Specifically, we estimate:

$$
Y_{i c t}=\beta_{0}+\beta_{1} 1\left(g_{i c} \geq 0\right)+\beta_{2} g_{i c}+\beta_{3} 1\left(g_{i c} \geq 0\right) \times g_{i c}+\epsilon_{i c t} .
$$

Second, we estimate a local linear regression using the Fuji et al. (2009) optimal bandwidth selector. This method has the advantage that it puts more weight on data points closer to the cutoff when estimating the discontinuity. The tradeoff is reduced precision since fewer data points may be used in its estimation and the fact that this method is less suited for discrete running variables such as gestation age, which is measured in days (Cattaneo et al., 2020). In all analyses, we cluster the standard errors at the individual level. ${ }^{42}$

We first present RD plots for each event year relative to the birth/counterfactual birth year (again we refer to this as "birth year" for simplicity). Appendix Figure A11 plots the financial distress index by days of gestation relative to the estimated clinic-specific cutoff. Note that we center the figures at zero, indicating the cutoff of the relevant clinic for each individual, but that the estimated cutoff age varies by clinic. Panels (a)-(c) show the difference at the cutoff during the three years prior to the birth.

\footnotetext{
${ }^{42}$ Note that our standard errors may somewhat overstate our precision since we must infer the clinic-level cutoffs.
} 
If women close to the cutoff differ systematically for reasons other than the abortion denial, we might expect to see discontinuities in these pre-pregnancy years. However, we do not see any evidence of differences at the cutoff prior to the birth year.

Panel (d) of Appendix Figure A11 shows the difference in the financial distress index at the cutoff in the year of the birth, and panels (e)-(i) show the differences in the years following the birth. In the first three years following the birth there appears to be a discontinuity at the cutoff, with women who were turned away experiencing relatively higher rates of financial distress. This difference becomes less apparent in years 4 and 5, consistent with the patterns documented in the plot of the data by event time in Figure 2. Similar results for the access and borrowing indices are presented in Appendix Figures A12 and A13. The figures associated with these outcomes are fairly noisy and the patterns are less clear.

When we run the regression analyses, we pool years to increase precision. Motivated by the pattern observed in Figure 2, we estimate the RD model in four time periods. In the first row of Appendix Table A10, we show the RD estimate pooling observations for one, two, or three years prior to the birth. Consistent with the figure, we do not find a statistically significant discontinuity in financial distress at the cutoff in this pre-birth period. In row 2, we present the RD estimates using observations from the year of the birth. In this year, we see a statistically significant increase in the financial distress index in the linear model, but not in the local linear regression specification. For observations one to two years after the birth year, reported in row 3, we observe significant increases in the financial distress measure in the parametric linear $(p \leq 0.05)$ and local linear $(p \leq 0.10)$ regression models. These estimates indicate that financial distress increased by between 0.18 and 0.19 standard deviations during these years. This increase is slightly larger to that estimated under the event study model in Figure 3 during these years. In row 4, we see a marginally significant increase in financial distress $(p \leq 0.10)$ during the period three to five years following the birth year under the parametric model but not under the local linear model. We do not find significant differences at the cutoff in our access or borrowing measures during any of the time periods. The results for all three indices are similar if we drop women whose gestational age is at or close to the cutoff (i.e. a "donut" RD). See Table A11 in the Appendix.

We further probe whether there are baseline differences across the gestational age cutoff using data from the initial Turnaway Study survey for those who responded. We find little evidence of statistically significant variation at the cutoff on these dimensions, although some point estimates are 
large (see Appendix Table A12 and Appendix Figure A14). We explore the extent to which these differences in baseline characteristics affect our estimates by controlling for these survey measures, using only the sample of women who completed the initial survey. We find similar estimates when including these variables as controls, although the reduced sample size does decrease precision somewhat (see Appendix Table A13). In addition to controlling for these survey measures, we also run an alternative specification that estimates the difference in the discontinuity over the pre- and post-periods. This "RD-DID" analysis accounts for any pre-existing differences in outcomes at the cutoff. Further details on this analysis and the results, which are consistent with those presented in the main RD analysis, may be found in Appendix Section C. Combined, this evidence suggests that the effects we are uncovering are due to the abortion denial, rather than unrelated changes in the sample occurring at the gestational age cutoff.

These RD estimates are broadly consistent with the patterns presented in Figures 2 and 3. Credit report outcomes were similar for the two groups of women prior to the birth but financial outcomes worsened for the Turnaway group after the birth, with the most pronounced effects appearing in the year of the birth and the two years immediately following the birth year.

\subsection{Exploration of Mechanisms from the Turnaway Study Follow-Up Surveys}

To better understand the economic circumstances of these women and clarify the mechanisms underlying our findings, we turn to additional data collected in the Turnaway Study. In the initial survey interview conducted one week after being denied an abortion, the majority of women in our sample in the Turnaway group were unmarried (83 percent), already had children (61 percent), and were unemployed (48 percent). Many were living with adult family members and few with a spouse or partner. More than 43 percent reported that they did not have enough money to cover housing, transportation, and food at least "most of the time." This suggests that women in the Turnaway group were already economically vulnerable prior to any additional financial consequences experienced as a result of the abortion denial.

We conduct an exploratory analysis of how survey outcomes evolved for these women in our sample relative to the Near Limit group. ${ }^{43}$ The outcomes examined here were analyzed previously in Foster et al. (2018), but we conduct our own analysis in order to limit the data to respondents included

\footnotetext{
${ }^{43}$ The sample for this analysis is necessarily restricted to women who responded to the Turnaway Study surveys. When we re-run our analysis of credit report data for the subgroup of women who continued to respond the Turnaway surveys until the end of the 5-year study, our point estimates are similar to what we find when using the full sample, although imprecisely estimated due to the much smaller sample size. We believe this highlights one of the advantages of our administrative data: that it allows us to have larger sample sizes because it does not rely on continued individual participation.
} 
in our main credit report sample (i.e. those who were matched to the credit record data for at least one year in the pre-period and who meet our age restrictions). Conducting our own analysis of the Turnaway data allows us to produce estimates that are the most relevant and comparable to our credit report results, although they differ somewhat from those presented in Foster et al. (2018), which used the entire sample of survey respondents and focused on the subset of women in the Turnaway group who carried their pregnancies to term. The analysis in Foster et al. (2018) also used different statistical methods, making their estimates not directly comparable to those presented here.

Because women were first interviewed one week after the abortion encounter, we have both pre- and post-data available for the birth (or counterfactual birth) and are able to estimate our main difference-in-differences specification (equation 2). However, in contrast to the credit report data, we are not able to evaluate whether pre-birth trends are similar across the Near Limit and Turnaway since we are limited to one observation period prior to the birth. In addition, a fairly large percent of respondents in our sample (24 percent at baseline) did not provide household income information, resulting in smaller sample sizes for this outcome. Because of these limitations, we consider our analysis in this subsection to be exploratory. We present yearly estimates, analogous to the event study coefficients, in Appendix Figures A15-A16 and difference-in-differences estimates in Appendix Tables A14-A15.

Consistent with Foster et al. (2018), we do not find strong evidence that monthly household income fell for the Turnaway group relative to the Near Limit group after the birth. However, because household size increased among Turnaway group respondents, their income as a percent of the FPL fell significantly, by about 28 percentage points. By year 4 after the birth year, this difference in income relative to FPL across the Near Limit and Turnaway Group appears to have closed (panel c of Appendix Figure A15).

We do not find evidence of changes in employment (panel d), but do find an increase in the receipt of public benefits. Specifically, we see that receipt of WIC increased significantly in the Turnaway group relative to the Near Limit group (panel e), with most of the increased receipt occurring in the year of the birth. We do not find statistically significant changes in TANF or food stamp receipt (panels e and g), although the estimated coefficients are positive for both of these outcomes, suggesting that use of these public programs may have increased as well. In addition, we are unable to examine changes in benefit amounts with the data available. Our point estimates suggest that child support payments to women in the Turnaway group increased following the abortion denial by about $\$ 20$ per month in the years following the birth year, but these effects are not statistically significant (panel h of 
Figure A15). Finally, we do not find a significant change in the share of women reporting they do not have enough money "most of the time" (panel i), although the point estimate is positive, indicating an increase in this measure.

We also see that the Turnaway group experienced significant changes in their living situation relative to the Near Limit group (Appendix Figure A16 and Table A15). Following the birth, the Turnaway group was no more likely than the Near Limit group to be living with a male partner and significantly more likely to be living alone with her child or children. The yearly estimates also suggest that the Turnaway group was somewhat less likely to be living with adult family or nonfamily roommates than the Near Limit group (panels b and e of Appendix Figure A15).

Taken together, these results suggest that women who were denied abortions needed to care for an additional child without experiencing increases in income or support from male partners. Women in the Turnaway group may have experienced higher housing costs, in addition to the expenses associated with a new baby, as they became less likely to live with family or roommates following the birth. Increased participation in public programs, in the form of higher levels of WIC receipt, was also short lived. Such patterns likely drive the patterns of the inability to meet financial obligations documented in our credit report analysis.

\subsection{Comparison to Subsequent Pregnancies in Near Limit Group}

By affecting a woman's ability to receive or not receive an abortion, gestational limits may remove the option for women to have no children, in addition to changing the timing of when they have a child. Notably, only 25 percent of women in the Near Limit group who received a wanted abortion went on to have a child during the 5-year study period. In addition, prior research has documented that access to abortion has effects on completed fertility rather than just delaying childbearing; abortion legalization led to an increase in the share of women remaining childless (Ananat et al., 2007).

While acknowledging this, it may still be of interest to know whether the financial distress experienced by the Turnaway group around the time of the birth was similar to that experienced by women with similar socioeconomic status giving birth after more wanted pregnancies. It may be the case that the burden experienced by the Turnaway group is particularly high when compared to an alternative where women are able to more optimally time childbearing. Such a comparison is difficult because, to our knowledge, there is no comprehensive data linking information on socioeconomic status, birth timing and wantedness, and credit report information. Even if such data existed, it would be difficult 
to match the Turnaway group to "equally" disadvantaged childbearing women since women seeking abortion may vary on unobservable or difficult-to-measure dimensions such as partner, family, or community support.

To shed light on this comparison, we conduct an exploratory analysis using members of the Near Limit group who gave birth in the five years following their abortion. This analysis takes advantage of information on subsequent births collected by the Turnaway Study follow-up surveys. These births represent a mix of wanted and unwanted births that is likely more representative of a "typical" birth among women in our sample, which we are able to compare to the explicitly unwanted births observed for the Turnaway group. ${ }^{44}$ Similar to our analysis of the Turnaway women, we restrict the sample to women in the Near Limit group who had a follow-up birth, were at least 20 years old in the year they gave birth, and had a match to the credit reporting agency database prior to the birth. We emphasize that this is exploratory as only 97 Near Limit participants had an observed birth over this period and meet our sample criteria. However, this sample does give us the opportunity to explore how financial outcomes change around childbirth for a sample of women with similar socioeconomic status as the Turnaway group, but whose birth did not necessarily result from an abortion denial.

Since we only observe most women for a limited time after their subsequent birth, which tended to occur between 1 and 3 years following their abortion, we define our follow up period in this analysis as the four years following the birth. We continue to define the pre-period as the three years prior to birth, to follow our approach in the main analysis for Turnaways. As a comparison group, we use Near Limit participants who did not give birth. We estimate the following model:

$$
Y_{i t}=\sum_{\substack{y=-3 \\ y \neq-1}}^{3} \beta_{y} I\left(t-t_{i}^{\dagger}=y\right)+v_{t}+\delta_{i}+\epsilon_{i t} .
$$

Here, $t_{i}^{\dagger}$ is the year in which the Near Limit participant gives birth, $v_{t}$ are calendar year fixed effects, and $\delta_{i}$ are individual fixed effects. The coefficients on the event study indicators, $\beta_{y}$, show how financial outcomes changed for the Near Limit group who gave birth relative to the time trend experienced by Near Limit participants who did not give birth, as captured by $v_{t}$. Robust standard errors are clustered by individual.

The results are presented in Appendix Figure A17. To facilitate comparison, we add the event

\footnotetext{
${ }^{44}$ On the London Measure of Unplanned Pregnancy, for which higher values (out of a maximum score of 12) indicate more planned births, subsequent children born to the Near Limit group scored a 6.8, while births to the Turnaway group following the abortion denial scored a 2.8 (Foster et al., 2018).
} 
time estimates for the Turnaway group, re-scaled by the fraction of women in the Turnaway group who gave birth; these estimates are plotted with a solid green line. ${ }^{45}$ The estimates of $\beta_{y}$ from the Near Limit model described in equation (4) are plotted with a dashed blue line. The point estimates on the effect of financial distress for subsequent Near Limit births are smaller than those observed among the Turnaway group and are not statistically significant (panel a). In addition, the confidence intervals on the estimates for the Near Limit births do not include the coefficient estimates for the Turnaway group. We see no evidence of changes in credit access or borrowing following the subsequent births of the Near Limit group, with coefficient estimates very close to zero.

These results suggest that births that occurred following a subsequent pregnancy result in less financial distress than those that occur after an abortion denial. In addition, this may be an underestimate of any difference in the financial effects between wanted and unwanted births, given that some of these subsequent births likely resulted from unplanned or unwanted pregnancies. ${ }^{46}$ However, we note that the confidence intervals of the two estimates do overlap, making it difficult to draw strong conclusions from this exercise.

\section{Conclusion}

Restrictions on abortion are growing in prevalence in the U.S. with nearly half of the 1,320 state laws restricting abortion access enacted since Roe $v$. Wade occurring over the last 10 years (Nash and Naide, 2021). Gestational limits are one of the most common types of restrictions for women seeking abortion services with limits currently in place in 43 states (Kaiser Family Foundation, 2019). These limits ban abortions for most women between 20 to 24 weeks from the date of their last menstrual period, or at the point of fetus viability. In recent years, as many as 13 states have attempted bans on abortion much earlier in pregnancy that have been challenged and stopped at court order. ${ }^{47}$ The upcoming Supreme Court case Dobbs v. Jackson Women's Health Organization may lead the court to rule that these types of pre-viability bans are constitutional.

Despite the fact that such laws are pervasive, we have little data documenting how being denied an abortion affects the financial and economic well-being of women. This paper provides the first

\footnotetext{
${ }^{45}$ For the purpose of this re-scaling, we apply the birth rate (68 percent) for the Turnaway group calculated among those individuals with observed pregnancy outcomes.

${ }^{46}$ Our rescaling of the Turnaway estimates assumes, however, that all financial effects are concentrated among the women who gave birth. This could lead to potentially overstating the difference between wanted and unwanted births if the financial consequences were shared more equally among women in the Turnaway group who did and did not give birth.

${ }^{47}$ These attempted bans include limits at 6 weeks after the woman's last menstrual period in 8 states and bans on abortion at any time during pregnancy in 3 states (Guttmacher Institute, 2021).
} 
evidence on this topic using longitudinal data that allows us to observe women both before and after the abortion denial. We link high-quality administrative data from credit reports to participants in the Turnaway Study. These data allow us to compare the trajectory of outcomes for women who were denied (Turnaway group) versus received wanted abortions (Near Limit group) on the basis of state and facility gestational limits.

We find evidence that being denied an abortion has large and persistent negative effects on a woman's financial well-being. Women denied an abortion experience a significant increase in financial distress during the year that they give birth (or, in some cases, would have given birth since some of them received an abortion elsewhere or miscarried), compared to their counterparts who received a wanted abortion. Unpaid debts that are 30 or more days past due more than double in size, and the number of public records, which include negative events such as evictions and bankruptcies, increases substantially. This financial impact extends throughout our sample period, with negative effects observed up to four years after the birth year. While we do not find as strong of evidence of changes in the financial independence of these women, as measured through markers of credit access, we do find that the women who were denied an abortion were significantly less likely to have a prime credit score in the two years following the birth. We find little evidence that the amount borrowed, measured by credit card balance, number of auto loans, and presence of a mortgage, changed following the abortion denial.

The size of the effects are substantial when compared to effects documented in other settings. While the women in our study differ from the populations analyzed in other settings, estimates based on other interventions could still provide a useful benchmark for what size of effects we might expect. For example, the impact of being denied an abortion on collections is as large as the effect of being evicted (Humphries et al., 2019) and the impact on unpaid bills is several times larger than the effect of losing health insurance (Argys et al., 2019). Although imprecisely estimated in our setting, it appears that denying a woman an abortion reduces her credit score by more than the impact of a health shock resulting in a hospitalization (Dobkin et al., 2018) or being exposed to high levels of flooding following Hurricane Harvey (Billings et al., 2019).

We can draw additional insights into the mechanisms behind these changes from the Turnaway Study follow-up surveys. Using survey data from Foster et al. (2018), but implementing our sample criteria and empirical approach, we find that women's household income as a percent of the FPL fell for the Turnaway group relative to the Near Limit group after the birth or counterfactual birth. At 
the same time, women in the Turnaway group did not experience significant relative increases in the probability of living with a male partner and, if anything, experienced decreases in the probability of living with adult family, such as parents, or other adult roommates. Instead, women in the Turnaway group became more likely to live alone with their children. The Turnaway group experienced relative increases in the use of WIC in the year of the birth and small, marginally statistically significant increases in the amount of child support received each month. In sum, while women's family obligations and need for resources increased following the abortion denial, they did not appear to experience increases in support from male partners, adult family, or the government to sufficiently offset these responsibilities, possibly driving the inability to meet financial obligations documented in our credit report analysis.

While acknowledging that abortion restrictions affect a woman's ability to decide not to have any children, in addition to the timing of such children, we also explore whether the financial consequences observed for births following an abortion denial are similar to those observed after a birth that results from a typical pregnancy. To do this, we use information for women in the Near Limit group who received a wanted abortion but who later became pregnant and gave birth. These women have similar socioeconomic characteristics to the Turnaway group. These births were a mixed of planned and unplanned births more similar to a "typical" birth experienced in this population, rather than an explicitly unwanted birth such as those experienced by the Turnaway group. Among these subsequent births, we find that the financial consequences of giving birth are less severe, although our confidence intervals are large and we cannot reject that the effects are the same as those for the Turnaway group who gave birth. However, this exploratory analysis documents the financial consequences of childbearing and suggests that more wanted or optimally timed births may impose a smaller financial penalty. Future research may investigate child penalties in women's financial outcomes and how they relate to the earnings penalties documented in many high-income countries (Kleven et al., 2019).

Our study indicates that laws that impose gestational limits for abortion result in worse financial and economic outcomes for the women who are denied an abortion. For the women who carry their pregnancies to term (the vast majority in our sample), there are likely to be important implications for the well-being of their offspring. There is a large literature documenting the importance of the early life environment for health and achievement over the life course. In particular, evidence indicates that human capital development under age 5 can have large long-term impacts (Currie and Almond, 2011). Given that we observe significant financial distress for the women who were turned away during this 
period, there may be negative consequences for children's basic needs and other investments during this critical period. Providing some evidence for this, the Turnaway Study documented that women from the Turnaway group who carried their pregnancies to term experienced worse bonding with their child than women who received an abortion and later had a subsequent child. Children of the Turnaway mothers also lived in households with lower income levels and were less likely to have money to cover their basic living expenses than these other subsequent children (Foster et al., 2018). ${ }^{48}$

There are several implications for public policy. If policymakers wish to avoid the adverse economic consequences documented here, one option would be to relax laws that impose a gestational limit for abortion. At clinics for which these laws are binding, increasing gestational age limits would allow more women to be served. At the same time, several clinics choose gestational age limits that are below those legally allowed, due to clinicians' training, availability, or preference. Increasing the number of clinicians available to perform these services (for example, by reducing the regulatory burdens imposed on abortion providers) may help alleviate these supply side constraints.

An alternative approach is to craft policies that make it less likely that women will seek abortions at later gestational ages. We can again benefit from data collected by the Turnaway Study to identify barriers to women seeking abortions earlier in their pregnancies (Upadhyay et al., 2014). The majority of women in the Near Limit (67 percent) and Turnaway (58 percent) study groups named travel and procedure costs as a reason for their delay in seeking an abortion. Reports of other common barriers include administrative and logistical problems related to insurance coverage for the procedure, not knowing where to get care, and not knowing how to get to a provider. These responses suggest that increasing the availability of abortion providers and the affordability of the procedure may help to reduce delays in seeking care. However, other reasons that may be more difficult to address are women not recognizing their pregnancy (reported by 43 percent of women in the Near Limit group and 48 percent of women in the Turnaway group), or difficulty deciding whether to have an abortion (44 percent and 40 percent, respectively). Given that the current trend has been for state laws to lower gestational limits, with recent efforts to ban abortions as early as 6 weeks or even throughout the entire pregnancy (Guttmacher Institute, 2019), it seems likely that the number of women being denied a wanted abortion in the U.S. will only continue to grow over time.

\footnotetext{
${ }^{48}$ The Turnaway Study also documents potential impacts for the other children of these women: the children that women already had at the time of seeking an abortion fare worse in terms of achieving developmental milestones and living in economic security when their mothers were denied, rather than receiving a wanted abortion (Foster et al., 2019). Also, women in the Turnaway group that carried the pregnancy to term were less likely to have subsequent pregnancies, and were less likely to express that they intended to become pregnant again in the future, compared to the Near Limit group (Upadhyay et al., 2019).
} 
Figure 1: Histogram of Gestational Age of Pregnancy at Time of Abortion Receipt or Denial

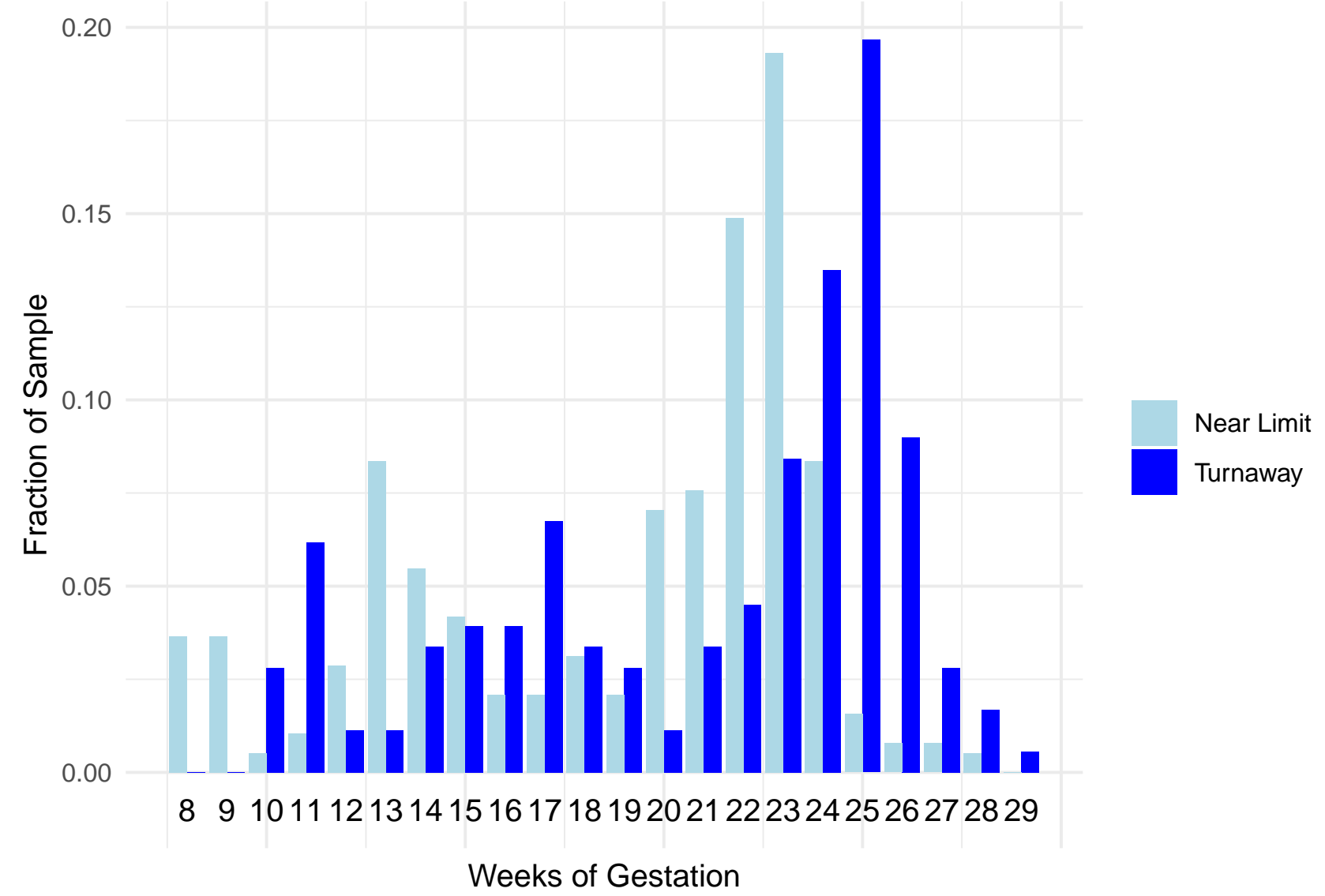

Note: These figures display histograms of the distribution of the sample for the Turnaway and Near Limit group based on the gestational age of the pregnancy at the time of abortion denial (in the case of the Turnaway group) and abortion receipt (in the case of the Near Limit group). 
Figure 2: Financial Outcomes Relative to Event Time, by Group

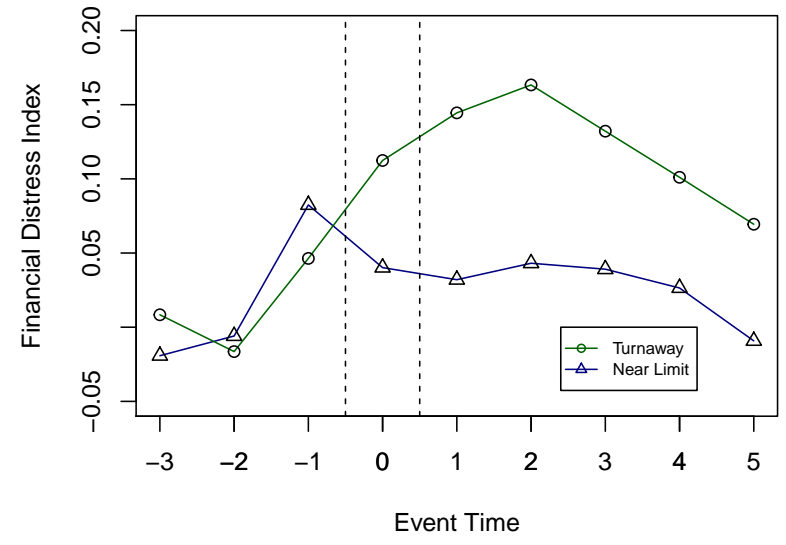

(a) Financial Distress Index

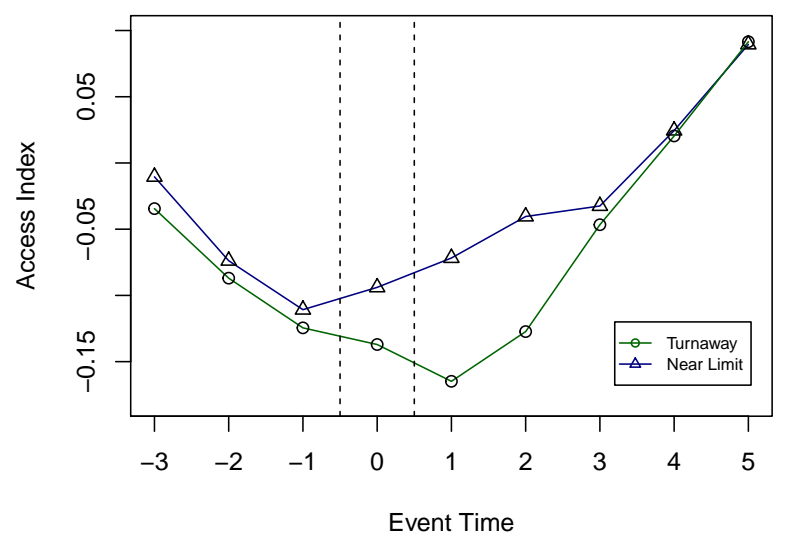

(b) Credit Access Index

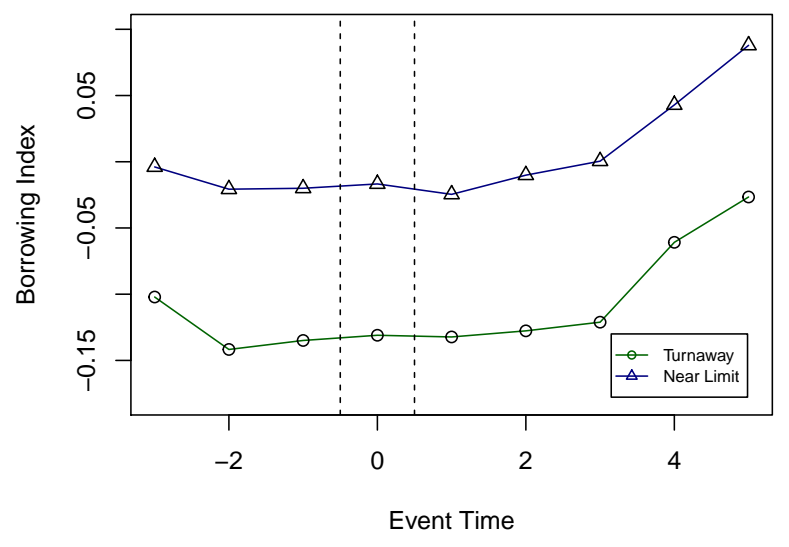

(c) Borrowing Index

Note: These figures show the average value of the financial distress index (panel a), credit access index (panel b), and borrowing index (panel c) by year for the Turnaway and Near Limit groups in the main sample. See text for more information. 
Figure 3: Event Study Estimates of Effect of an Abortion Denial on Financial Outcome: Unweighted (Black) and Reweighted (Blue)

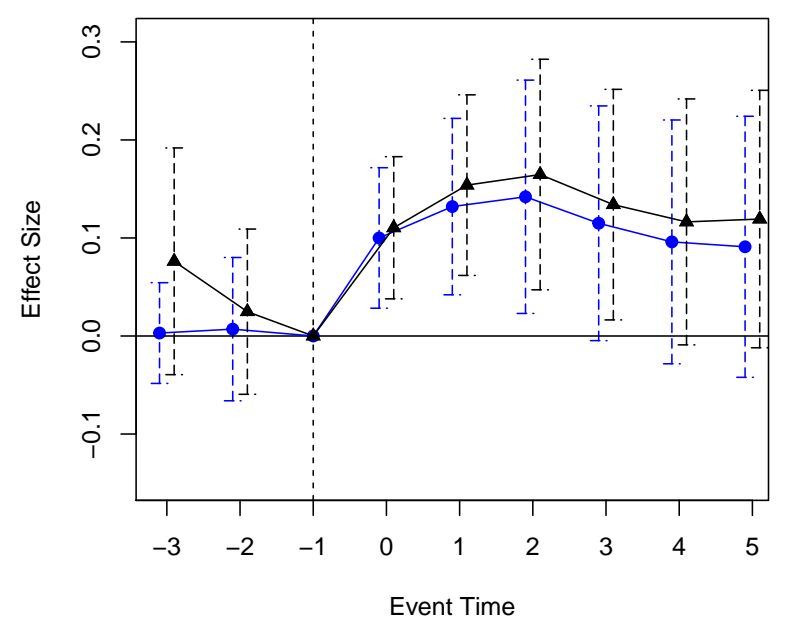

(a) Financial Distress Index

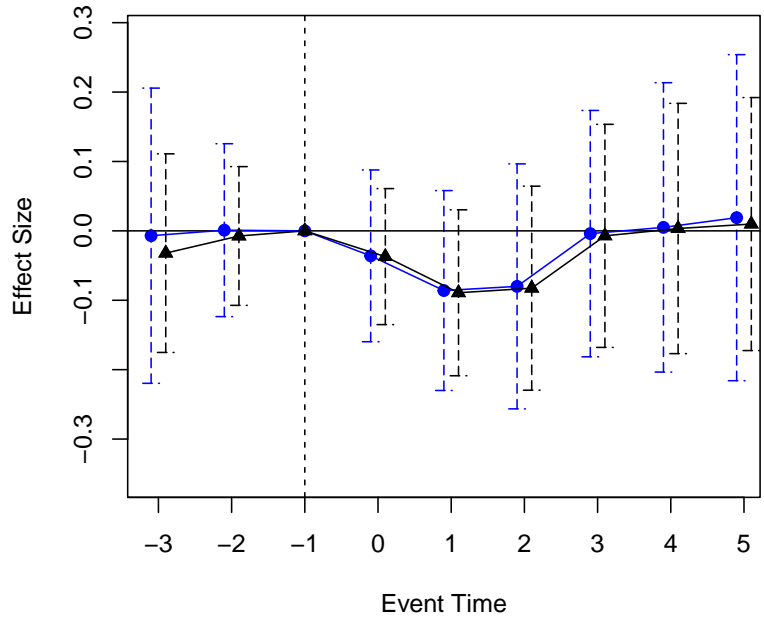

(b) Credit Access Index

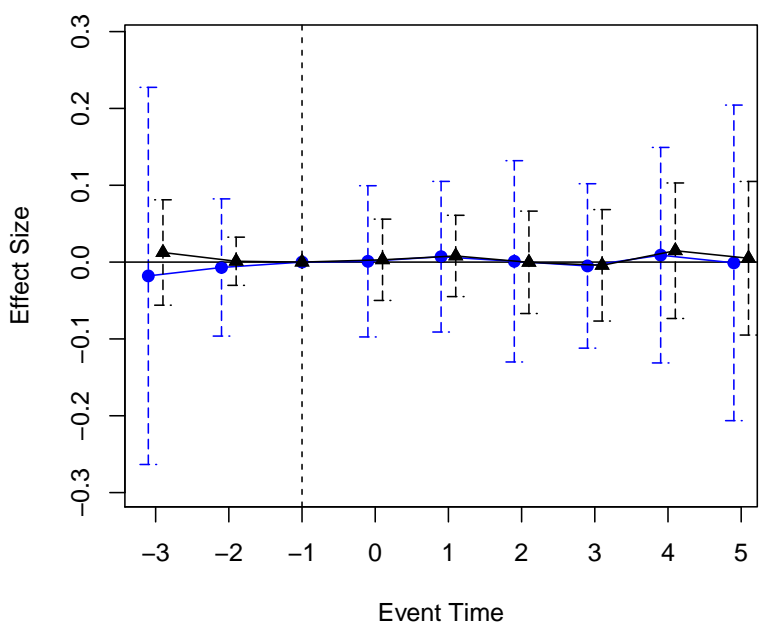

(c) Borrowing Index

Note: These figures report coefficients from the estimation of Equation (1) for the financial distress index (panel a), credit access index (panel b), and borrowing index (panel c). The coefficients represent the change in each outcome for Turnaway group members relative to Near Limit group members in the three years before and six years after the time of birth or counterfactual birth, as compared to the year immediately prior to this event. See text for more information. 


\section{Figure 4: Robustness to Alternative Samples and Specifications}

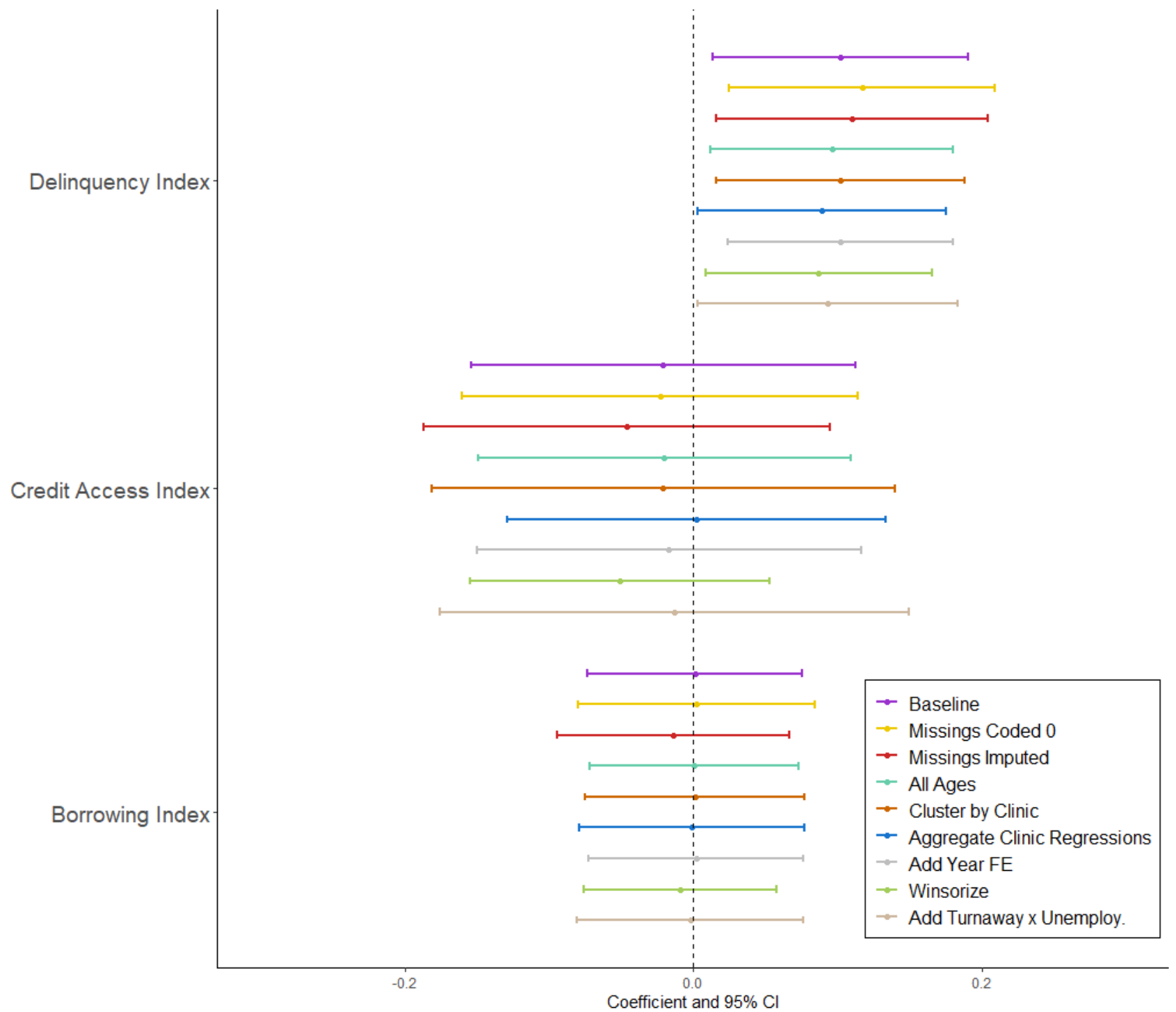

Note: This figure displays difference-in-differences coefficients and $95 \%$ confidence intervals for specifications and sample definitions described in Section 4.1. See text for more information. 
Table 1: Initial Survey Measures Across Study Groups (Survey Respondents Who Matched to Credit Records)

\begin{tabular}{lc|c|c|cc}
\hline Characteristic & First Trimester & Near Limit & Turnaway & \multicolumn{2}{|c}{ Diff b/w Turnaway and } \\
& & & & First Trimester & Near Limit \\
\hline HS Education or Less & 0.422 & 0.480 & 0.453 & $0.032(0.052)$ & $-0.027(0.049)$ \\
Married & 0.113 & 0.081 & 0.0933 & $-0.020(0.039)$ & $0.012(0.028)$ \\
Full Time Employed & 0.430 & 0.357 & 0.267 & $-0.164(0.049)^{* *}$ & $-0.091(0.045)^{* *}$ \\
Part Time Employed & 0.213 & 0.219 & 0.233 & $0.020(0.044)$ & $0.014(0.041)$ \\
Enough Money & 0.648 & 0.553 & 0.570 & $-0.077(0.051)$ & $0.018(0.049)$ \\
In Poverty & 0.394 & 0.555 & 0.529 & $0.136(0.061)^{* *}$ & $-0.026(0.058)$ \\
Age at Survey & 26.5 & 25.6 & 24.8 & $-1.75(0.556)^{* * *}$ & $-0.807(0.513)$ \\
Received WIC & 0.130 & 0.153 & 0.160 & $0.030(0.037)$ & $0.007(0.036)$ \\
Received TANF & 0.087 & 0.117 & 0.127 & $0.040(0.033)$ & $0.010(0.032)$ \\
Received Food Stamps & 0.287 & 0.345 & 0.400 & $0.113(0.050)^{* *}$ & $0.055(0.048)$ \\
Black & 0.291 & 0.303 & 0.267 & $-0.025(0.047)$ & $-0.037(0.044)$ \\
White & 0.439 & 0.357 & 0.420 & $-0.019(0.052)$ & $0.063(0.048)$ \\
Latina & 0.192 & 0.187 & $-0.005(0.041)$ & $-0.006(0.039)$ \\
Other Race & 0.191 & 0.147 & 0.127 & $0.048(0.032)$ & $-0.020(0.033)$ \\
\# Individuals & 0.078 & 333 & 150 & & \\
\hline
\end{tabular}

Note: This table presents means for characteristics observed in the initial survey of the Turnaway Study for individuals matched to the credit records in any year who are at least 20 years old in the birth year. The final columns show the difference between the Turnaway group and the First Trimester and Near Limit groups, respectively. Asterisks indicate statistically significant differences: ${ }^{* * *} \mathrm{p}<0.01,{ }^{* *} \mathrm{p}<0.05,{ }^{*} \mathrm{p}<0.1$. 


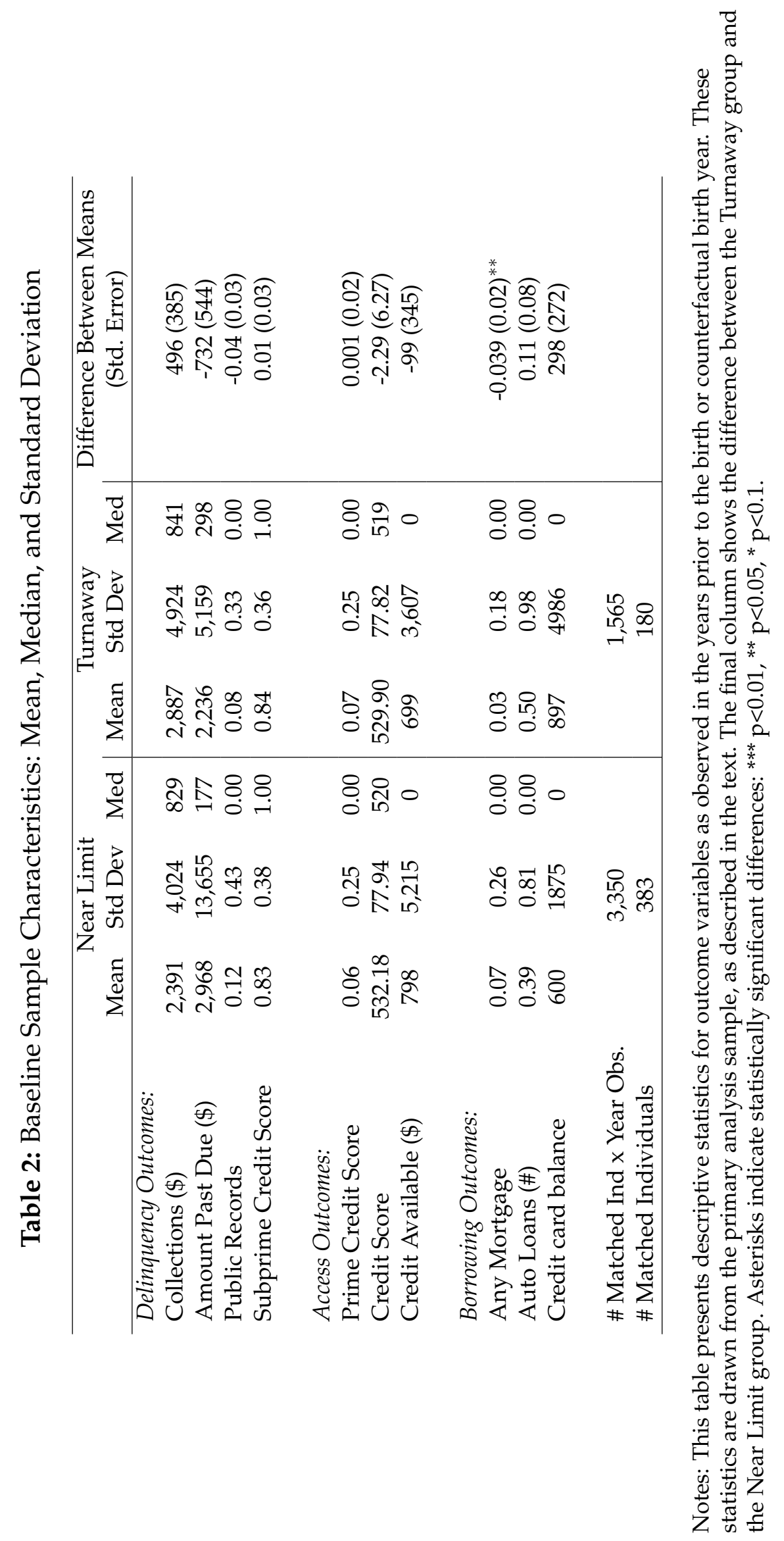




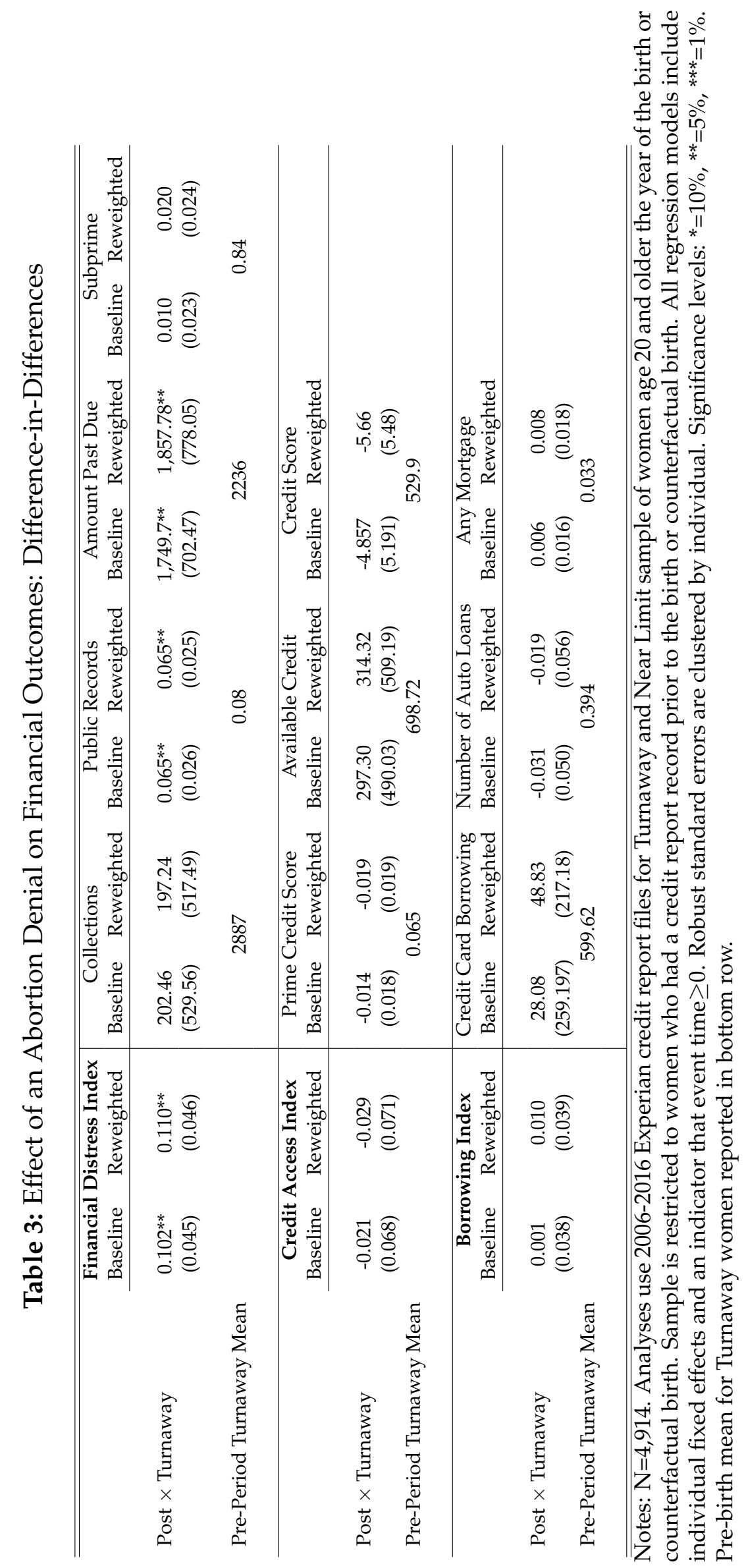




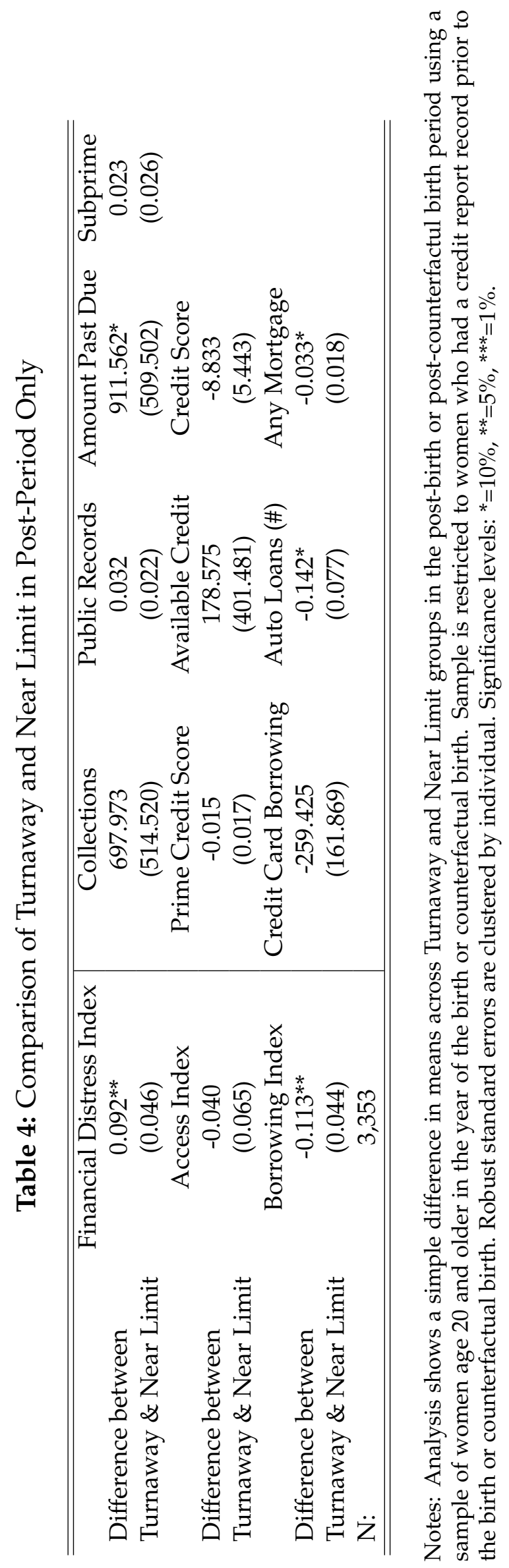




\section{References}

Adda, J., C. Dustmann, and K. Stevens (2017, April). The Career Costs of Children. Journal of Political Economy 125(2), 293-337.

Agüero, J. M. and M. S. Marks (2008). Motherhood and Female Labor Force Participation: Evidence from Infertility Shocks. The American Economic Review 98(2), 500-504.

Ananat, E. O., J. Gruber, and P. Levine (2007). Abortion Legalization and Life-Cycle Fertility. The Journal of Human Resources 42(2), 375-397.

Ananat, E. O., J. Gruber, P. B. Levine, and D. Staiger (2009). Abortion and Selection. The Review of Economics and Statistics 91(1), 124-136.

Angrist, J. D. and W. N. Evans (2000). Schooling and Labor Market Consequences of the 1970 State Abortion Reforms. Research in Labor Economics 18, 75-113.

Argys, L. M., A. I. Friedson, M. M. Pitts, and D. S. Tello-Trillo (2019, October). Losing Public Health Insurance: TennCare Disenrollment and Personal Financial Distress. Technical Report Working Paper 2017-6a, Federal Reserve Bank of Atlanta.

Ashcraft, A., I. Fernández-Val, and K. Lang (2013). The Consequences of Teenage Childbearing: Consistent Estimates When Abortion Makes Miscarriage Non-random. The Economic Journal 123(571), 875-905. _eprint: https://onlinelibrary.wiley.com/doi/pdf/10.1111/ecoj.12005.

Assifi, A. R., B. Berger, Ö. Tunçalp, R. Khosla, and B. Ganatra (2016, March). Women's Awareness and Knowledge of Abortion Laws: A Systematic Review. PLOS ONE 11(3), e0152224.

Bailey, M. J. (2006). More Power to the Pill: The Impact of Contraceptive Freedom on Women's Life Cycle Labor Supply. The Quarterly Journal of Economics 121(1), 289-320.

Bailey, M. J., M. Guldi, and B. J. Hershbein (2013). Further Evidence on the Internal Validity of the Early Legal Access Research Design. Journal of Policy Analysis and Management 32(4), 899-904.

Bailey, M. J., B. Hershbein, and A. R. Miller (2012, July). The Opt-In Revolution? Contraception and the Gender Gap in Wages. American Economic Journal: Applied Economics 4(3), 225-254. 
Bailey, M. J., H. W. Hoynes, M. Rossin-Slater, and R. Walker (2020, April). Is the Social Safety Net a Long-Term Investment? Large-Scale Evidence from the Food Stamps Program. Working Paper 26942, National Bureau of Economic Research. Series: Working Paper Series.

Bailey, M. J. and J. M. Lindo (2017, September). Access and Use of Contraception and Its Effects on Women's Outcomes in the United States, Volume 1. Oxford University Press.

Barr, A. and C. R. Gibbs (2019, October). Breaking the Cycle? Intergenerational Effects of an AntiPoverty Program in Early Childhood. Technical Report 19-141, Annenberg Institute at Brown University.

Barreca, A. I., J. M. Lindo, and G. R. Waddell (2016). Heaping-Induced Bias in Regression-Discontinuity Designs. Economic Inquiry 54(1), 268-293. _eprint: https://onlinelibrary.wiley.com/doi/pdf/10.1111/ecin.12225.

Biggs, M. A., U. D. Upadhyay, C. E. McCulloch, and D. G. Foster (2017, February). Women's Mental Health and Well-being 5 Years After Receiving or Being Denied an Abortion: A Prospective, Longitudinal Cohort Study. JAMA Psychiatry 74(2), 169-178.

Billings, S. B., E. Gallagher, and L. Ricketts (2019, May). Let the Rich Be Flooded: The Unequal Impact of Hurricane Harvey on Household Debt. SSRN Scholarly Paper ID 3396611, Social Science Research Network, Rochester, NY.

Bitler, M. and M. Zavodny (2001, November). The effect of abortion restrictions on the timing of abortions. Journal of Health Economics 20(6), 1011-1032.

Bitler, M. and M. Zavodny (2002, April). Child Abuse and Abortion Availability. American Economic Review 92(2), 363-367.

Bitler, M. P. and M. Zavodny (2004, June). Child Maltreatment, Abortion Availability, and Economic Conditions. Review of Economics of the Household 2(2), 119-141.

Blank, R. M., C. C. George, and R. A. London (1996). State Abortion Rates: The Impact of Policies, Providers, Politics, Demographics, and Economic Environment. Journal of Health Economics 15, 513553.

Busso, M., J. Gregory, and P. Kline (2013, April). Assessing the Incidence and Efficiency of a Prominent Place Based Policy. American Economic Review 103(2), 897-947. 
Cattaneo, M. D., R. Titiunik, and G. Vazquez-Bare (2020, June). The Regression Discontinuity Design. In Handbook of Research Methods in Political Science and International Relations, pp. 835-857. Sage Publications. arXiv: 1906.04242.

Colman, S., S. Colman, and T. Joyce (2011). Regulating Abortion: Impact on Patients and Providers in Texas. Journal of Policy Analysis and Management 30(4), 775-797.

Colman, S. and T. Joyce (2009, June). Minors' Behavioral Responses to Parental Involvement Laws: Delaying Abortion Until Age 18. Perspectives on Sexual and Reproductive Health 41(2), 119-126.

Colman, S., T. Joyce, and R. Kaestner (2008, October). Misclassification Bias and the Estimated Effect of Parental Involvement Laws on Adolescents' Reproductive Outcomes. American Journal of Public Health 98(10), 1881-1885.

Cowles, C. (2018, November). What to Know About the Cost of an Abortion.

Cristia, J. P. (2008). The Effect of a First Child on Female Labor Supply: Evidence from Women Seeking Fertility Services. The Journal of Human Resources 43(3), 487-510. Publisher: [University of Wisconsin Press, Board of Regents of the University of Wisconsin System].

Currie, J. and D. Almond (2011). Human capital development before age five. In Handbook of Labor Economics, Volume 4, pp. 1315-1486. Elsevier.

Deshpande, M., T. Gross, and Y. Su (2019, March). Disability and Distress: The Effect of Disability Programs on Financial Outcomes. Technical Report w25642, National Bureau of Economic Research.

Dobkin, C., A. Finkelstein, R. Kluender, and M. J. Notowidigdo (2018, February). The Economic Consequences of Hospital Admissions. American Economic Review 108(2), 308-352.

Dobkin, L. M., H. Gould, R. E. Barar, M. Ferrari, E. I. Weiss, and D. G. Foster (2014, January). Implementing a Prospective Study of Women Seeking Abortion in the United States: Understanding and Overcoming Barriers to Recruitment. Women's Health Issues 24(1), e115-e123.

Donohue, III, J. J. and S. D. Levitt (2001). The Impact of Legalized Abortion on Crime. Quarterly Journal of Economics 116(2), 379-420.

Drey, E. A., D. G. Foster, R. A. Jackson, S. J. Lee, L. H. Cardenas, and P. D. Darney (2006, January). 
Risk Factors Associated With Presenting for Abortion in the Second Trimester:. Obstetrics E Gynecology 107(1), 128-135.

Experian (2015, January). VantageScore 3.0. Technical report, Experian Information Solutions, Inc.

Finer, L. B., L. F. Frohwirth, L. A. Dauphinee, S. Singh, and A. M. Moore (2005). Reasons U.S. Women Have Abortions: Quantitative and Qualitative Perspectives. Perspectives on Sexual and Reproductive Health 37(3), 110-118.

Finer, L. B., L. F. Frohwirth, L. A. Dauphinee, S. Singh, and A. M. Moore (2006, October). Timing of steps and reasons for delays in obtaining abortions in the United States. Contraception 74(4), 334-344.

Finer, L. B. and M. R. Zolna (2016, March). Declines in Unintended Pregnancy in the United States, 2008-2011. New England Journal of Medicine 374(9), 843-852.

Finkelstein, A., S. Taubman, B. Wright, M. Bernstein, J. Gruber, J. P. Newhouse, H. Allen, and K. Baicker (2012, August). The Oregon Health Insurance Experiment: Evidence from the First Year. The Quarterly Journal of Economics 127(3), 1057-1106.

Fischer, S., H. Royer, and C. White (2018, November). The impacts of reduced access to abortion and family planning services on abortions, births, and contraceptive purchases. Journal of Public Economics 167, 43-68.

Fletcher, J. M. and B. L. Wolfe (2009, March). Education and Labor Market Consequences of Teenage Childbearing Evidence Using the Timing of Pregnancy Outcomes and Community Fixed Effects. Journal of Human Resources 44(2), 303-325.

Foster, D. G. (2017, November). Dramatic Decreases in US Abortion Rates: Public Health Achievement or Failure? American Journal of Public Health 107(12), 1860-1862.

Foster, D. G., M. A. Biggs, S. Raifman, J. Gipson, K. Kimport, and C. H. Rocca (2018, November). Comparison of Health, Development, Maternal Bonding, and Poverty Among Children Born After Denial of Abortion vs After Pregnancies Subsequent to an Abortion. JAMA Pediatrics 172(11), 1053.

Foster, D. G., M. A. Biggs, L. Ralph, C. Gerdts, S. Roberts, and M. M. Glymour (2018, January). Socioeconomic Outcomes of Women Who Receive and Women Who Are Denied Wanted Abortions in the United States. American Journal of Public Health 108(3), 407-413. 
Foster, D. G., L. M. Dobkin, and U. D. Upadhyay (2013, January). Denial of abortion care due to gestational age limits. Contraception $87(1), 3-5$.

Foster, D. G., S. E. Raifman, J. D. Gipson, C. H. Rocca, and M. A. Biggs (2019, February). Effects of Carrying an Unwanted Pregnancy to Term on Women's Existing Children. The Journal of Pediatrics 205, 183-189.e1.

Fuji, D., G. Imbens, and K. Kalyanaraman (2009, September). Notes for Matlab and Stata Regression Discontinuity Software.

Garnsey, C., G. Zanini, S. De Zordo, J. Mishtal, A. Wollum, and C. Gerdts (2021, May). Cross-country abortion travel to England and Wales: results from a cross-sectional survey exploring people's experiences crossing borders to obtain care. Reproductive Health 18(1), 103.

Gerdts, C., L. Dobkin, D. G. Foster, and E. B. Schwarz (2016, January). Side Effects, Physical Health Consequences, and Mortality Associated with Abortion and Birth after an Unwanted Pregnancy. Women's Health Issues 26(1), 55-59.

Girma, S. and D. Paton (2013, December). Does Parental Consent for Birth Control Affect Underage Pregnancy Rates? The Case of Texas. Demography 50(6), 2105-2128.

Goldin, C. and L. F. Katz (2002). The Power of the Pill: Oral Contraceptives and Women's Career and Marriage Decisions. Journal of Political Economy 110(4), 730-770.

Gross, T., M. J. Notowidigdo, and J. Wang (2020, April). The Marginal Propensity to Consume over the Business Cycle. American Economic Journal: Macroeconomics 12(2), 351-384.

Grossman, D., S. Baum, L. Fuentes, K. White, K. Hopkins, A. Stevenson, and J. E. Potter (2014, November). Change in abortion services after implementation of a restrictive law in Texas. Contraception 90(5), 496-501.

Gruber, J., P. Levine, and D. Staiger (1999). Abortion Legalization and Child Living Circumstances: Who is the Marginal Child? Quarterly Journal of Economics 114(1), 263-291.

Guttmacher Institute (2019, October). State Bans on Abortion Throughout Pregnancy. Guttmacher Institute (2021, July). State Bans on Abortion Throughout Pregnancy. 
Hock, H. (2008). The Pill and the College Attainment of American Women and Men. SSRN Electronic Journal.

Hoynes, H., D. W. Schanzenbach, and D. Almond (2016, April). Long-Run Impacts of Childhood Access to the Safety Net. American Economic Review 106(4), 903-934.

Hu, L., R. Kaestner, B. Mazumder, S. Miller, and A. Wong (2018, July). The Effect of the Patient Protection and Affordable Care Act Medicaid Expansions on Financial Wellbeing. Journal of Public Economics 163(99-112).

Humphries, J. E., N. S. Mader, D. I. Tannenbaum, and W. L. van Dijk (2019, August). Does Eviction Cause Poverty? Quasi-Experimental Evidence from Cook County, IL. Working Paper 26139, National Bureau of Economic Research.

Jatlaoui, T. C., M. E. Boutot, M. G. Mandel, M. K. Whiteman, A. Ti, E. Petersen, and K. Pazol (2018, November). Abortion Surveillance - United States, 2015. MMWR. Surveillance Summaries 67(13), $1-45$.

Jerman, J. and R. K. Jones (2014, July). Secondary Measures of Access to Abortion Services in the United States, 2011 and 2012: Gestational Age Limits, Cost, and Harassment. Women's Health Issues 24(4), e419-e424.

Jerman, J., R. K. Jones, and T. Onda (2016, May). Characteristics of U.S. Abortion Patients in 2014 and Changes Since 2008. Technical report, Guttmacher Institute, New York.

Jones, R. K. and J. Jerman (2017, October). Population Group Abortion Rates and Lifetime Incidence of Abortion: United States, 2008-2014. American Journal of Public Health 107(12), 1904-1909.

Joyce, T. (2004). Did Legalized Abortion Lower Crime? The Journal of Human Resources 39(1), 1-28.

Joyce, T. (2009, February). A Simple Test of Abortion and Crime. Review of Economics and Statistics 91(1), $112-123$.

Joyce, T. (2010, September). Parental Consent for Abortion and the Judicial Bypass Option in Arkansas: Effects and Correlates. Perspectives on Sexual and Reproductive Health 42(3), 168-175.

Joyce, T. (2013). How Important Was the Pill to Women's Economic Well-Being? If Roe V. Wade Were Overturned, How Might Society Change? Journal of Policy Analysis and Management 32(4), 879-887. 
Joyce, T. and R. Kaestner (1996). State reproductive policies and adolescent pregnancy resolution: the case of parental involvement laws. Journal of Health Economics 15, 579-607.

Joyce, T. and R. Kaestner (2000). The Impact of Mississippi's Mandatory Delay Law on the Timing of Abortion. Family Planning Perspectives 32(1), 4-13.

Joyce, T. and R. Kaestner (2001, March). The Impact of Mandatory Waiting Periods and Parental Consent Laws on the Timing of Abortion and State of Occurrence among Adolescents in Mississippi and South Carolina. Journal of Policy Analysis and Management 20(2), 263-282.

Joyce, T., R. Kaestner, and S. Colman (2006). Changes in Abortions and Births and the Texas Parental Notification Law. The New England Journal of Medicine, 8.

Kaiser Family Foundation (2019, June). States with Gestational Limits for Abortion. Technical report.

Kaiser Family Foundation (2020, September). State Restriction of Health Insurance Coverage of Abortion.

Kaiser Family Foundation, P. (2020, December). Paid Family and Sick Leave in the U.S.

Kelly, A. M. (2019, November). When Capacity Constraints Bind: Evidence from Reproductive Health Clinic Closures. Texas AEM University Working Paper.

Klepinger, D., S. Lundberg, and R. Plotnick (1999). How Does Adolescent Fertility Affect the Human Capital and Wages of Young Women? The Journal of Human Resources 34(3), 421-448.

Kleven, H., C. Landais, J. Posch, A. Steinhauer, and J. Zweimüller (2019, May). Child Penalties across Countries: Evidence and Explanations. AEA Papers and Proceedings 109, 122-126.

Kleven, H., C. Landais, and J. E. Søgaard (2019, October). Children and Gender Inequality: Evidence from Denmark. American Economic Journal: Applied Economics 11(4), 181-209.

Kline, P. (2011). Oaxaca-Blinder as a Reweighting Estimator. American Economic Review Papers $\mathcal{E}$ Proceedings 101(3), 532-537.

Kling, J. R., J. B. Liebman, and L. F. Katz (2007). Experimental Analysis of Neighborhood Effects. Econometrica 75(1), 83-119. _eprint: https://onlinelibrary.wiley.com/doi/pdf/10.1111/j.14680262.2007.00733.x. 
Lara, D., K. Holt, M. Peña, and D. Grossman (2015, December). Knowledge of Abortion Laws and Services Among Low-Income Women in Three United States Cities. Journal of Immigrant and Minority Health 17(6), 1811-1818.

Lee, D. S. and T. Lemieux (2010, June). Regression Discontinuity Designs in Economics. Journal of Economic Literature 48(2), 281-355.

Levine, P. B. (2003, September). Parental involvement laws and fertility behavior. Journal of Health Economics 22(5), 861-878.

Levine, P. B., A. B. Trainor, and D. J. Zimmerman (1996). The Effect of Medicaid Abortion Funding Restrictions on Abortions, Pregnancies and Births. Journal of Health Economics 15, 555-578.

Lindo, J., C. Myers, A. Schlosser, and S. Cunningham (2019). How Far is Too Far? New Evidence on Abortion Clinic Closures, Access, and Abortions. Journal of Human Resources (an_). type: dataset.

Lindo, J. M. and M. Pineda-Torres (2019, September). New Evidence on the Effects of Mandatory Waiting Periods for Abortion. Working Paper 26228, National Bureau of Economic Research.

Lino, M., K. Kuczynski, N. Rodriguez, and T. Schap (2017, March). Expenditures on Children by Families, 2015. Miscellaneous Report No. 1528-2015, United States Department of Agriculture, Center for Nutrition Policy and Promotion.

Lundborg, P., E. Plug, and A. W. Rasmussen (2017). Can Women Have Children and a Career? IV Evidence from IVF Treatments. The American Economic Review 107(6), 1611-1637. Publisher: American Economic Association.

Mian, A. and A. Sufi (2010, May). The Great Recession: Lessons from Microeconomic Data. American Economic Review 100(2), 51-56.

Miller, A. R. (2011). The effects of motherhood timing on career path. Journal of Population Economics 24(3), 1071-1100.

Miller, S., L. Hu, R. Kaestner, B. Mazumder, and A. Wong (2021). The ACA Medicaid Expansion in Michigan and Financial Health. Journal of Policy Analysis and Management 40(2), 348-375. _eprint: https://onlinelibrary.wiley.com/doi/pdf/10.1002/pam.22266. 
Miller, S. and C. K. Soo (2018, September). Do Neighborhoods Affect Credit Market Decisions of LowIncome Borrowers? Evidence from the Moving to Opportunity Experiment. Working Paper 25023, National Bureau of Economic Research.

Miller, S., L. R. Wherry, and D. G. Foster (2020, May). What Happens After an Abortion Denial? A Review of Results from the Turnaway Study. American Economic Association Papers E Proceedings.

Myers, C. (2021, June). Cooling off or Burdened?? The Effects of Mandatory Waiting Periods on Abortions and Births. IZA Discussion Paper Series No. 14434.

Myers, C. K. (2017). The Power of Abortion Policy: Reexamining the Effects of Young Women's Access to Reproductive Control. Journal of Political Economy 125(6), 2178-2224.

Nash, E., R. Benson Gold, A. Rowan, G. Rathburn, and Y. Vierboom (2013, December). Laws Affecting Reproductive Health and Rights: 2013 State Policy Review. Technical report, Guttmacher Institute, New York, NY.

Nash, E., R. B. Gold, L. Mohammed, Z. Ansari-Thomas, and O. Cappello (2018, January). Policy Trends in the States, 2017. Technical report, Guttmacher Institute, New York, NY.

Nash, E. and S. Naide (2021, July). State Policy Trends at Midyear 2021: Already the Worst Legislative Year Ever for U.S. Abortion Rights. Technical report, Guttmacher Institute, New York, NY.

Quast, T., F. Gonzalez, and R. Ziemba (2017, March). Abortion Facility Closings and Abortion Rates in Texas. Inquiry : A Journal of Medical Care Organization, Provision and Financing 54.

Ralph, L. J., E. B. Schwarz, D. Grossman, and D. G. Foster (2019, June). Self-reported Physical Health of Women Who Did and Did Not Terminate Pregnancy After Seeking Abortion Services: A Cohort Study. Annals of Internal Medicine.

Roberts, S. C., M. A. Biggs, K. S. Chibber, H. Gould, C. H. Rocca, and D. G. Foster (2014, December). Risk of violence from the man involved in the pregnancy after receiving or being denied an abortion. BMC Medicine 12(1), 144.

Roberts, S. C. M., H. Gould, and U. D. Upadhyay (2015, August). Implications of Georgia's 20-Week Abortion Ban. American Journal of Public Health 105(8), e77-e82. 
Roth, J. (2019, July). Pre-test with Caution: Event-study Estimates After Testing for Parallel Trends. Harvard University Working Paper.

Salganicoff, A., L. Sobel, and A. Ramaswamy (2019, July). Coverage for Abortion Services in Medicaid, Marketplace Plans, and Private Plans. Technical report, Henry J. Kaiser Family Foundation, Washington, DC.

Salganicoff, A., L. Sobel, and A. Ramaswamy (2020, January). The Hyde Amendment and Coverage for Abortion Services. Technical report, Henry J. Kaiser Family Foundation, Washington, DC.

Sandler, D. and N. Szembrot (2019). Maternal Labor Dynamics: Participation, Earnings, and Employer Changes. Denter for Economic Studies Working Paper No. CES 19-33, U.S. Census Bureau, Washington, DC.

Schulkind, L. and D. H. Sandler (2019, February). The Timing of Teenage Births: Estimating the Effect on High School Graduation and Later-Life Outcomes. Demography 56(1), 345-365.

Singh, S., L. Remez, G. Sedgh, L. Kwok, and T. Onda (2018). Abortion Worldwide 2017: Uneven Progress and Unequal Access. Technical report, Guttmacher Institute, New York, NY.

Sun, S. (2019). Less is More: How Family Size in Childhood Affects Long-Run Human Capital and Economic Opportunity. Working Paper, 50.

Tavernise, S. (2019, May). 'The Time is Now': States Are Rushing to Restrict Abortion, or to Protect It. The New York Times.

Upadhyay, U. D., E. A. Aztlan-James, C. H. Rocca, and D. G. Foster (2019, January). Intended Pregnancy after Receiving vs. Being Denied a Wanted Abortion. Contraception 99(1), 42-47.

Upadhyay, U. D., T. A. Weitz, R. K. Jones, R. E. Barar, and D. G. Foster (2014, September). Denial of Abortion Because of Provider Gestational Age Limits in the United States. American Journal of Public Health 104(9), 1687-1694.

Venator, J. and J. Fletcher (2019, October). Undue Burden Beyond Texas: An Analysis of Abortion Clinic Closures, Births, And Abortions in Wisconsin. Working Paper 26362, National Bureau of Economic Research. 
Zedlewski, S. and O. Golden (2010, February). Next Steps for Temporary Assistance for Needy Families. Brief 11, The Urban Institute, Washington, DC. 


\title{
The Economic Consequences of Being Denied an Abortion
}

\author{
Appendix \\ Sarah Miller Laura R. Wherry Diana Greene Foster
}

This appendix provides further details and additional results to supplement those presented in the main text. Details on match rates by participant age and differential match rates by study group are reported in Figures A1 and A2. Analytic sample inclusion criteria are found in Figure A3; each column represents a step in the sample inclusion criteria process and shows the number of observations that meet this and all previous inclusion criteria. Plots of the summary index components are reported in Figures A4 and A5. These plots are analogous to those presented in Figure 2 in the main text, but for component outcomes. Table A2 further breaks down the components of public records, while Table A4 shows changes in the distribution of collections and amount past due. Table A3 shows collection amounts by type of collection.

Tables A5 - A8 present results from alternative sample definitions and specifications described in Section 3 and reported in Section 4.1. Section A provides additional details on the reweighting procedure described in Section 3 and additional analyses assessing the robustness of our results to changes in this procedure (with results in Figure A18).

Tables A9-A15 and Figures A10-A17 present results from additional analyses described in Section 5. Table A9 runs the main analysis by state groups defined using the generosity of state welfare programs. Tables A10-A13 and Figures A10-A14 show the results for the regression discontinuity analysis. Figure A10 shows the change in the fraction of women turned away at each estimated clinic cutoff. Figures A11-A13 and Table A10 present the results of the RD analysis, while results for a "donut" RD that drops women with gestational ages equal to or within one day of the cutoff are in Table A11. Figure A14 and Table A12 report checks for discontinuities across the gestational age cutoff for women who responded to the baseline survey, while Table A13 adds control for baseline characteristics. More details on our estimation of the clinic-specific gestational age cutoffs are below in Section B. Tables A14-A15 and Figures A15- A15 show the results from analyses exploring mechanisms in the Turnaway survey data. Finally, Figure A17 shows the results for the analysis that compares outcomes for subsequent births of the Near Limit group to the Turnaway births. 


\section{A Re-Weighting Approaches}

In our main analyses, we present results from a specification that re-weights the Near Limit group to better resemble the Turnaway group in the pre-birth period. The Oaxaca-Blinder (OB) weights are constructed following Kline (2011). For re-weighting variables, we use the change in the delinquency index, credit access index, and borrowing index between periods -3 and -1 . If this variable is missing (e.g. due to a missing value in period -3 or -1 ), we code the change as zero, but also include indicator variables that the variable is missing in the re-weighting process. This procedure produces weights for the Near Limit group; the Turnaway group receives weights of 1 . Furthermore, the weights are constructed such that values of the included variables are equal across the Turnaway and Near Limit groups.

To conduct inference, we use a clustered bootstrap that re-samples our data at the individual level, selecting all yearly observations for each individual with replacement. We then re-estimate both the OB weights and the coefficients. By re-estimating the weights with each bootstrap draw, we incorporate any uncertainty due to estimating the weights into our inference. Once we have reestimated 1,000 coefficients using this procedure, we take the standard deviation of these estimated coefficients as our standard error, following Kline (2011).

We conduct a series of robustness checks to verify that our results are not overly sensitive to the variables we include in the weighting procedure or the exact method used to estimate the weights. The results of these checks are reported in Figure A18. The first two estimates show the coefficient and 95\% confidence intervals for our unweighted baseline results (purple) and our primary reweighted specification which we report in the main text (yellow). The next estimate uses the same procedure but adds an indicator for having a mortgage in the pre-birth period to the variables used to estimate the weights (red). This may be desirable if different rates of having a mortgage capture differential exposure to the Great Recession. We find similarly-sized effects when this variable is included, and continue to find statistically significant impacts of an abortion denial on the delinquency index, consistent with our main results. The next estimate (aquamarine) adds several demographic measures included in the baseline survey to the weighting procedure: the respondent's age at the time of birth, race (Black, white, Latina or other), an indicator that the woman had a high school degree or less, an indicator that the woman is married, whether the woman is employed full time, part time, or not at all, and whether the woman received WIC, TANF, or Food Stamps at the time of the initial survey. When we 
include these variables, we cannot estimate weights for women who did not complete the baseline survey; so, we assign Near Limit non-respondents the average weight among the Near Limit group, while Turnaway non-respondents continue to get a weight of 1 . We find very similar effects under this procedure.

Finally, we use the same sets of variables but conduct the re-weighting using an inverse propensity score method rather than the OB weights. To implement this method, we first estimate a logit model using baseline covariates, where the dependent variable is whether the woman is in the Tur-

naway group. From this model, we obtain predicted probabilities $\hat{p}$. We then assign weights of $\frac{\hat{p}}{1-\hat{p}}$ to the Near Limit group, with the Turnaway group again receiving a weight of 1 . To construct confidence intervals, we use a clustered bootstrap procedure implemented in a similar fashion as described above. The results of this analysis are presented in Figure A18. The estimate using just the change in the indices to weight is presented in orange, while the version that uses only survey respondents to construct the weights is given in blue. We again find similar estimates using this procedure as in our baseline model.

\section{B Estimation of Clinic-Specific Gestational Age Cutoffs}

Over the period of the Turnaway Study, several clinics changed their policies regarding the latest gestational age at which they would provide an abortion. These policy changes were not recorded. Furthermore, clinic policies could change on a day-to-day basis depending on the availability of providers. In order to estimate an RD model using gestational age, we must first estimate the most likely gestational age at each clinic. To do this, we implement a simple RD model for each site that estimates the probability that a woman was turned away at different gestation week cutoffs. Our candidate cutoffs include the earliest cutoff at which we observe a woman being turned away (which may be a fraction of gestational weeks-e.g., 16 weeks and 5 days) and all possible cutoffs at round numbers of weeks (i.e. not fractions of weeks) within the entire distribution of gestational ages of women turned away from that given clinic. We estimate a linear RD model that identifies the change in the likelihood of being turned away among all participants in the Near Limit and Turnaway groups at the clinic at each of these cutoffs with an indicator variable for women with pregnancies of gestational age at or above the cutoff. It includes a running variable measuring distance in gestational age from the cutoff and we allow the slope to vary before and after the cutoff. This model is estimated separately for each clinic and for all possible cutoffs. We select the clinic-specific cutoff using the largest t-statistic 
associated with this indicator variable across all candidate cutoffs. Note that only one cutoff is chosen per clinic, the cutoff that performs best (i.e. generates the largest t-statistic) at predicting Turnaway status.

\section{Additional "RD-DD" Analysis}

In addition to our main RD analysis, we also estimate an alternative "RD-DD" specification that differences the discontinuity observed at the gestational age cutoff before and after the birth year in the linear parametric model. To do this, we pool all years, including those prior to the birth, and estimate:

$$
\begin{aligned}
Y_{i c t}= & \beta_{R D, D D} 1\left(g_{i c} \geq 0\right) \times \text { Post }_{t}+\beta_{1} 1\left(g_{i c} \geq 0\right)+\beta_{2} g_{i c}+\beta_{3} 1\left(g_{i c} \geq 0\right) \times g_{i c}+ \\
& \beta_{4} \text { Post }_{t} \times g_{i c}+\beta_{5} \text { Post }_{t} \times 1\left(g_{i c} \geq 0\right) \times g_{i c}+\epsilon_{i c t} .
\end{aligned}
$$

Here, the coefficient $\beta_{R D, D D}$ provides the difference in the discontinuity estimated before the birth year $\left(\right.$ Post $\left._{t}=0\right)$, and in the year of the birth and later $\left(\right.$ Post $\left._{t}=1\right)$. In this way, the analysis uses preperiod data to control for any pre-existing differences in outcomes at the cutoff. As in all RD models, we cluster the standard errors at the individual level.

We present estimates for the RD-DD model in the last row of Table A10. This model estimates the difference in the parametric linear RD estimate before and after the birth year. Estimates generated from this model are consistent with the previous event study and RD results: we find large and statis-

tically significant increases in financial distress associated with abortion denial but little evidence of change in the credit access index. 
Figure A1: Fraction Not Matched by Age for Near Limit (Light Blue) and Turnaway Group (Dark Blue)

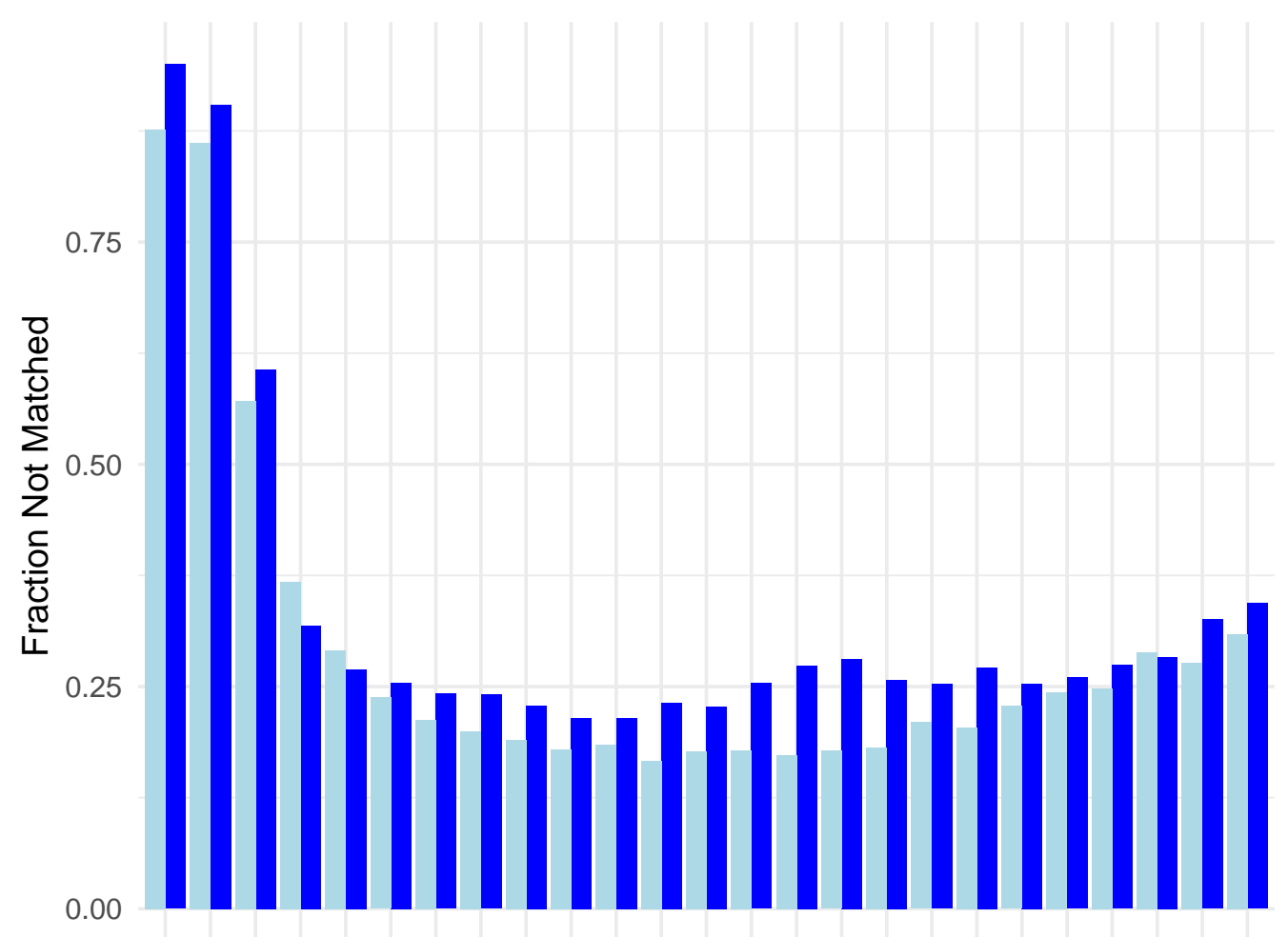

16171819202122232425262728293031323334353637383940

Age

Note: This bar chart shows the fraction of the Near Limit (light blue) and Turnaway Group (dark blue) who are not matched to the credit report data at each age we observe them. 
Figure A2: Changes in Probability of Not Matching to Credit Reporting Agency Data by Event Year

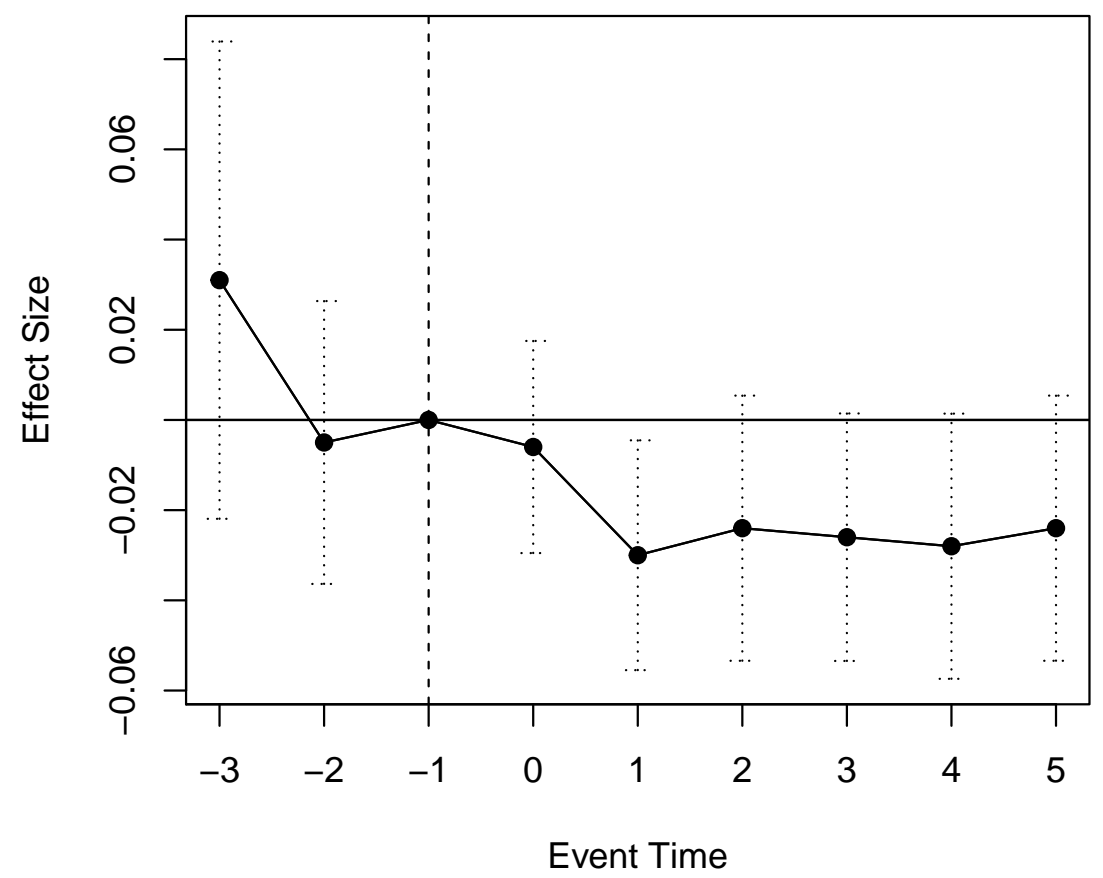

Note: This event study figures shows estimates of equation (1) where the dependent variable equals 1 if the woman did not match to the credit reporting data in that year. Note that this estimation includes those with no pre-period match to the credit reporting data.

Figure A3: Sample Size by Inclusion Criteria

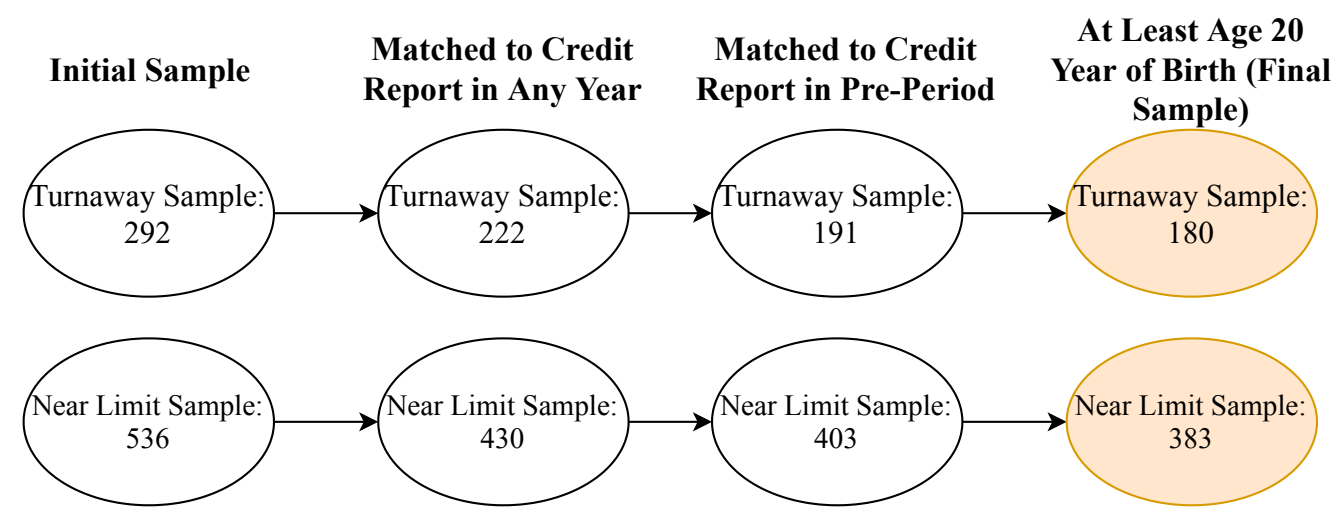

Note: This flow chart demonstrates how sample sizes change for each sample inclusion criteria for the Turnaway (top) and Near Limit (bottom) groups. 
Figure A4: Financial Distress Component Outcomes Relative to Event Time, for the Turnaway Group (Green) and Near Limit Group (Blue)

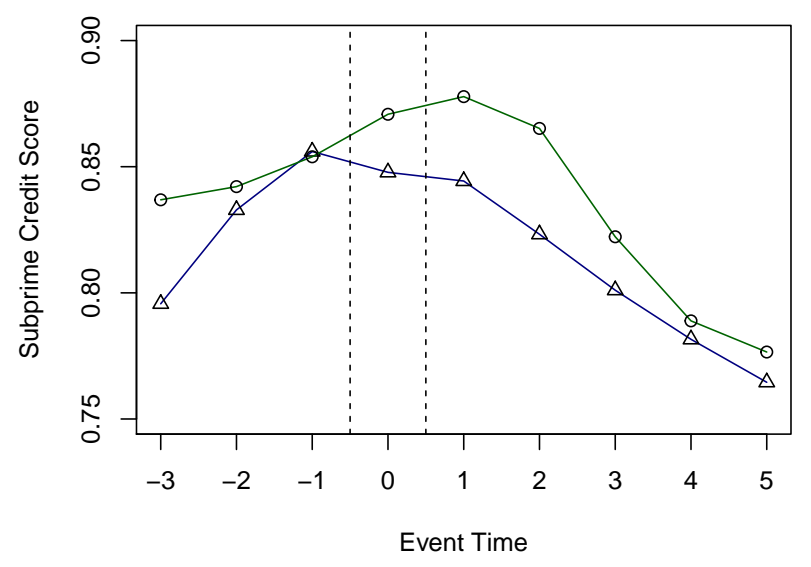

(a) Subprime

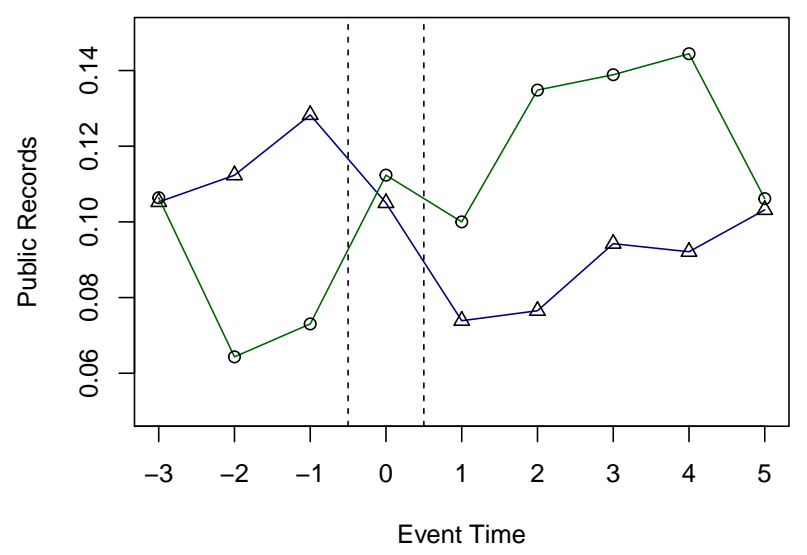

(c) Public Records

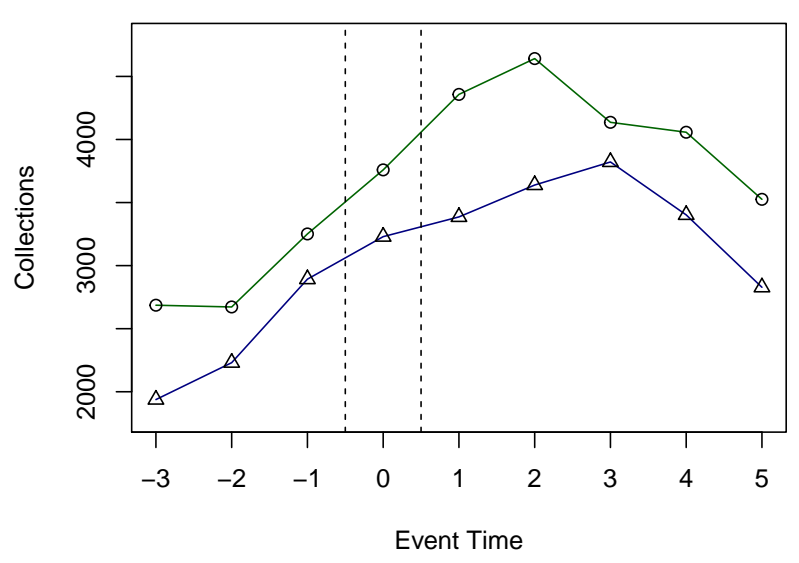

(b) Collections

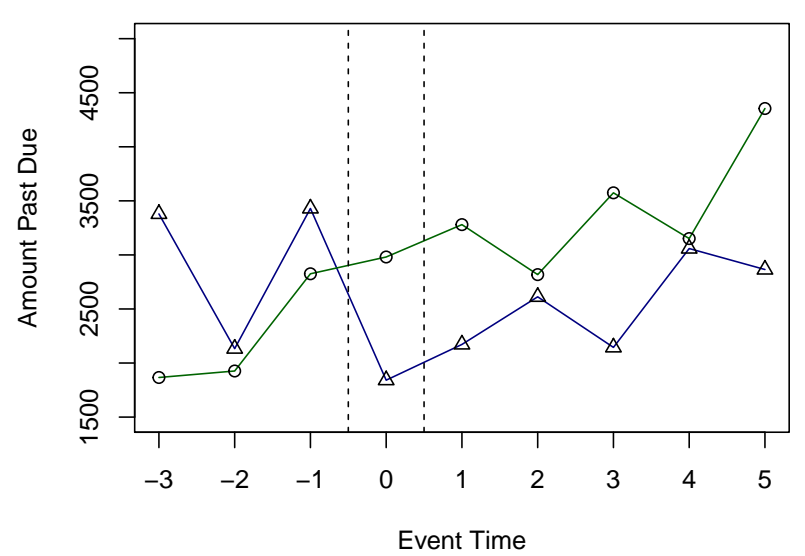

(d) Past Due

Note: This figure plots average outcomes relative to event time for the Turnaway group (green with circle points) and the Near Limit group (blue with triangle points). 
Figure A5: Access Component Outcomes Relative to Event Time, for the Turnaway Group (Green) and Near Limit Group (Blue)

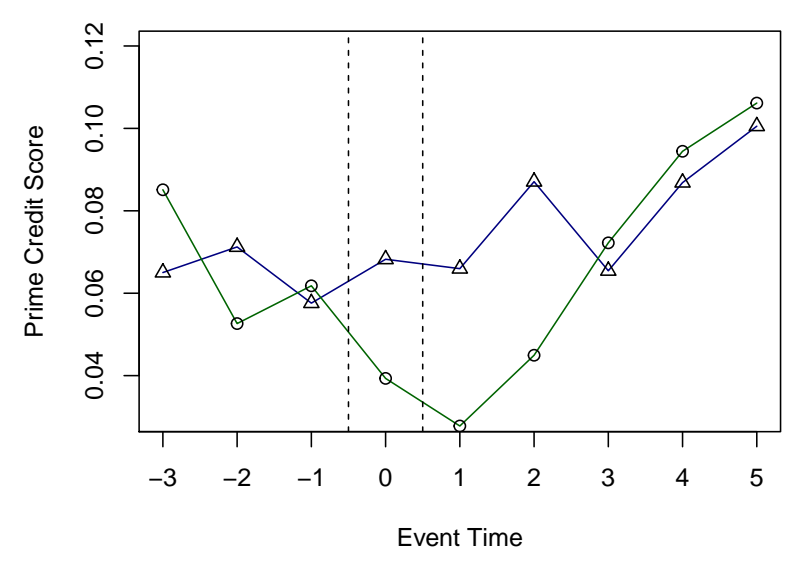

(a) Prime Credit Score

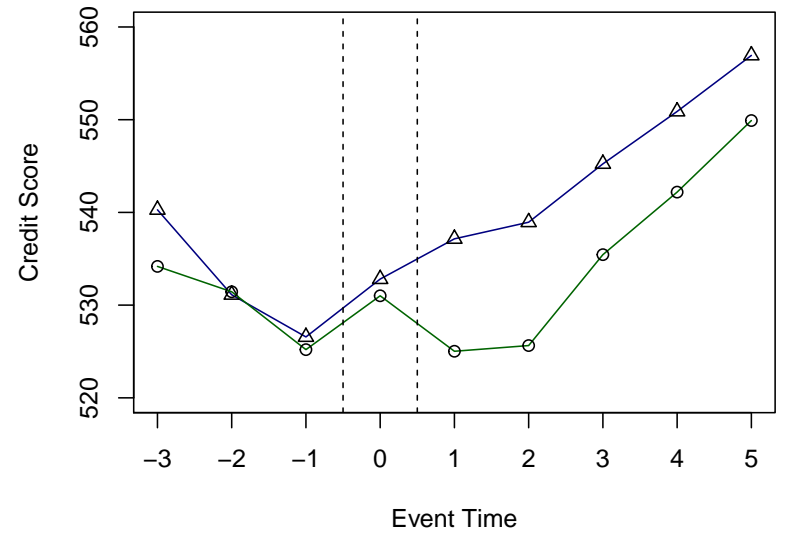

(b) Credit Score

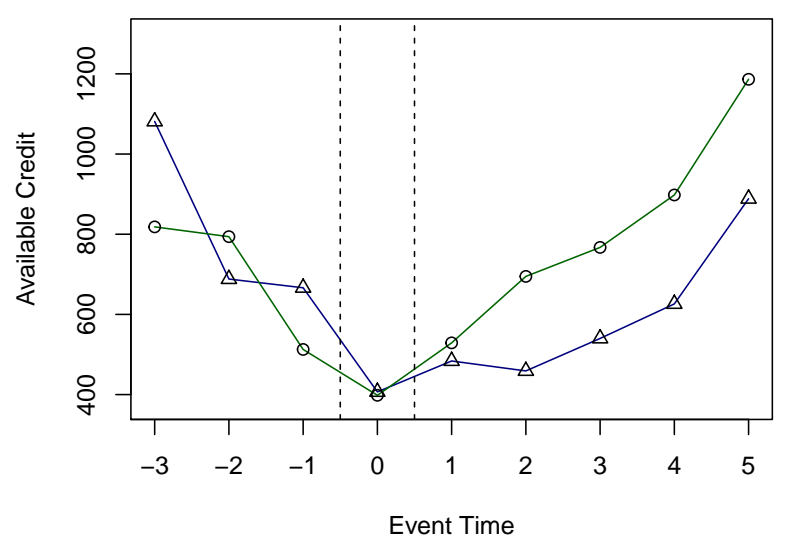

(c) Credit Card Credit Available

Note: This figure plots average outcomes relative to event time for the Turnaway group (green with circle points) and the Near Limit group (blue with triangle points). 
Figure A6: Borrowing Component Outcomes Relative to Event Time, for the Turnaway Group (Green) and Near Limit Group (Blue)

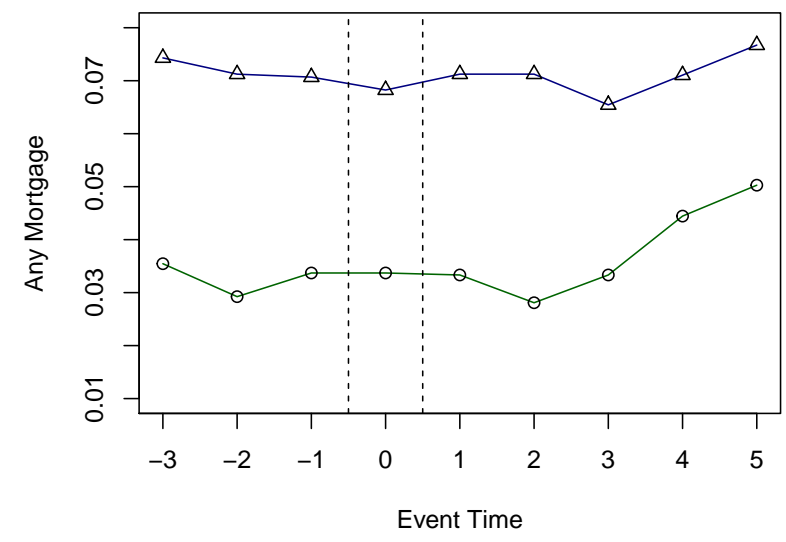

(a) Mortgage

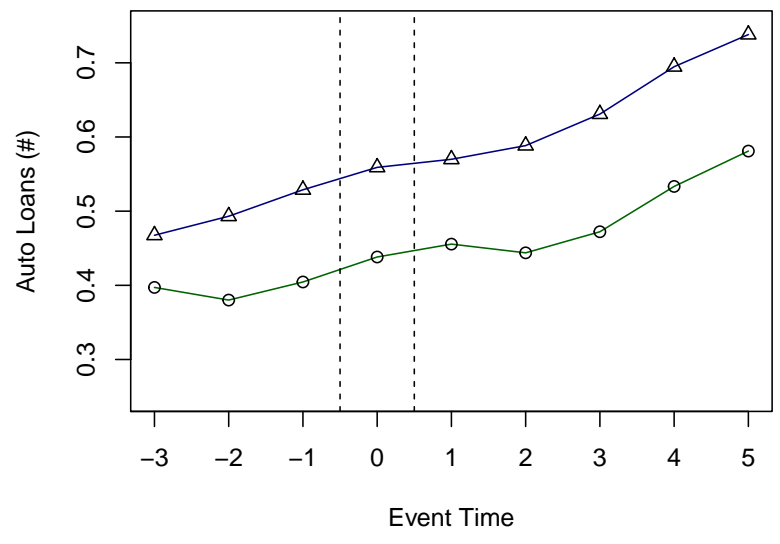

(b) Automobile Loans

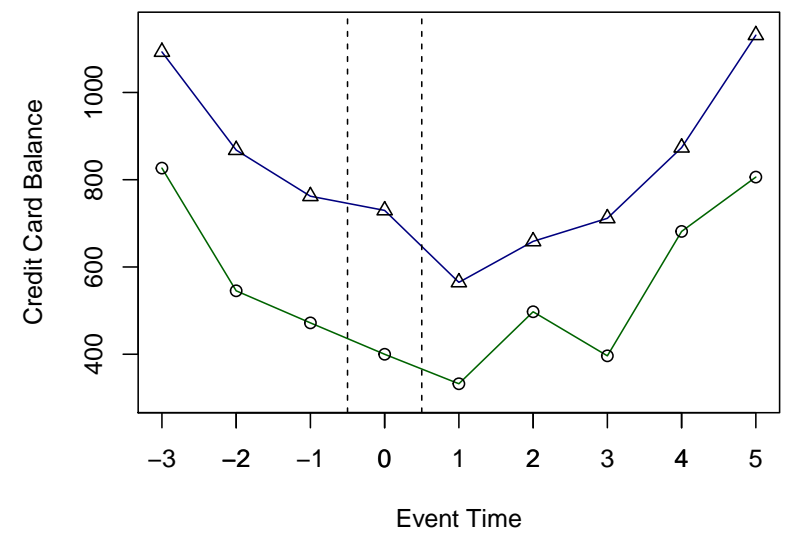

(c) Credit Card Balance

Note: This figure plots average outcomes relative to event time for the Turnaway group (green with circle points) and the Near Limit group (blue with triangle points). 
Figure A7: Event Study Coefficients Financial Distress Component Measures: Unweighted (Black) and Reweighted (Blue)

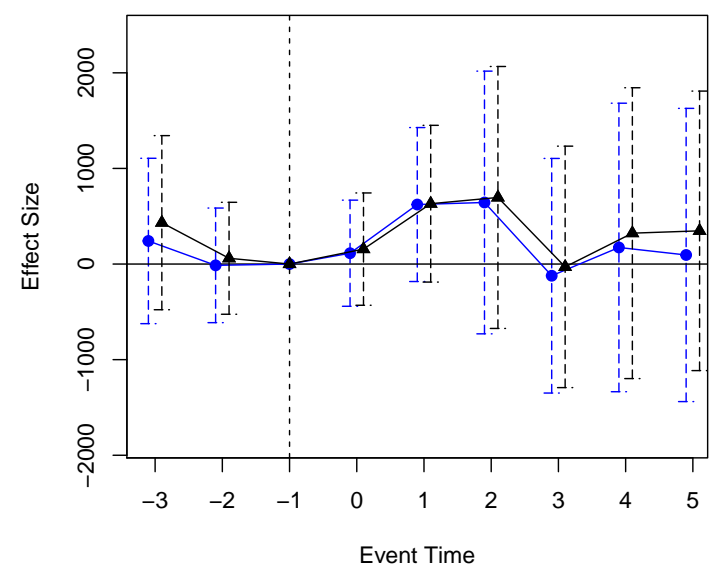

(a) Collections

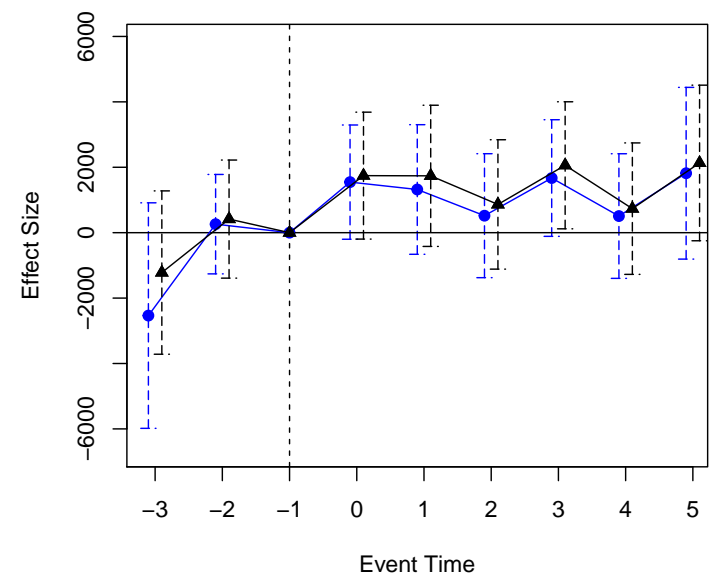

(c) Amount Past Due

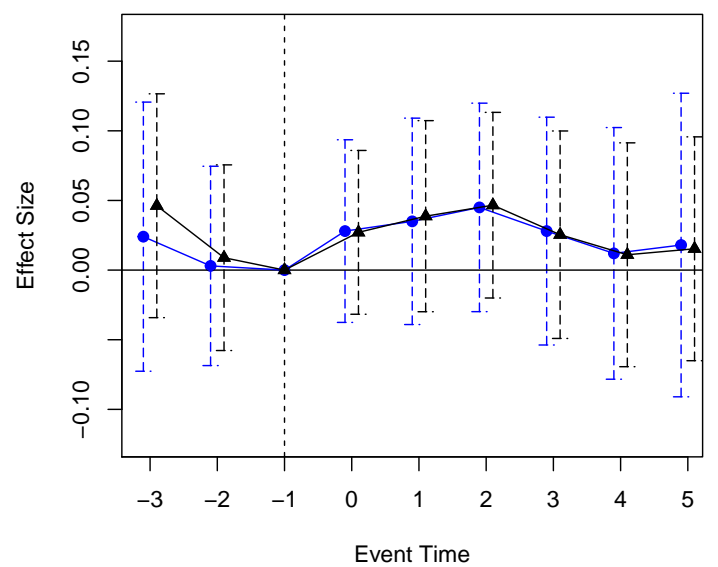

(b) Subprime Credit Score

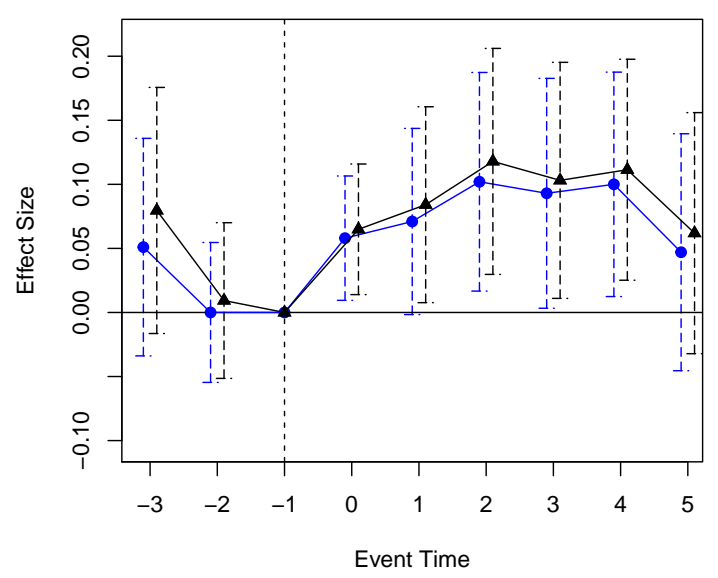

(d) Public Records

Note: These figures report coefficients from the estimation of Equation (1) for the specified outcome. The coefficients represent the change in the outcome for Turnaway group members relative to Near Limit group members in the three years before and six years after the time of birth or counterfactual birth, as compared to the year immediately prior to this event. See text for more information. 
Figure A8: Event Study Coefficients Access Component Measures: Unweighted (Black) and Reweighted (Blue)

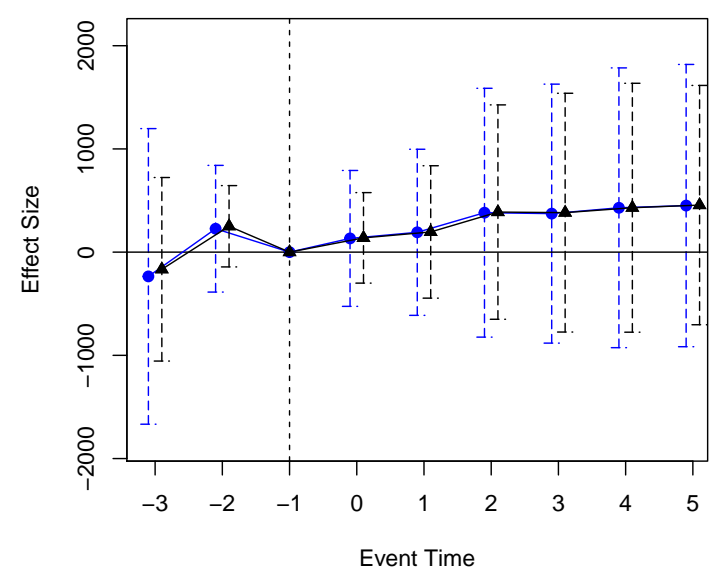

(a) Credit Available

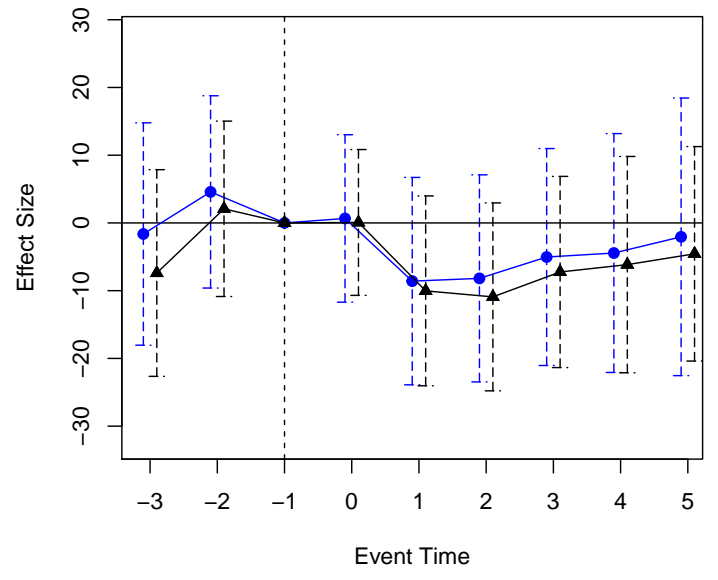

(b) Credit Score

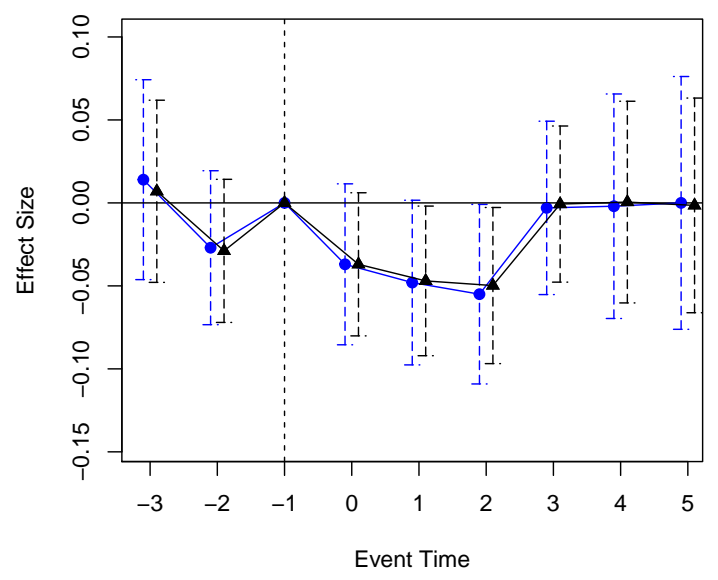

(c) Prime Credit Score

Note: These figures report coefficients from the estimation of Equation (1) for the specified outcome. The coefficients represent the change in the outcome for Turnaway group members relative to Near Limit group members in the three years before and six years after the time of birth or counterfactual birth, as compared to the year immediately prior to this event. See text for more information. 
Figure A9: Event Study Coefficients Borrowing Component Measures: Unweighted (Black) and Reweighted (Blue)

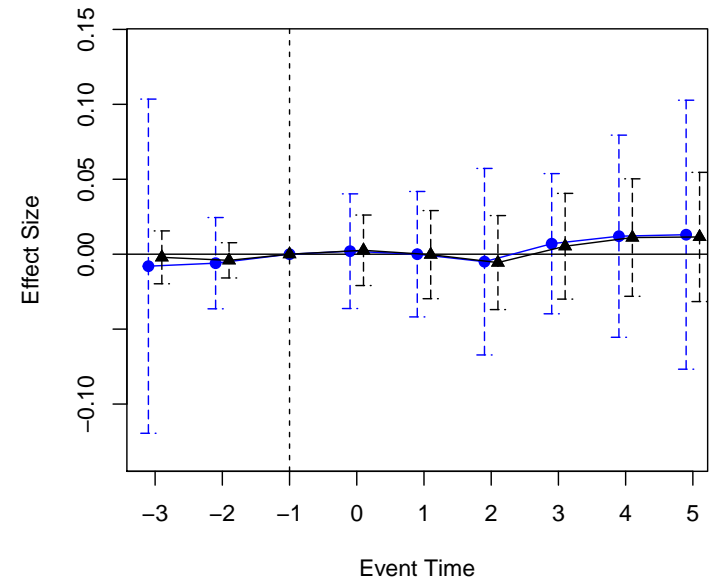

(a) Any Mortgage

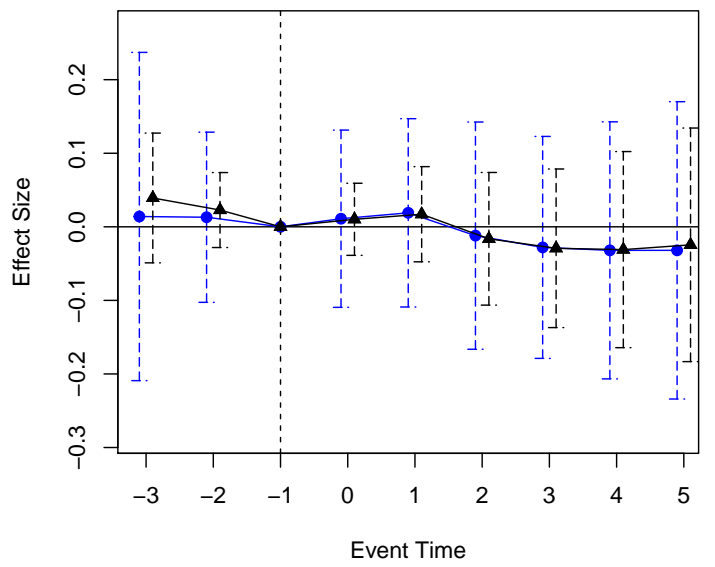

(b) Auto Loans (\#)

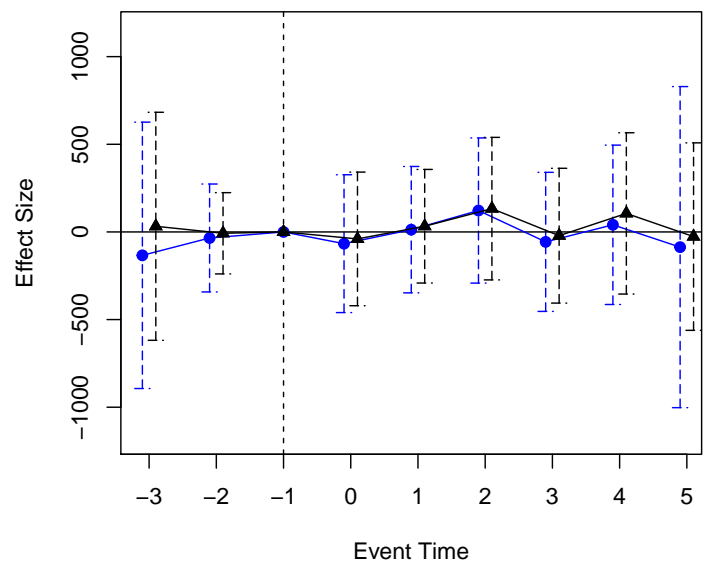

(c) Credit card balance

Note: These figures report coefficients from the estimation of Equation (1) for the specified outcome. The coefficients represent the change in the outcome for Turnaway group members relative to Near Limit group members in the three years before and six years after the time of birth or counterfactual birth, as compared to the year immediately prior to this event. See text for more information. 
Figure A10: Change in Fraction Turned Away Relative to Estimated Clinic Cutoff

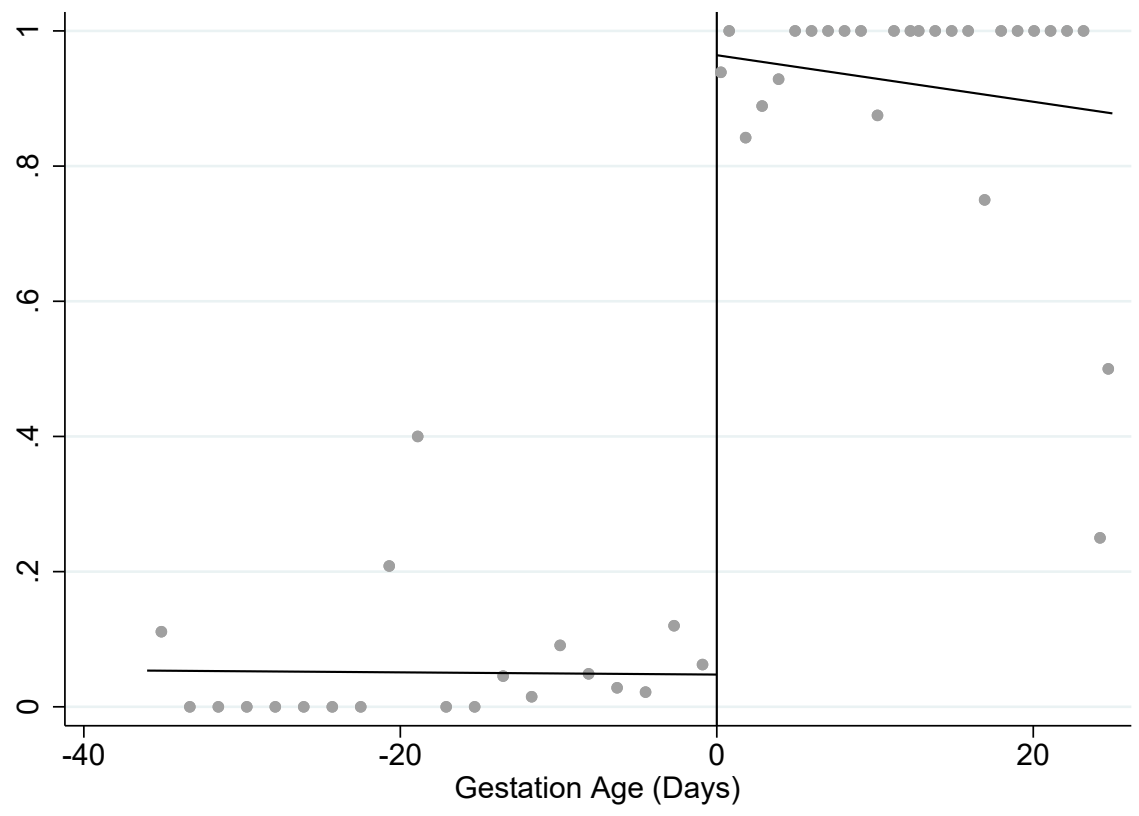

Note: This figure shows the fraction of women who were turned away at each day relative to the estimated clinic-specific cutoff. Points represent means of the gestation age-specific denial rate. The lines are fitted values from a regression that includes a linear trend in gestational age and a dummy for gestation ages greater than or equal to the cutoff age. 
Figure A11: RDD Graphs By Event Time, Outcome: Financial Distress Index

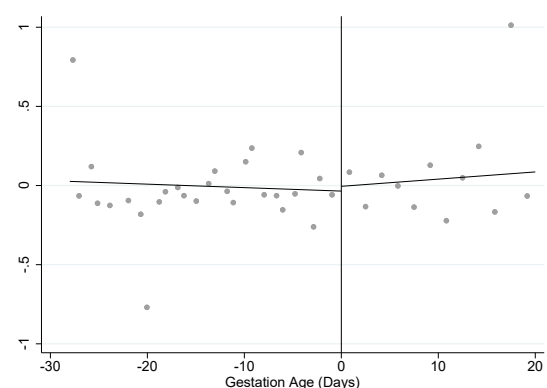

(a) Event time $=-3$

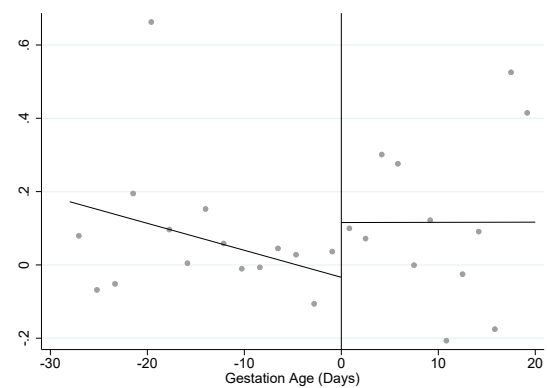

(d) Event time $=0$ (Year of Birth)

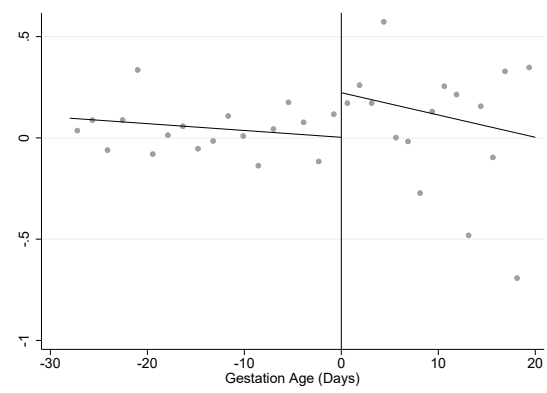

(g) Event time=3

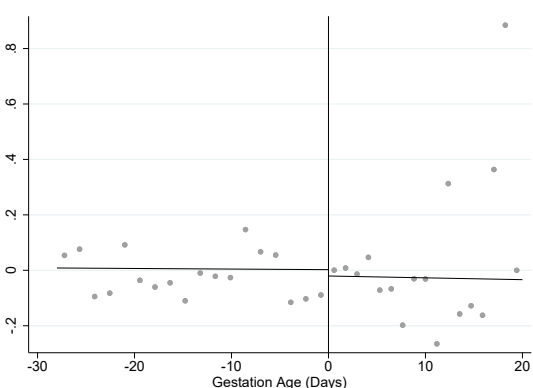

(b) Event time $=-2$

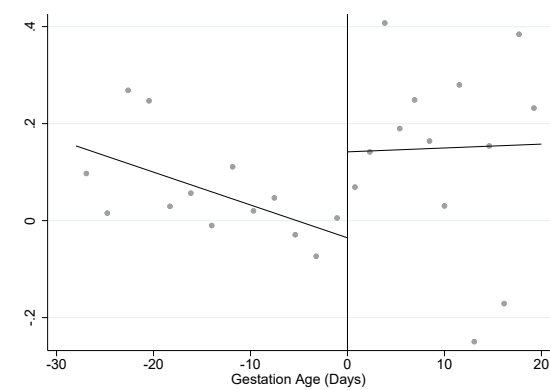

(e) Event time=1

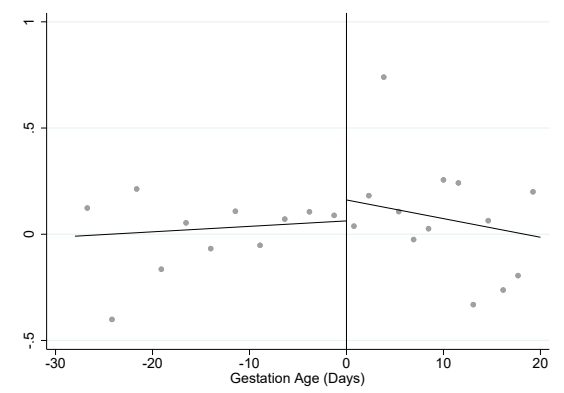

(h) Event time=4

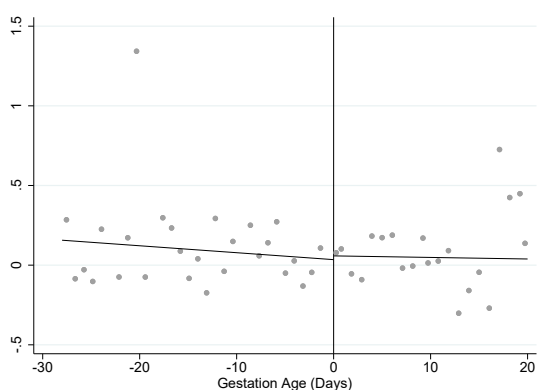

(c) Event time $=-1$

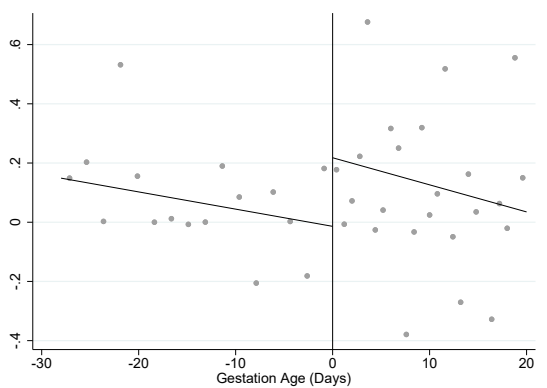

(f) Event time=2

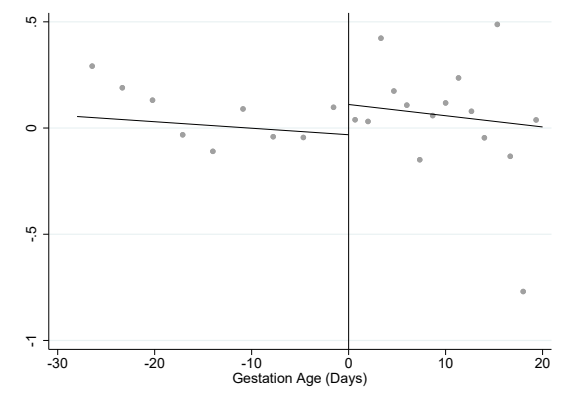

(i) Event time $=5$

Note: For each outcome, points represent means for each gestation age relative to the cutoff. The lines are fitted values from a regression that includes a linear trend in gestational age and a dummy for gestation ages greater than or equal to the cutoff age. 


\section{Figure A12: RDD Graphs By Event Time, Outcome: Credit Access Index}

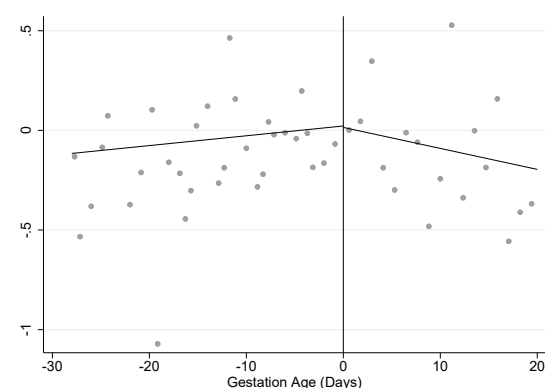

(a) Event time $=-3$

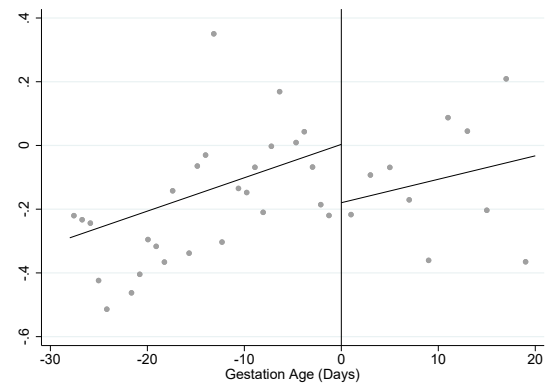

(d) Event time $=0$ (Year of Birth)

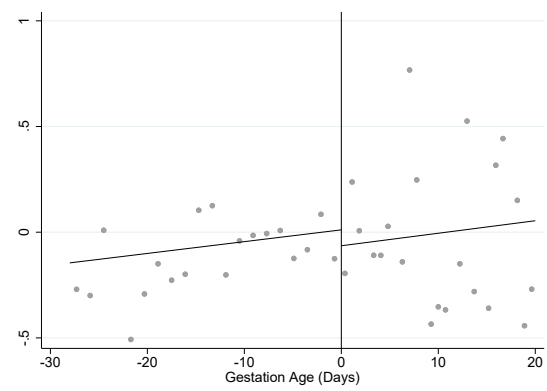

(g) Event time=3

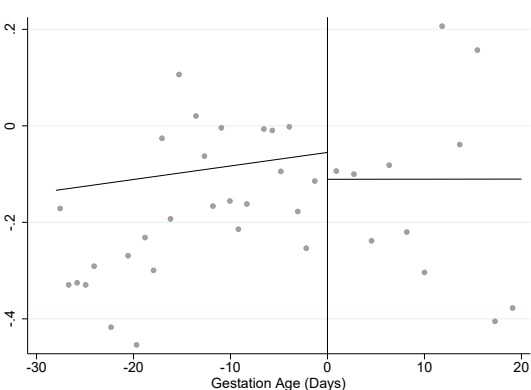

(b) Event time $=-2$

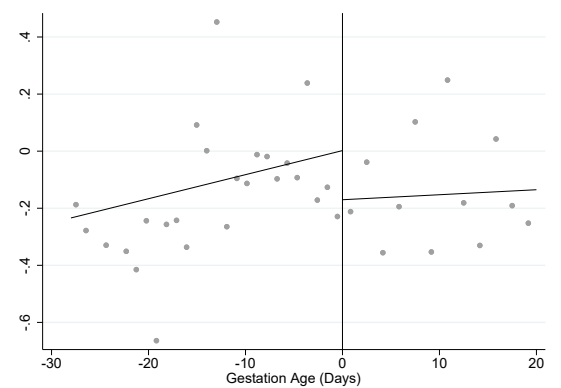

(e) Event time=1

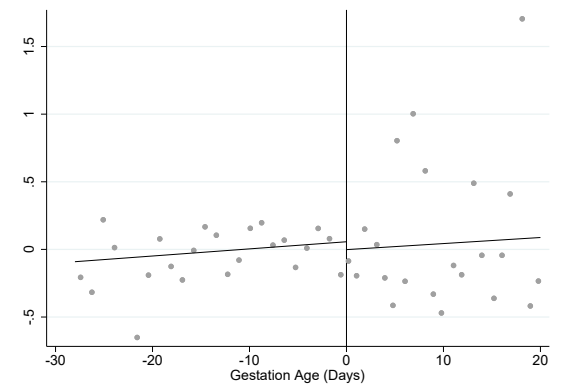

(h) Event time $=4$

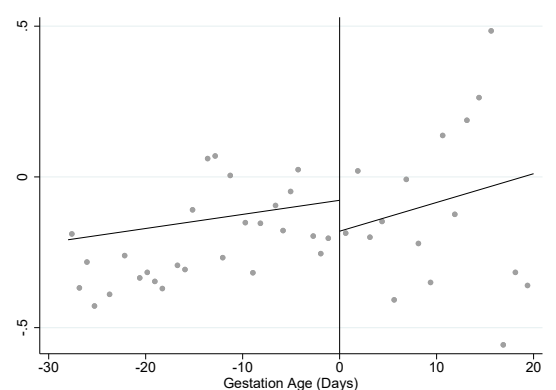

(c) Event time $=-1$

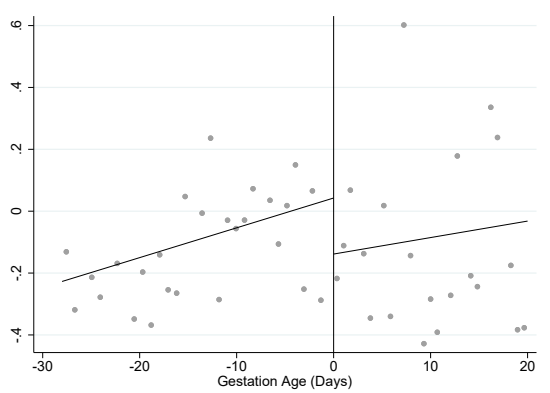

(f) Event time $=2$

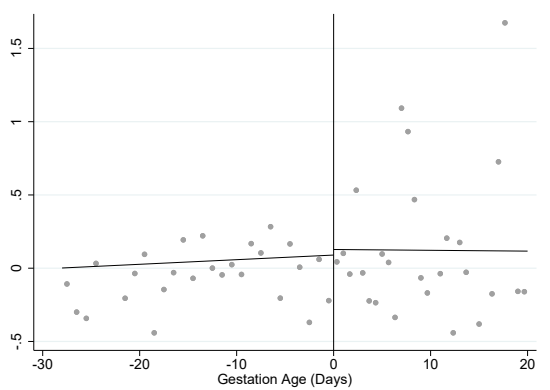

(i) Event time $=5$

Note: For each outcome, points represent means for each gestation age relative to the cutoff. The lines are fitted values from a regression that includes a linear trend in gestational age and a dummy for gestation ages greater than or equal to the cutoff age. 


\section{Figure A13: RDD Graphs By Event Time, Outcome: Borrowing Index}

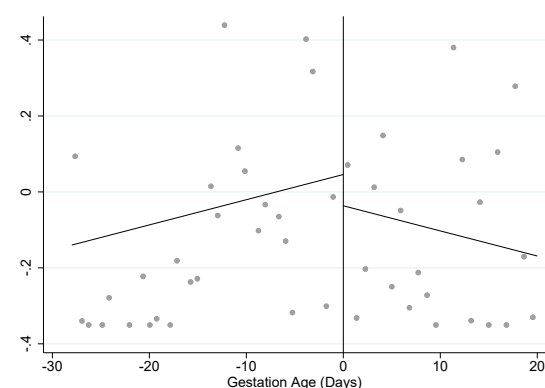

(a) Event time $=-3$

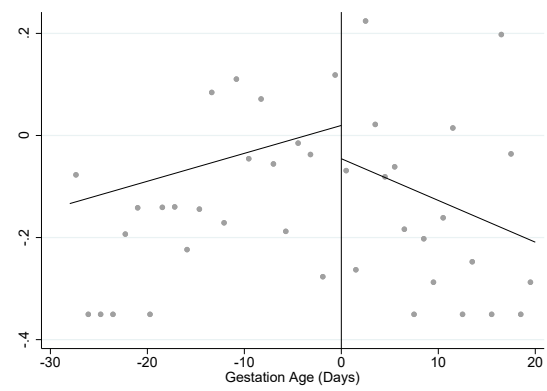

(d) Event time $=0$ (Year of Birth)

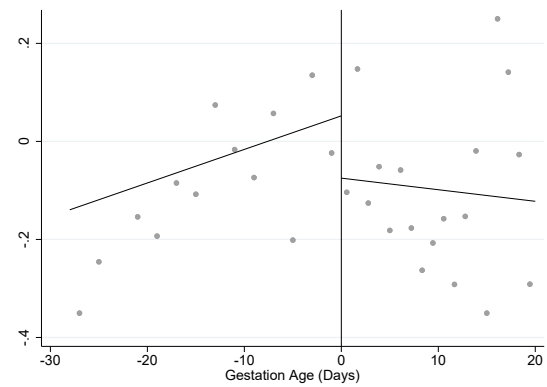

(g) Event time=3

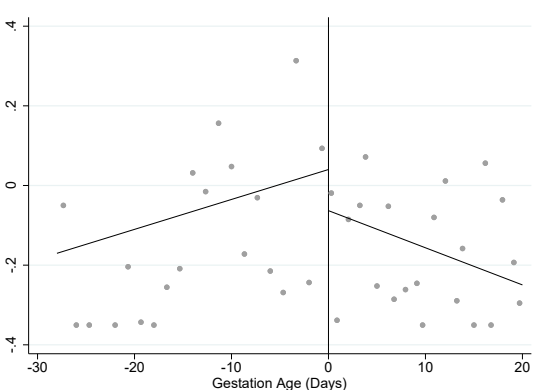

(b) Event time $=-2$

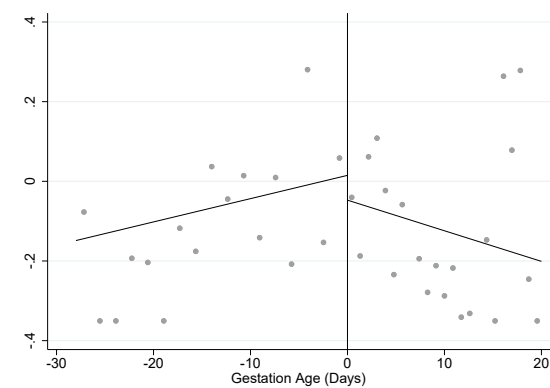

(e) Event time=1

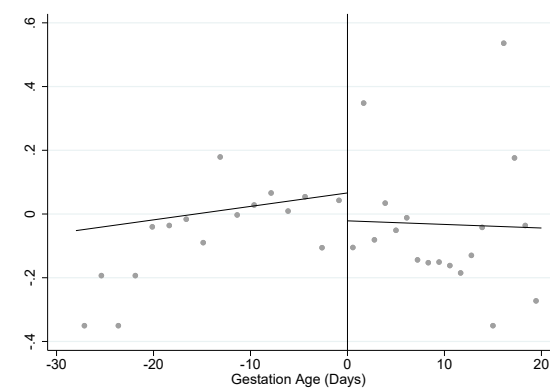

(h) Event time=4

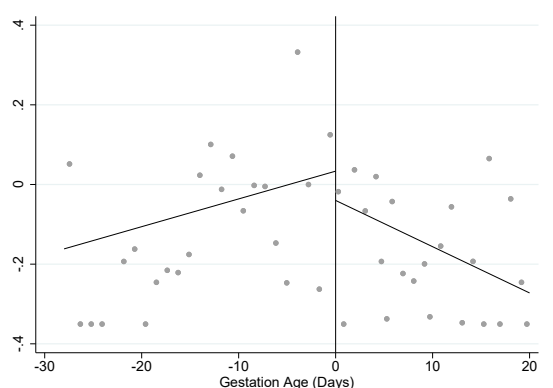

(c) Event time $=-1$

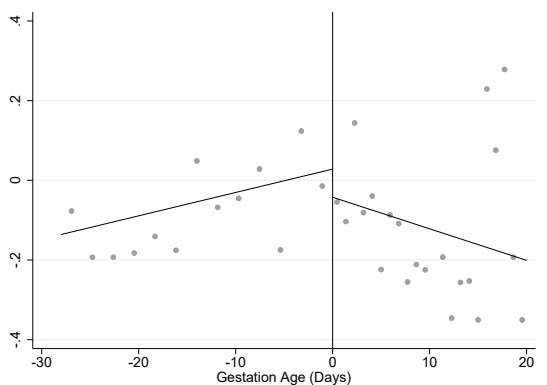

(f) Event time=2

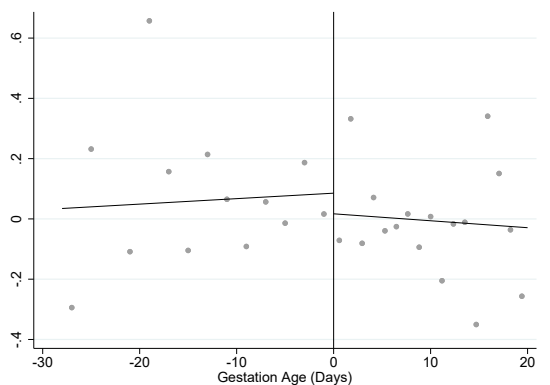

(i) Event time $=5$

Note: For each outcome, points represent means for each gestation age relative to the cutoff. The lines are fitted values from a regression that includes a linear trend in gestational age and a dummy for gestation ages greater than or equal to the cutoff age. 
Figure A14: RDD Graphs for Characteristics at Baseline Survey

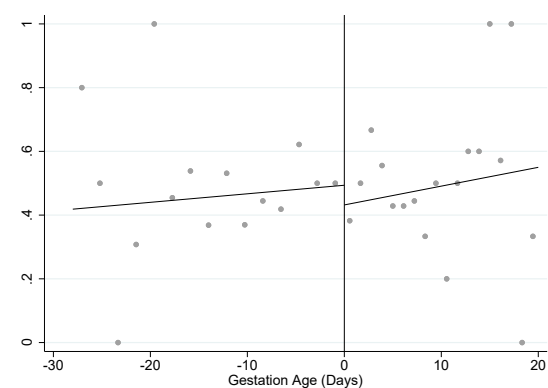

(a) High School Education or Less

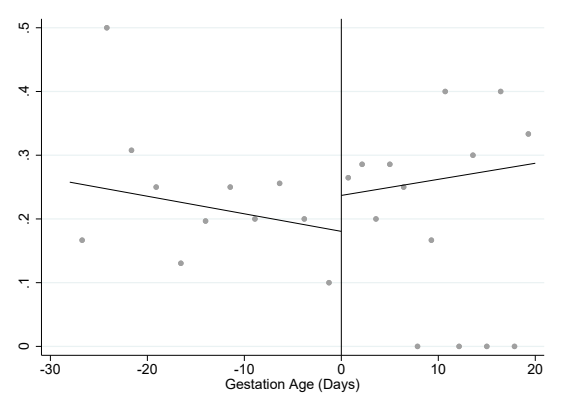

(d) Part Time Employed

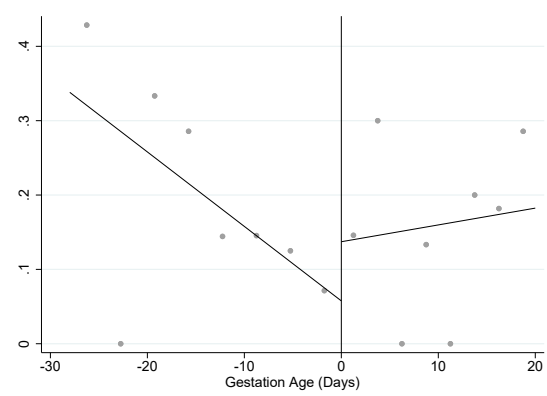

(g) Received WIC

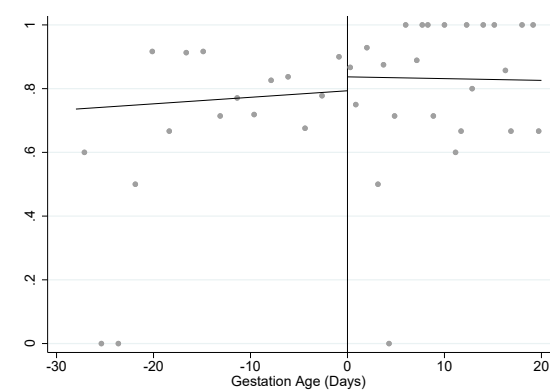

(b) Unmarried

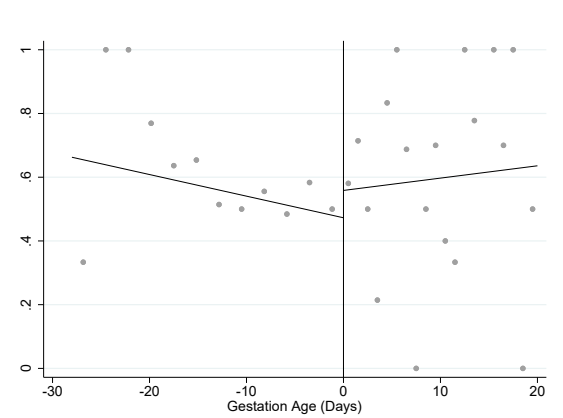

(e) Enough Money

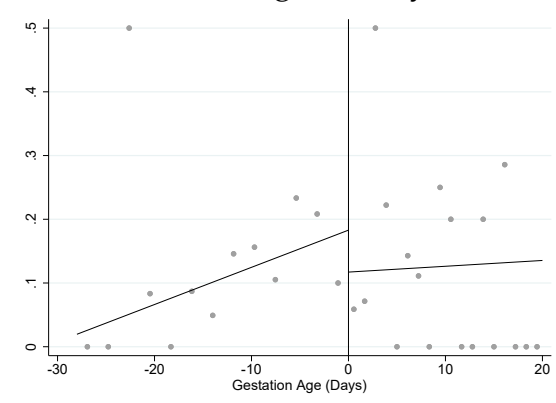

(h) Received TANF

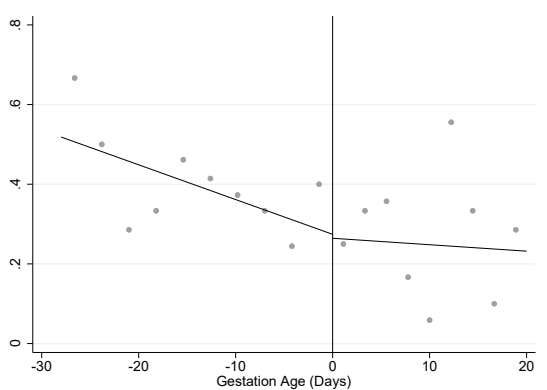

(c) Full Time Employed

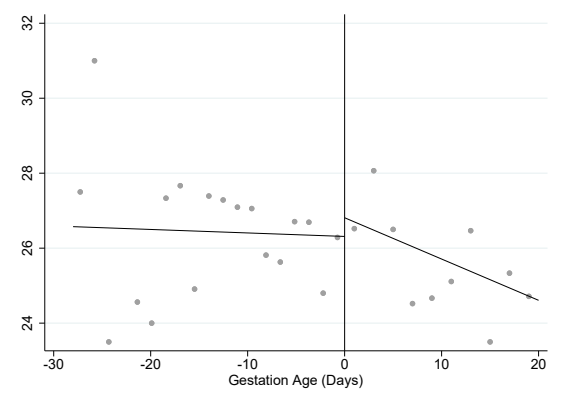

(f) Age at Birth or Counterfactual Birth

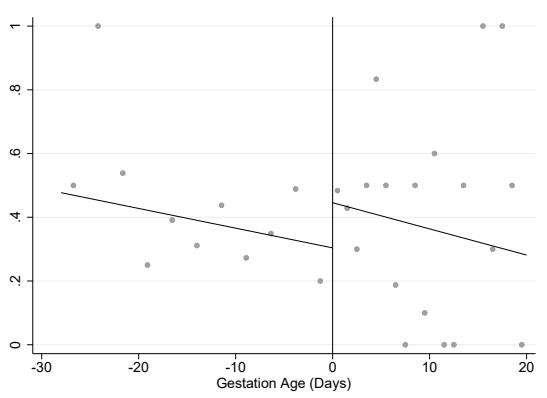

(i) Received Food Stamps

Note: For each characteristics, points represent means for each gestation age relative to the cutoff. The lines are fitted values from a regression that includes a linear trend in gestational age and a dummy for gestation ages greater than or equal to the cutoff age. 


\section{Figure A15: Exploring Mechanisms with Survey Data: Economic Outcomes}

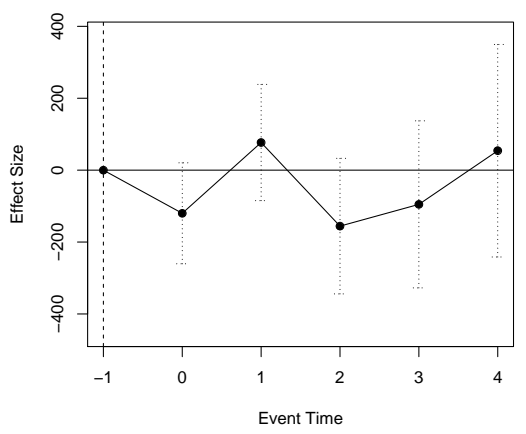

(a) Personal Income

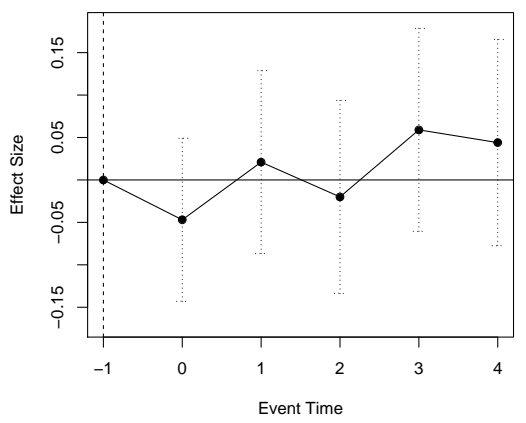

(d) Employed

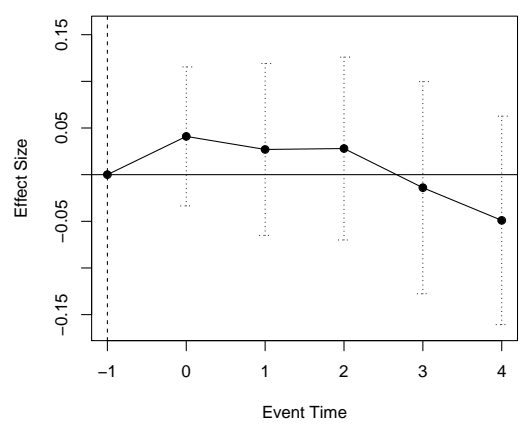

(g) Receives Food Stamps

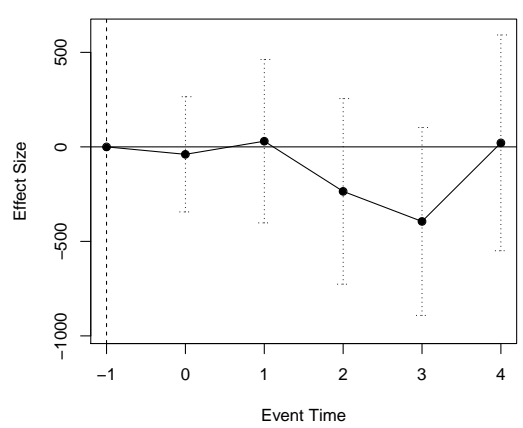

(b) Household Income

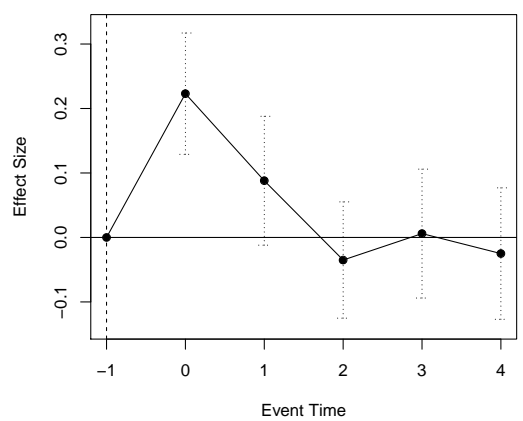

(e) Receives WIC

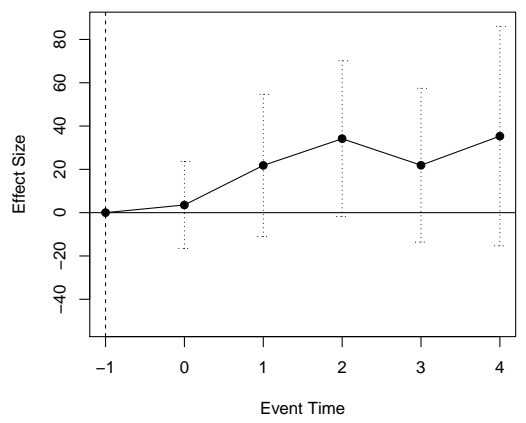

(h) Child support

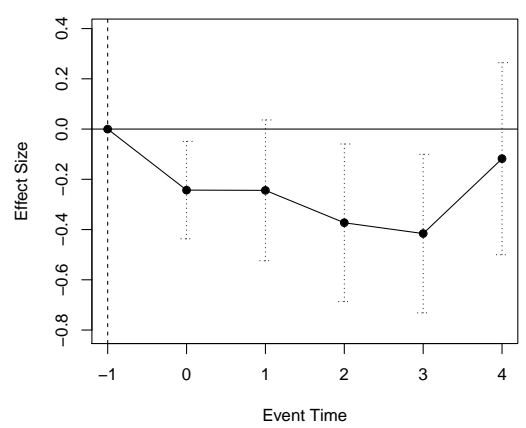

(c) Income Relative to FPL

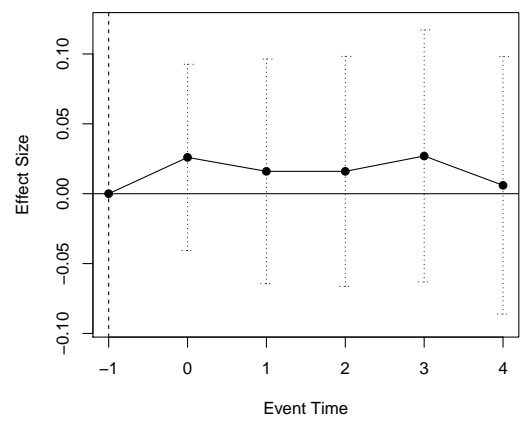

(f) Receives TANF

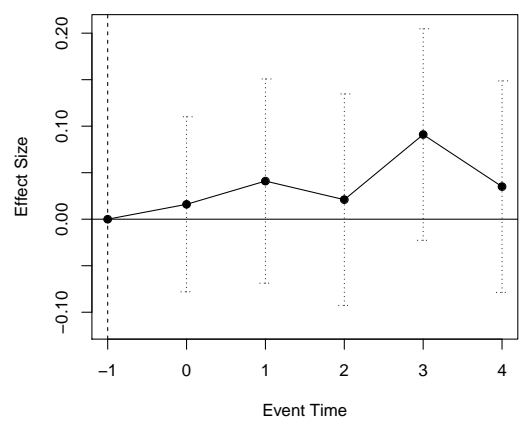

(i) Not enough money "most of the time" or more

Note: These figures report coefficients from a variant of Equation (1) estimated with available data for the specified outcome. The coefficients represent the change in the outcome for Turnaway group members relative to Near Limit group members in the one year before and five years after the time of birth or counterfactual birth, as compared to the year immediately prior to this event. See text for more information. 


\section{Figure A16: Exploring Mechanisms with Survey Data: Living Situation}

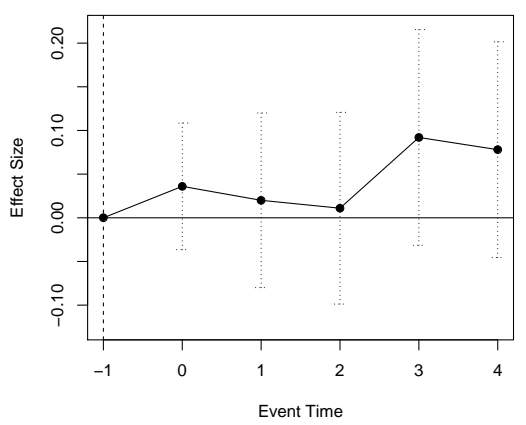

(a) Living with Male Partner

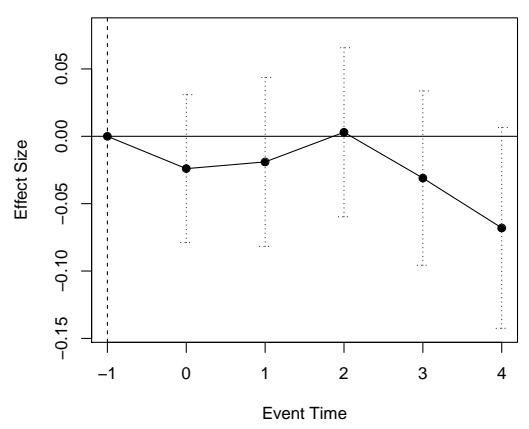

(d) Living Alone

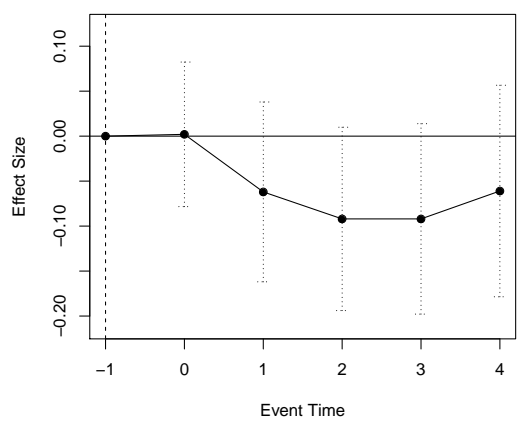

(b) Living with Adult Family

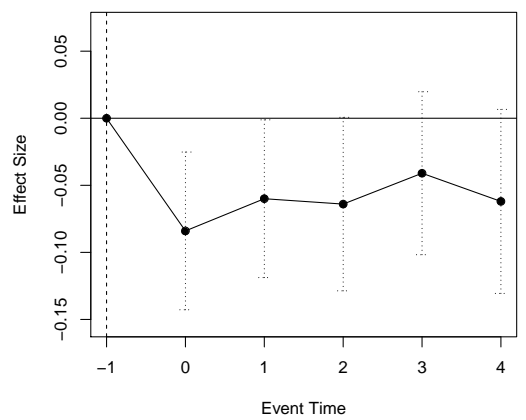

(e) Living with (Non-Family)

Roommates

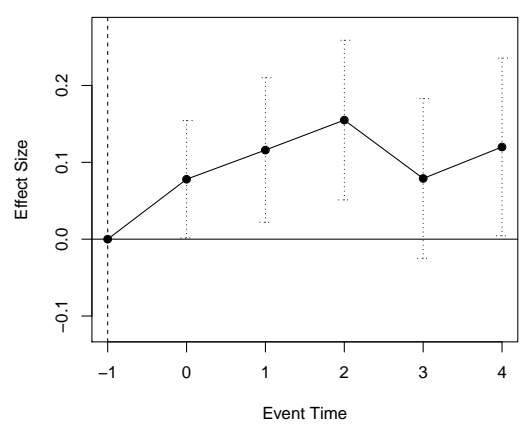

(c) Living Alone with Child/Children

Note: These figures report coefficients from a variant of Equation (1) estimated with available data for the specified outcome. The coefficients represent the change in the outcome for Turnaway group members relative to Near Limit group members in the one year before and five years after the time of birth or counterfactual birth, as compared to the year immediately prior to this event. See text for more information. 
Figure A17: Effect of Turnaway Births (Green) relative to Near Limit Subsequent Births (Blue)

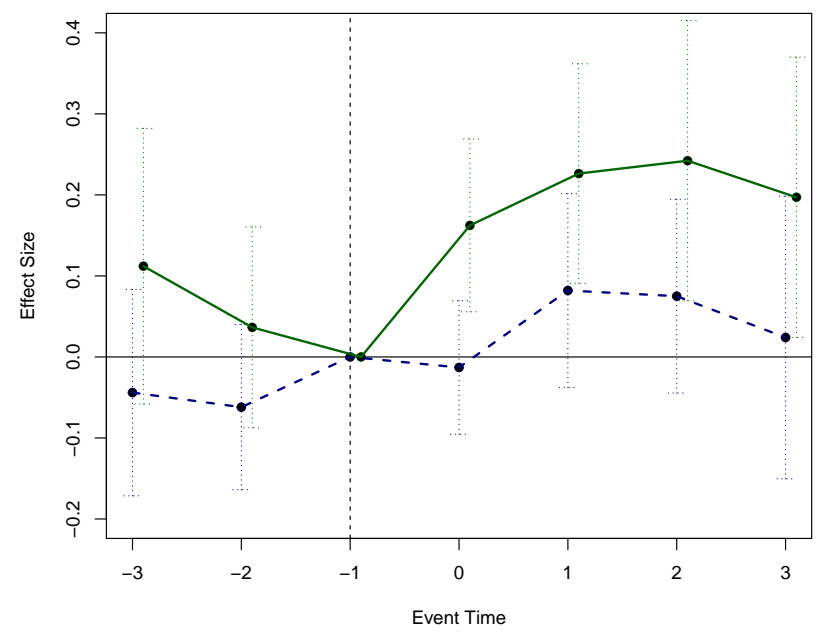

(a) Financial Distress Index

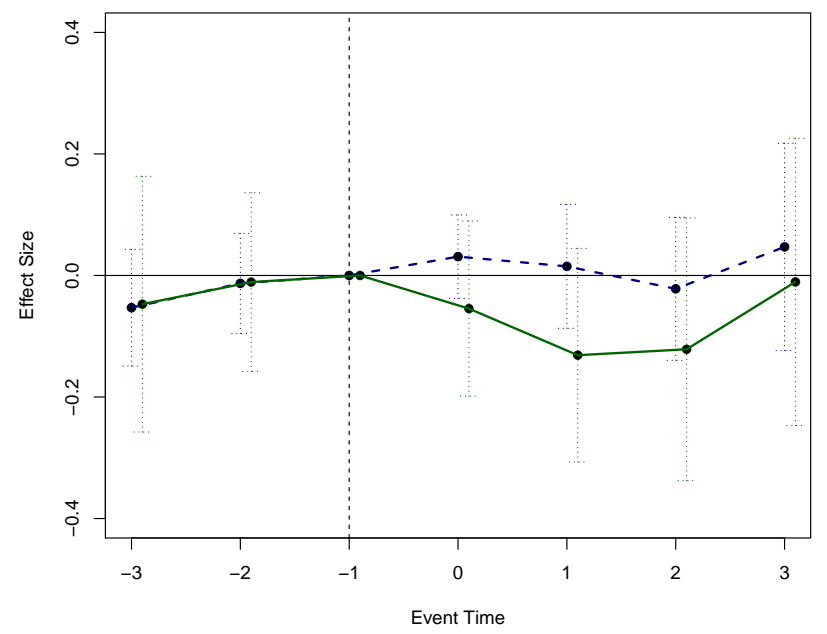

(b) Credit Access Index

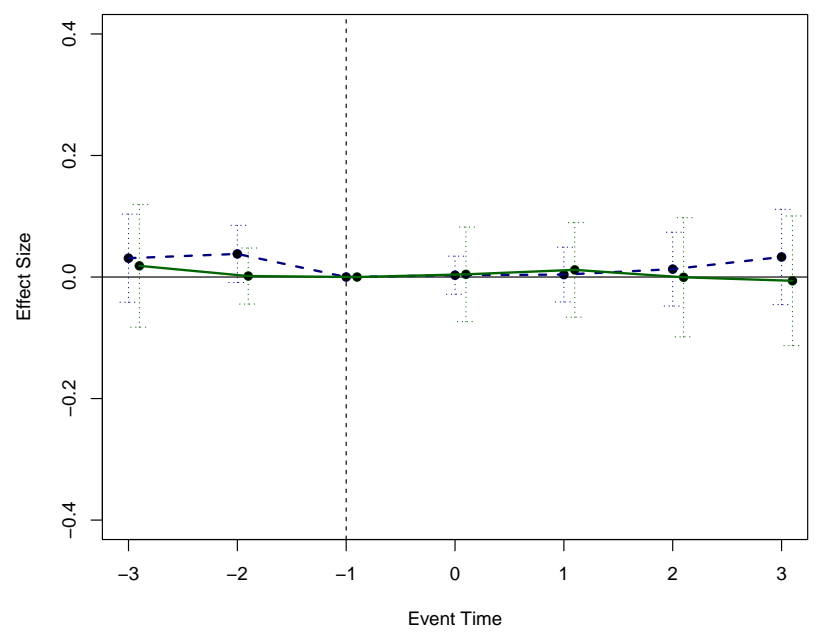

(c) Borrowing Index

Note: These figures show estimates of coefficients $\beta_{y}$ (from equations 1 and 4) among the Turnaway group (in solid green) and the Near Limit group who gave birth following their abortion (in dashed blue). Coefficients 


\section{Figure A18: Robustness to Alternative Re-Weighting Approaches}

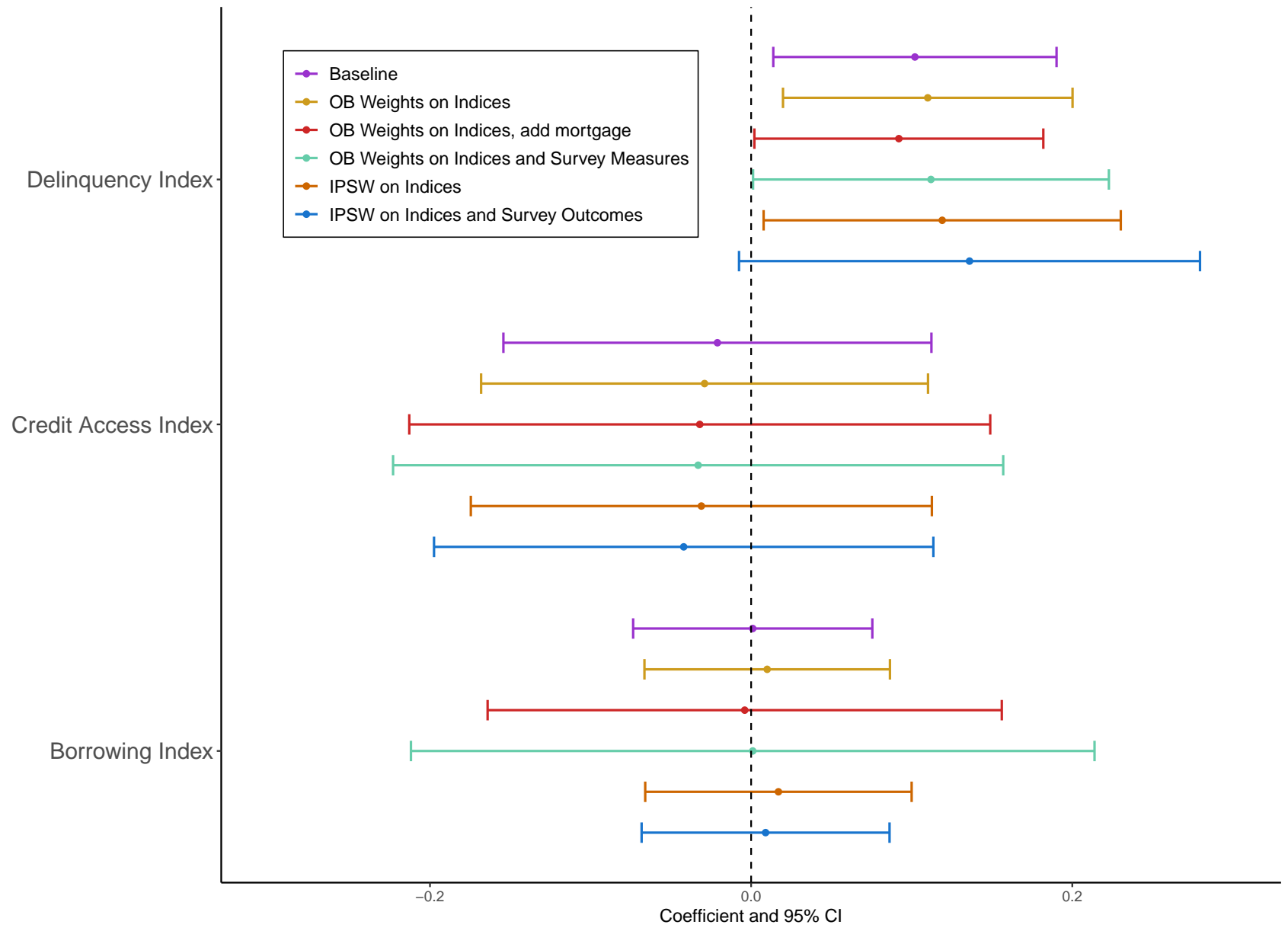

Note: This figure displays difference-in-differences coefficients and $95 \%$ confidence intervals for specifications using alternative approaches to re-weighting the Near Limit group. See text for more information. 


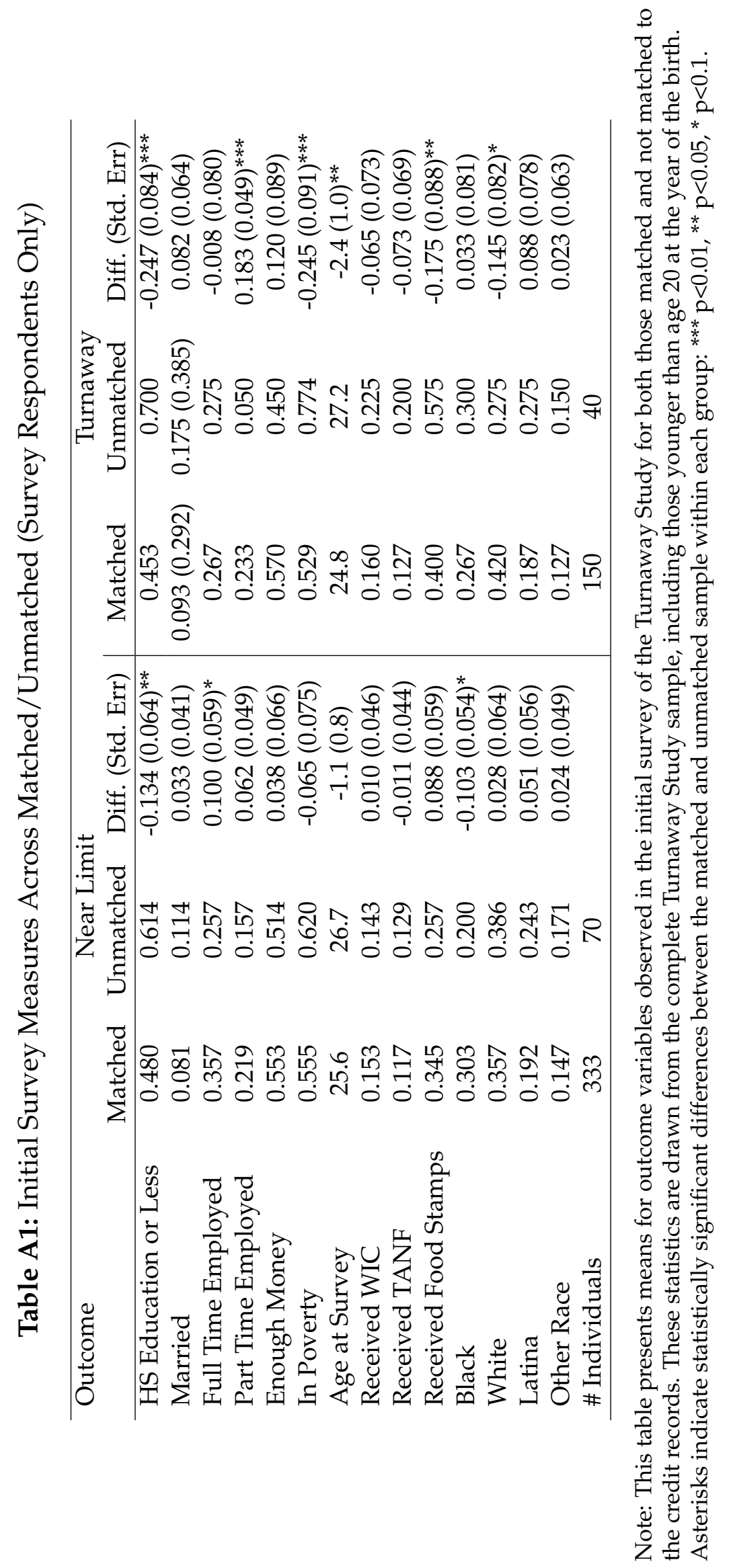


Table A2: Analysis by Type of Public Record

\begin{tabular}{lccc}
\hline \hline & Tax Liens & Bankruptcies & Judgements \\
Post $\times$ Turnaway & $0.025(0.010)^{* *}$ & $0.008(0.011)$ & $0.038(0.024)$ \\
Pre-Period Turnaway Mean: & 0.007 & 0.018 & 0.069 \\
$\mathrm{~N}:$ & 4,914 & & \\
\hline \hline
\end{tabular}

Notes: Analyses use 2006-2016 Experian credit report files for Turnaway and Near Limit sample of women age 20 and older in the year of the birth or counterfactual birth. Sample is restricted to women who had a credit report record prior to the birth or counterfactual birth. All regression models include individual fixed effects and an indicator that event time $\geq 0$. Robust standard errors are clustered by individual. Significance levels: ${ }^{*}=10 \%,{ }^{* *}=5 \%,{ }^{* * *}=1 \%$.

Table A3: Collection Amounts by Types of Collection (only available in "post" period)

\begin{tabular}{lccccc}
\hline \hline & Turnaway & Near Limit & P-value of Difference & & \\
Medical collections & $\$ 1733.99$ & $\$ 1262.44$ & 0.176 & & \\
Retail collections & $\$ 242.37$ & $\$ 211.32$ & 0.543 & Notes: & Table \\
Utility collections & $\$ 491.05$ & $\$ 434.99$ & 0.360 & & \\
Banking or financial collections & $\$ 303.02$ & $\$ 344.22$ & 0.743 & \\
\hline \hline
\end{tabular}

presents mean collection balances by type of collection for the years 2011 forward. Previous years are unavailable. Third column denotes p-value associated with the difference in means across the Turnaway and Near Limit groups.

Table A4: Effect of an Abortion Denial on Distribution of Collections and Amount Past Due

\begin{tabular}{|c|c|c|c|c|c|}
\hline \multirow[t]{2}{*}{ Collections: } & \# Collections & $\$ 0$ & $\$ 1-\$ 732$ & \$733-\$2994 & \$2995-\$19648 \\
\hline & & Quartile 1 & Quartile 2 & Quartile 3 & Quartile 4 \\
\hline \multirow[t]{2}{*}{ Post $\times$ Turnaway } & 0.606 & $-0.082^{* *}$ & 0.025 & 0.001 & 0.056 \\
\hline & $(0.559)$ & $(0.033)$ & $(0.029)$ & $(0.035)$ & $(0.036)$ \\
\hline $\mathrm{N}$ & 4,914 & 4,914 & 4,914 & 4,914 & \\
\hline \multirow[t]{2}{*}{ Past Due: } & \# Trades Past Due & $\$ 0$ & $\$ 1-\$ 160$ & $\$ 161-\$ 1311$ & $\$ 1312-\$ 41044$ \\
\hline & & Quartile 1 & Quartile 2 & Quartile 3 & Quartile 4 \\
\hline \multirow[t]{2}{*}{ Post $\times$ Turnaway } & 0.158 & -0.023 & 0.003 & 0.009 & 0.010 \\
\hline & $(0.200)$ & $(0.033)$ & $(0.013)$ & $(0.030)$ & $(0.032)$ \\
\hline $\mathrm{N}$ & 4,914 & 4,914 & 4,914 & 4,914 & 4,914 \\
\hline
\end{tabular}

Notes: Analyses use 2006-2016 Experian credit report files for Turnaway and Near Limit sample of women age 20 and older in the year of the birth or counterfactual birth. Sample is restricted to women who had a credit report record prior to the birth or counterfactual birth. Outcome variables are indicators that collections or past due balance take a value in the ranges specified, 0 otherwise. All regression models include individual fixed effects and an indicator that event time $\geq 0$. Robust standard errors are clustered by individual. Significance levels: ${ }^{*}=10 \%,{ }^{* *}=5 \%,{ }^{* * *}=1 \%$. 


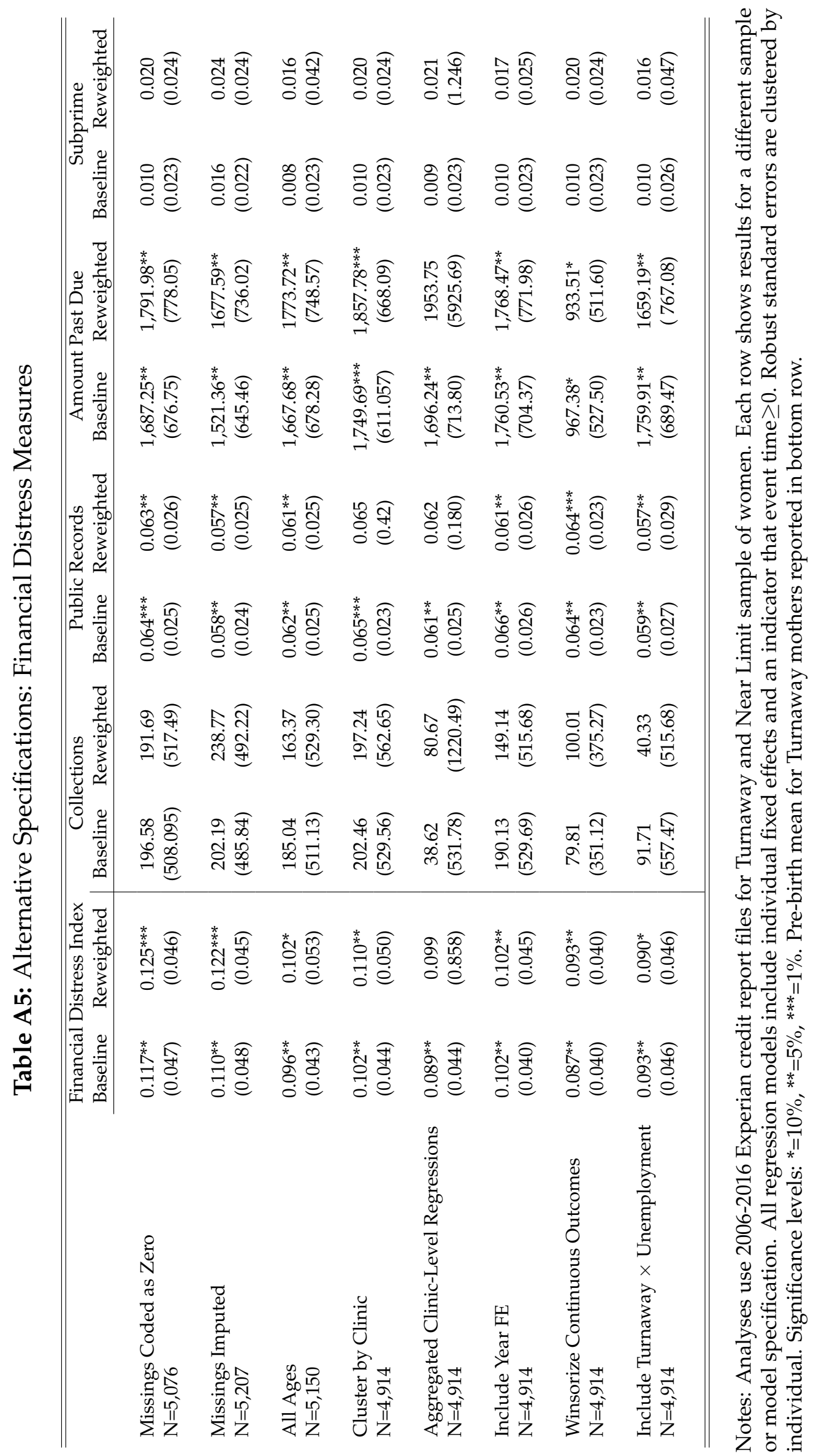




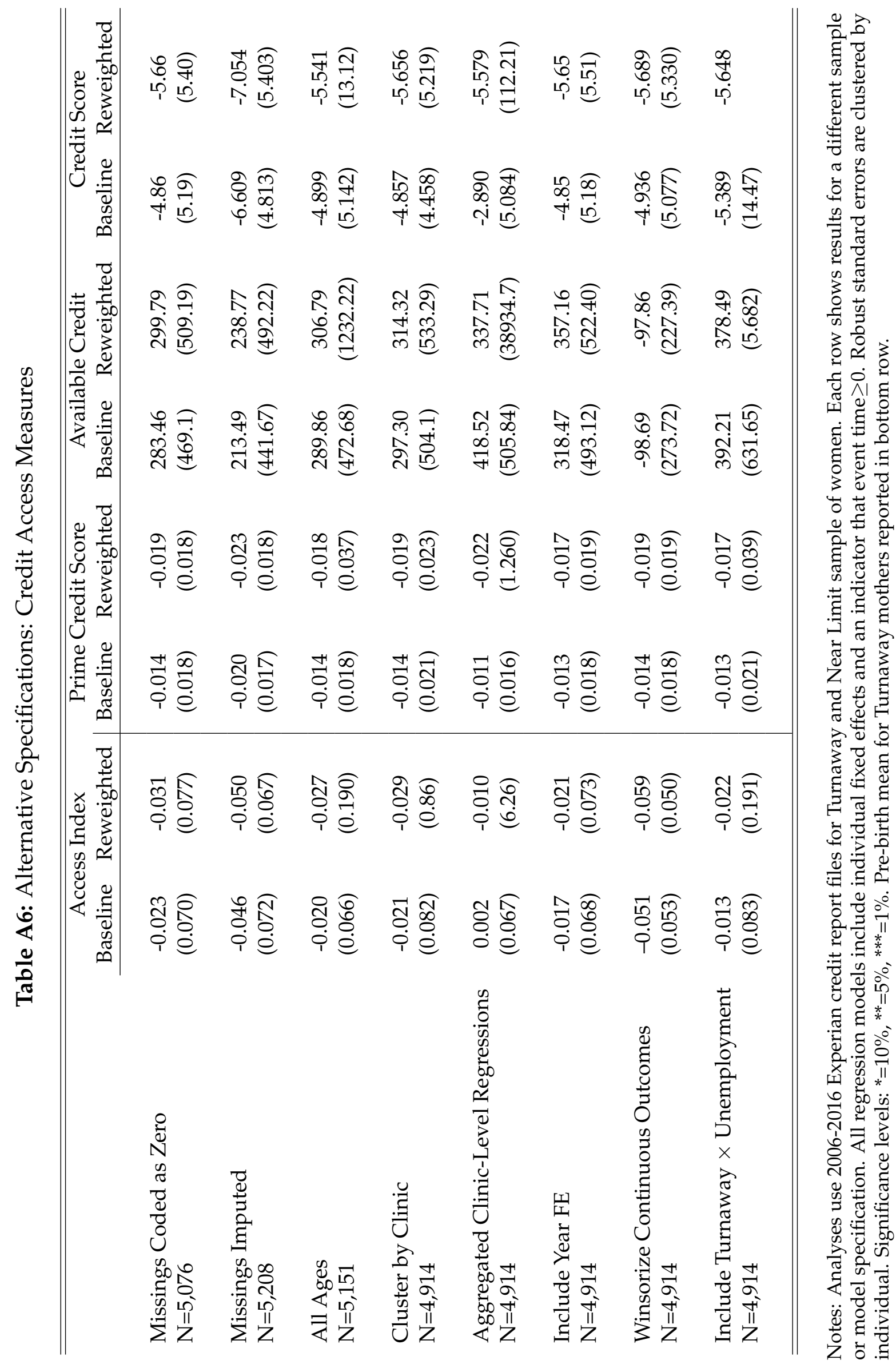




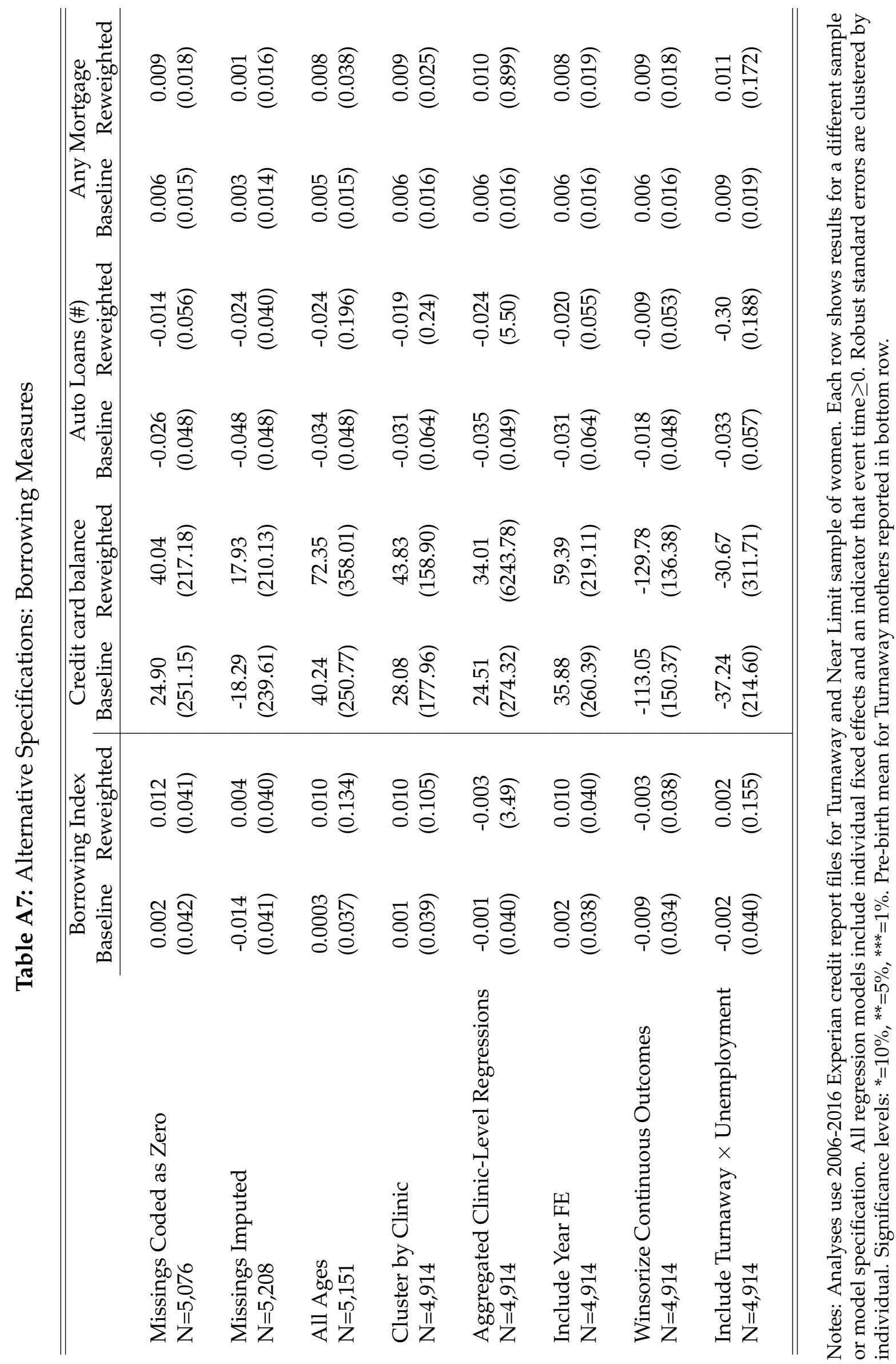




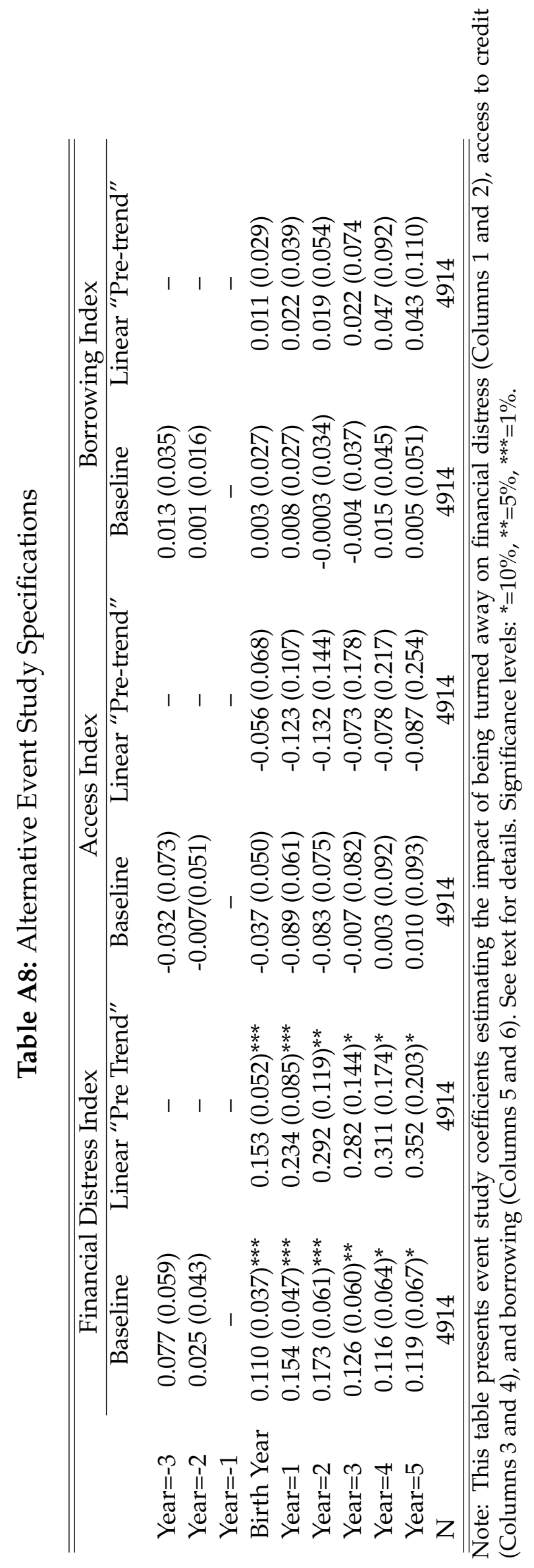


Table A9: Heterogeneous Effects for High Versus Low TANF Generosity States

\begin{tabular}{lccc}
\hline \hline & Full Sample & High Generosity States & Low Generosity States \\
\cline { 2 - 3 } Financial Distress Index & & & \\
Post $\times$ Turnaway & $0.102^{* *}$ & 0.036 & $0.150^{* *}$ \\
& $(0.045)$ & $(0.054)$ & $(0.066)$ \\
Credit Access Index & & & \\
Post $\times$ Turnaway & -0.021 & 0.047 & -0.072 \\
& $(0.068)$ & $(0.076)$ & $(0.104)$ \\
Borrowing Index & & & -0.030 \\
Post $\times$ Turnaway & 0.001 & 0.044 & $(0.048)$ \\
& $(0.038)$ & $(0.062)$ & 2,756 \\
$\mathrm{~N}$ & 4,914 & 2,158 & \\
\hline \hline
\end{tabular}

Notes: Analyses use 2006-2016 Experian credit report files for Turnaway and Near Limit sample of women age 20 and older the year of the birth or counterfactual birth. Sample is restricted to women who had a credit report record prior to the birth or counterfactual birth. All regression models include individual fixed effects and an indicator that event time $\geq 0$. Robust standard errors are clustered by individual. Significance levels: ${ }^{*}=10 \%,{ }^{* *}=5 \%,{ }^{* * *}=1 \%$. 


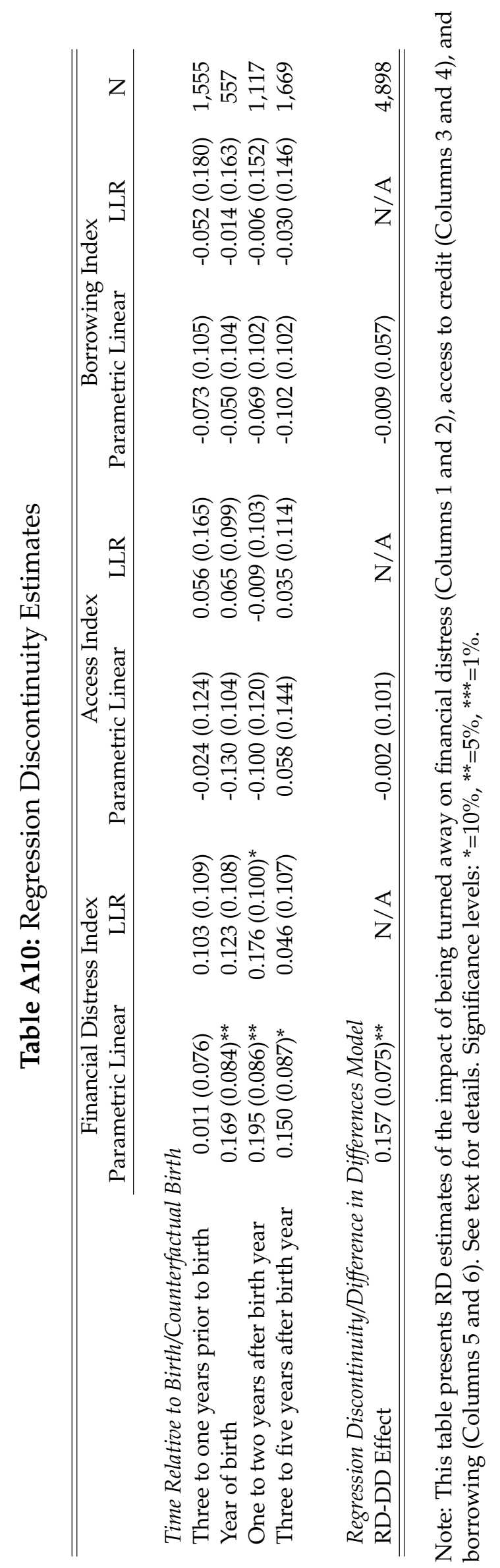




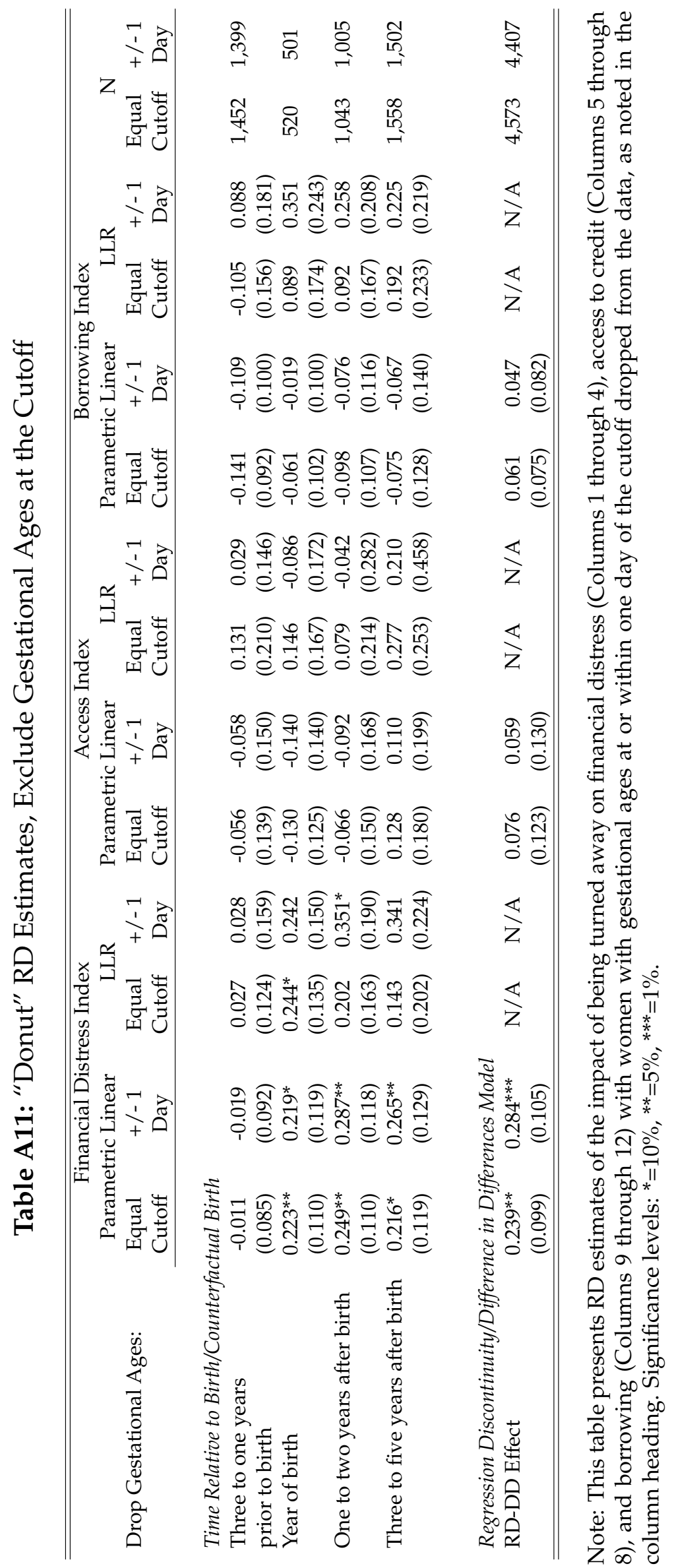


Table A12: Regression Discontinuity Estimates in Initial Survey Responses (Survey Respondents Only)

\begin{tabular}{lcc}
\hline \hline & Parametric Linear & LLR \\
\cline { 2 - 3 } HS Education or Less & $-0.022(0.082)$ & $-0.155(0.122)$ \\
Single & $0.011(0.067)$ & $0.054(0.085)$ \\
Full Time Employed & $-0.053(0.076)$ & $-0.153(0.137)$ \\
Part Time Employed & $0.161(0.103)$ & $0.057(0.066)$ \\
Enough Money & $0.112(0.080)$ & $0.23(0.132)$ \\
Age at birth & $0.201(0.810)$ & $1.038(1.316)$ \\
Received WIC & $0.067(0.058)$ & $0.064(0.076)$ \\
Received TANF & $-0.062(0.052)$ & $-0.069(0.072)$ \\
Received Food Stamps & $0.181(0.122)$ & $0.158(0.079)^{* *}$ \\
\hline \hline
\end{tabular}

Note: Table shows RD estimates of outcome variables listed in each row. These outcome variables were recorded on the initial survey that participants completed approximately one week after the abortion encounter. Significance levels: ${ }^{*}=10 \%,{ }^{* *}=5 \%,{ }^{* * *}=1 \%$. 
Table A13: Regression Discontinuity Estimates: Robustness to Including Controls (Parametric Linear Model)

\begin{tabular}{|c|c|c|c|c|}
\hline & Financial Distress Index & Access Index & Borrowing Index & $\mathrm{N}$ \\
\hline \multicolumn{5}{|l|}{ Three to one years prior to birth } \\
\hline Baseline & $\begin{array}{c}0.011 \\
(0.076)\end{array}$ & $\begin{array}{c}-0.024 \\
(0.124)\end{array}$ & $\begin{array}{c}-0.073 \\
(0.105)\end{array}$ & 1,555 \\
\hline Survey Respondents Only & $\begin{array}{c}-0.004 \\
(0.086)\end{array}$ & $\begin{array}{c}-0.021 \\
(0.145)\end{array}$ & $\begin{array}{c}-0.108 \\
(0.122)\end{array}$ & 1,301 \\
\hline Add Controls & $\begin{array}{c}-0.016 \\
(0.086)\end{array}$ & $\begin{array}{c}-0.038 \\
(0.142)\end{array}$ & $\begin{array}{c}-0.124 \\
(0.104)\end{array}$ & 1,301 \\
\hline \multicolumn{5}{|l|}{ Year of Birth } \\
\hline Baseline & $\begin{array}{l}0.169^{* *} \\
(0.084)\end{array}$ & $\begin{array}{c}-0.130 \\
(0.104)\end{array}$ & $\begin{array}{c}-0.050 \\
(0.104)\end{array}$ & 557 \\
\hline Survey Respondents Only & $\begin{array}{c}0.175^{*} \\
(0.097)\end{array}$ & $\begin{array}{c}-0.111 \\
(0.118)\end{array}$ & $\begin{array}{c}-0.076 \\
(0.121)\end{array}$ & 465 \\
\hline Add Controls & $\begin{array}{l}0.159^{*} \\
(0.096)\end{array}$ & $\begin{array}{l}-0.120 \\
(0.118)\end{array}$ & $\begin{array}{l}-0.075 \\
(0.103)\end{array}$ & 465 \\
\hline \multicolumn{5}{|l|}{ One to two years after the birth } \\
\hline Baseline & $\begin{array}{l}0.195^{* *} \\
(0.086)\end{array}$ & $\begin{array}{c}-0.100 \\
(0.120)\end{array}$ & $\begin{array}{c}-0.069 \\
(0.102)\end{array}$ & 1117 \\
\hline Survey Respondents Only & $\begin{array}{l}0.185^{*} \\
(0.097)\end{array}$ & $\begin{array}{c}-0.083 \\
(0.138)\end{array}$ & $\begin{array}{c}-0.099 \\
(0.116)\end{array}$ & 932 \\
\hline Add Controls & $\begin{array}{l}0.178^{*} \\
(0.097)\end{array}$ & $\begin{array}{l}-0.089 \\
(0.137)\end{array}$ & $\begin{array}{c}-0.100 \\
(0.100)\end{array}$ & 932 \\
\hline \multicolumn{5}{|l|}{ Three to five years after the birth } \\
\hline Baseline & $\begin{array}{c}0.150^{*} \\
(0.087)\end{array}$ & $\begin{array}{c}0.058 \\
(0.144)\end{array}$ & $\begin{array}{c}-0.102 \\
(0.102)\end{array}$ & 1,673 \\
\hline Survey Respondents Only & $\begin{array}{c}0.170^{*} \\
(0.101)\end{array}$ & $\begin{array}{c}0.107 \\
(0.166)\end{array}$ & $\begin{array}{c}-0.162 \\
(0.110)\end{array}$ & 1,400 \\
\hline Add Controls & $\begin{array}{c}0.155 \\
(0.100)\end{array}$ & $\begin{array}{c}0.121 \\
(0.161)\end{array}$ & $\begin{array}{c}-0.176^{*} \\
(0.101)\end{array}$ & 1,400 \\
\hline \multicolumn{5}{|l|}{$R D$-DD Effect } \\
\hline Baseline & $\begin{array}{l}0.157^{* *} \\
(0.075)\end{array}$ & $\begin{array}{c}-0.002 \\
(0.101)\end{array}$ & $\begin{array}{c}-0.009 \\
(0.057)\end{array}$ & 4,898 \\
\hline Survey Respondents Only & $\begin{array}{l}0.179 * * \\
(0.085)\end{array}$ & $\begin{array}{c}0.028 \\
(0.119)\end{array}$ & $\begin{array}{c}-0.018 \\
(0.065)\end{array}$ & 4,089 \\
\hline Add Controls & $\begin{array}{l}0.184^{* *} \\
(0.085)\end{array}$ & $\begin{array}{c}0.023 \\
(0.119) \\
\end{array}$ & $\begin{array}{c}-0.021 \\
(0.064)\end{array}$ & 4,089 \\
\hline
\end{tabular}

Note: This table presents RD estimates of the impact of being turned away on financial distress (Column 1), access to credit (Column 2), and borrowing (Column 3). Significance levels: ${ }^{*}=10 \%,{ }^{* *}=5 \%,{ }^{* * *}=1 \%$. 


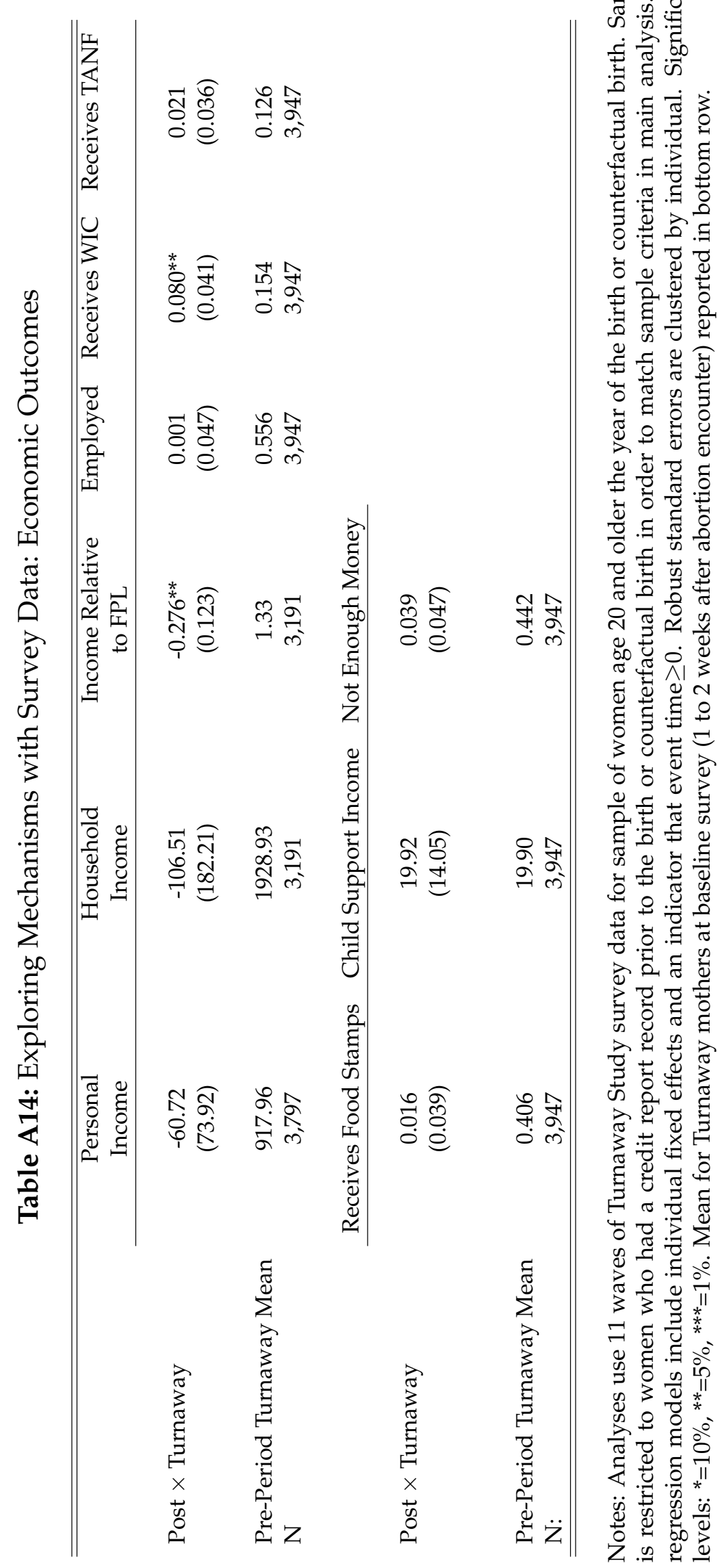


Table A15: Exploring Mechanisms with Survey Data: Living Situation

\begin{tabular}{lccccc}
\hline \hline & Alone with Child & $\begin{array}{c}\text { With Male } \\
\text { Partner }\end{array}$ & $\begin{array}{c}\text { With Adult } \\
\text { Family }\end{array}$ & $\begin{array}{c}\text { With Room } \\
\text { Mates }\end{array}$ & Alone \\
\cline { 2 - 6 } & $0.106^{* * *}$ & 0.039 & -0.051 & $-0.064^{* *}$ & -0.024 \\
Post $\times$ Turnaway & $(0.041)$ & $(0.043)$ & $(0.044)$ & $(0.028)$ & $(0.028)$ \\
Pre-Period Turnaway Mean & 0.406 & 19.90 & 0.442 & & \\
N: & 3,947 & 3,947 & 3,947 & 3,947 & 3,947 \\
\hline \hline
\end{tabular}

Notes: Analyses use 11 waves of Turnaway Study survey data for sample of women age 20 and older the year of the birth or counterfactual birth. Sample is restricted to women who had a credit report record prior to the birth or counterfactual birth in order to match sample criteria in main analysis. All regression models include individual fixed effects and an indicator that event time $\geq 0$. Robust standard errors are clustered by individual. Significance levels: ${ }^{*}=10 \%,{ }^{* *}=5 \%,{ }^{* * *}=1 \%$. Mean for Turnaway mothers at initial survey (approximately 1 week after abortion encounter) reported in bottom row. 